\title{
MEASUREMENT OF THERMAL CONDUCTIVITY OF SMALLER THERMAL INSULATION SPECIMENS USING STANDARD HEAT FLOW METER APPARATUS
}

\author{
A thesis submitted to \\ the Faculty of Graduate and Postdoctoral Affairs \\ in Partial Fulfillment of the requirements for the degree \\ Masters of Applied Science
}

by

Graziela Girardi

Department of Civil and Environmental Engineering

Carleton University

Ottawa-Carleton Institute of Civil and Environmental Engineering

May, 2013

C2013 Graziela Girardi 
Library and Archives

Canada

Published Heritage

Branch

395 Wellington Street

Ottawa ON K1A ON4

Canada
Bibliothèque et

Archives Canada

Direction du

Patrimoine de l'édition

395 , rue Wellington

Ottawa ON K1A ON4

Canada
Your file Votre référence

ISBN: 978-0-494-94671-8

Our file Notre référence

ISBN: $978-0-494-94671-8$
NOTICE:

The author has granted a nonexclusive license allowing Library and Archives Canada to reproduce, publish, archive, preserve, conserve, communicate to the public by telecommunication or on the Internet, loan, distrbute and sell theses worldwide, for commercial or noncommercial purposes, in microform, paper, electronic and/or any other formats.

The author retains copyright ownership and moral rights in this thesis. Neither the thesis nor substantial extracts from it may be printed or otherwise reproduced without the author's permission.
AVIS:

L'auteur a accordé une licence non exclusive permettant à la Bibliothèque et Archives Canada de reproduire, publier, archiver, sauvegarder, conserver, transmettre au public par télécommunication ou par l'Internet, prêter, distribuer et vendre des thèses partout dans le monde, à des fins commerciales ou autres, sur support microforme, papier, électronique et/ou autres formats.

L'auteur conserve la propriété du droit d'auteur et des droits moraux qui protege cette thèse. $\mathrm{Ni}$ la thèse ni des extraits substantiels de celle-ci ne doivent être imprimés ou autrement reproduits sans son autorisation.
In compliance with the Canadian Privacy Act some supporting forms may have been removed from this thesis.

While these forms may be included in the document page count, their removal does not represent any loss of content from the thesis.
Conformément à la loi canadienne sur la protection de la vie privée, quelques formulaires secondaires ont été enlevés de cette thèse.

Bien que ces formulaires aient inclus dans la pagination, il n'y aura aucun contenu manquant. 


\section{Abstract}

Thermal insulation is used to maintain comfortable temperatures inside buildings and reduce energy loss to the external environment. A variety of materials have been used as thermal insulation, and new products are constantly being developed. The thermal properties of these materials must be assessed to determine appropriate applications. The American Society for Testing and Materials (ASTM) developed the Standard Test Method for Steady-State Thermal Transmission Properties by Means of the Heat Flow Meter Apparatus (ASTM C518), which specifies that the test should be conducted on a sample that is at least $300 \times 300 \mathrm{~mm}$. When an insulation manufacturer develops a new product, usually, a small quantity of an experimental product is produced and samples with the minimum size required for heat flow meter tests are not always available. It is also not feasible to build a new apparatus or modify an existing apparatus, with different size heat flow sensors, every time a different size sample needs to be tested. The research reported in this thesis examined a new method for testing thermal conductivity using smaller samples of six commercial insulation material, and correlate results to testing of the standard size samples. The tests were carried out using the heat flow meter apparatus, and results were subsequently analyzed using the finite element modelling tool, HEAT3. 


\section{Acknowledgements}

I would like to thank my supervisor Dr. Ehab Zalok for this opportunity, and for his support and patience along this process.

Special thanks go to my co-supervisor at NRC, Dr. Phalguni Mukhopadhyaya, he taught me to think critically and helped me go through this research motivating me with wise words. Thank you for your time!

I would like to thank all NRC staff from building M-24. Special thanks to Mr. Gordon Sherrer for his laboratory support that allowed the experimental tests to be completed. I am also grateful for Mr. David Van Reenen who helped me to understand and use Heat3 model.

I would like to thank my friends at Carleton University for their support and motivation, especially Sabah Ali, and Omar Abdelalim.

Finally, I would like to express my gratitude to my fiancé, Iman Faris, family and friends for their support and tolerance as I put in innumerable long days at work and too many nights and weekends in front of a laptop. 


\section{Table of Contents}

Abstract

Acknowledgements

Table of Contents iv

List of Tables vii

List of Figures $\quad$ ix

Nomenclature $\quad$ xi

Chapter 1: Introduction 1

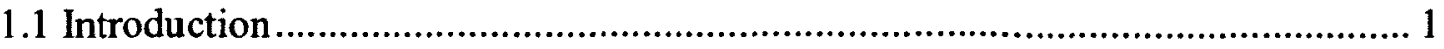

1.2 Study Goals and Specific Objectives ..................................................... 2

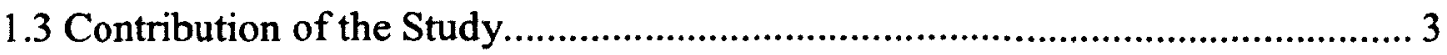

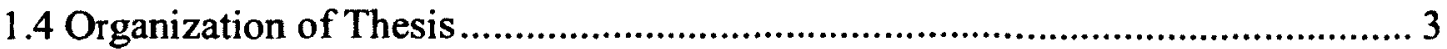

Chapter 2: Background and Literature Review 5

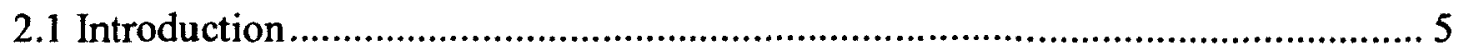

2.2 Heat Transfer Mechanisms .................................................................... 5

2.2.1 Conduction Heat Transfer ............................................................. 7

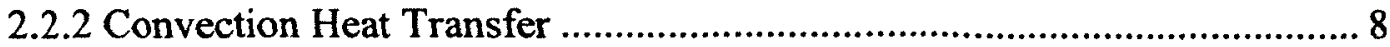

2.2.3 Radiation Heat Transfer ................................................................. 8

2.3 Thermal Performance and Insulating Material .......................................... 9

2.3.1 Thermal Insulation Materials ...................................................... 12

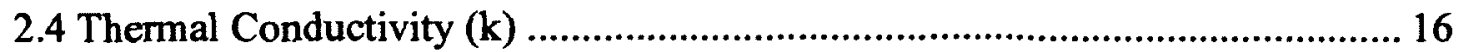

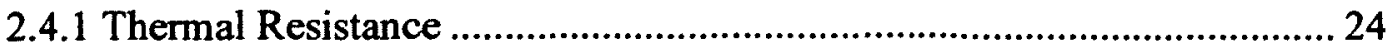


2.4.2 Thermal Conductivity Measurement......................................................... 25

2.4.3 Techniques for Thermal Conductivity Measurement............................... 26

2.4.4 Use of the Guarded Hot Plate Apparatus to Measure Thermal

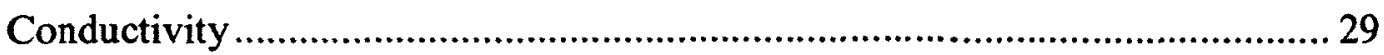

2.4.5 Use of Heat Flow meter Apparatus to Measure Thermal Conductivity... 30

2.5 Measuring Thermal Conductivity of Smaller Specimens .................................. 32

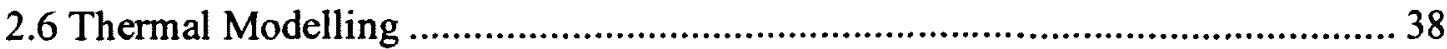

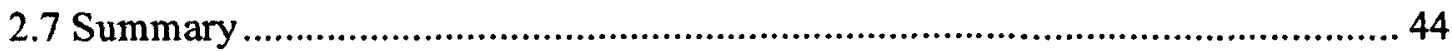

Chapter 3: Experimental Work $\quad 46$

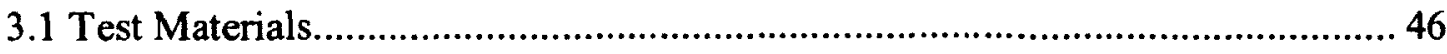

3.2 Test Apparatus and Methods ................................................................................ 47

3.2.1 Heat Flow Meter Apparatus ..................................................................... 47

3.2.2 Thermal Conductivity Measurements Using the Heat Flow Meter ......... 49

3.2.3 Calibration of the Heat Flow Meter Apparatus ........................................ 50

3.2.4 Data Acquisition System ………............................................................... 50

3.2.5 Environmental Conditions................................................................... 52

3.2.6 Specimen Preparation............................................................................... 52

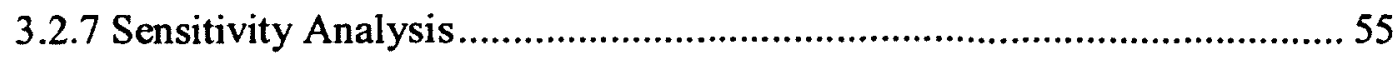

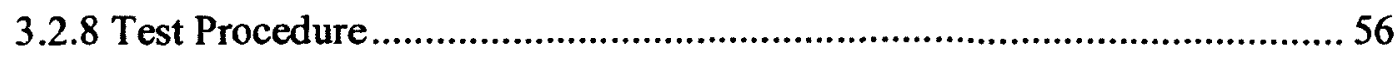

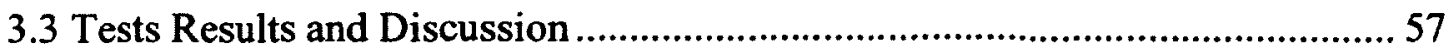

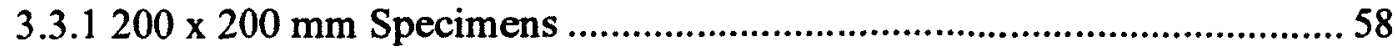

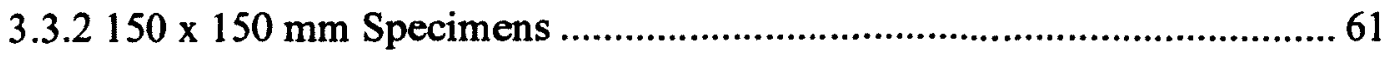

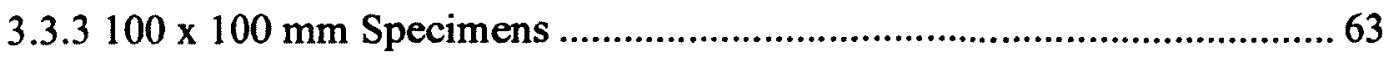




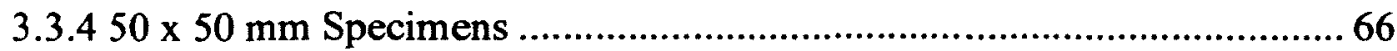

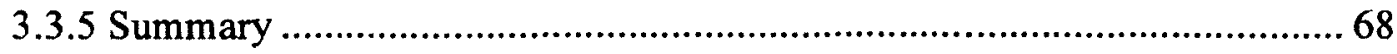

$\begin{array}{ll}\text { Chapter 4: Modelling } & \mathbf{7 0}\end{array}$

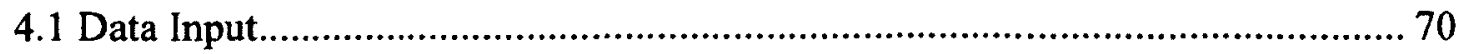

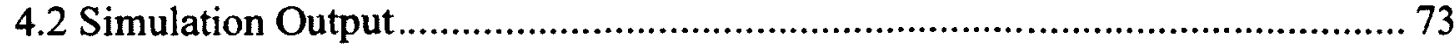

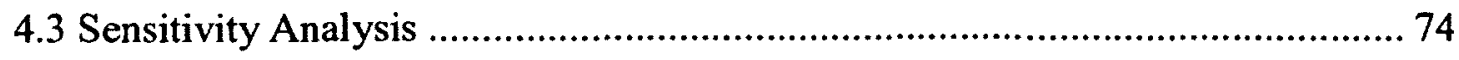

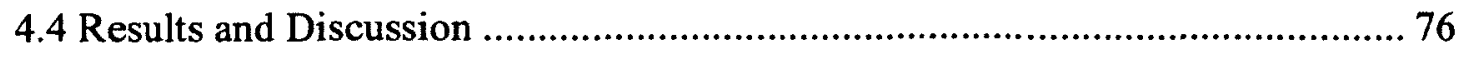

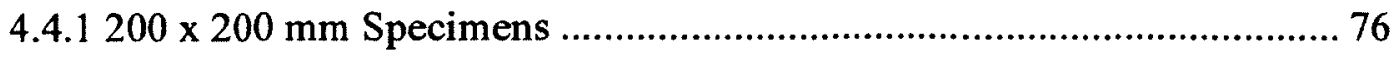

4.4.2 $150 \times 150 \mathrm{~mm}$ Specimens ....................................................................... 78

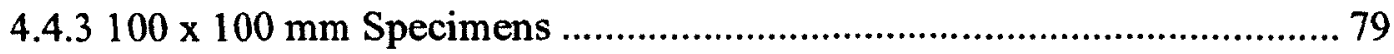

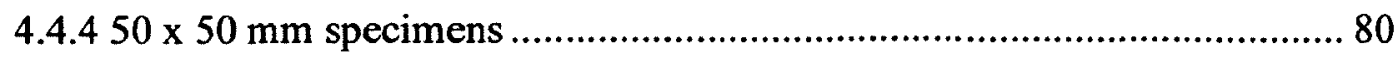

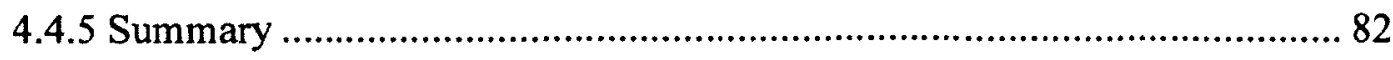

Chapter 5: Conclusions and Recommendations $\quad 83$

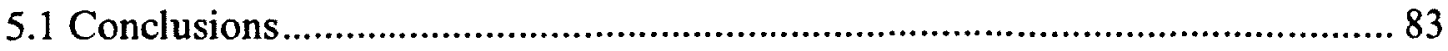

5.2 Recommendations for Future Work.............................................................. 85

References $\quad \mathbf{8 6}$

Appendix A. Thermal Conductivity of Small Specimen with 25 and $12.5 \mathrm{~mm}$ thickness. 


\section{List of Tables}

Table 2.1. Characteristics of common insulation materials [13] ................................. 15

Table 2.2. Blowing Agent types [20]........................................................................ 18

Table 2.3. Standard techniques for measuring thermal conductivity............................... 28

Table 3.1. Type, density and thickness of insulation materials. ....................................... 47

Table 3.2. Number of samples tested for each sample size, per thickness. ...................... 54

Table 3.3 Repeatability of thermal conductivity tests ...................................................... 55

Table 3.4. Thermal conductivity of intact $300 \times 300 \mathrm{~mm}$ specimens (k) and masked $200 \times$

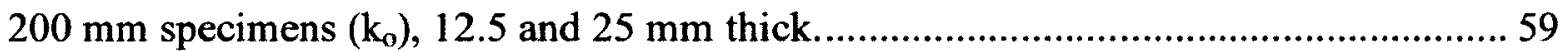

Table 3.5. Measured (k) and derived ( $\left.k^{\prime}\right)$ thermal conductivities of intact $300 \times 300 \mathrm{~mm}$ specimens and masked $200 \times 200 \mathrm{~mm}$ specimens, with 12.5 and $25 \mathrm{~mm}$ thicknesses.... 60 Table 3.6. Thermal conductivity of intact $300 \times 300 \mathrm{~mm}$ specimens $(\mathrm{k})$ and masked $150 \mathrm{x}$ $150 \mathrm{~mm}$ specimens $\left(\mathrm{k}_{\mathrm{o}}\right), 12.5$ and $25 \mathrm{~mm}$ thick

Table 3.7. Measured $(\mathrm{k})$ and derived $\left(\mathrm{k}^{\prime}\right)$ thermal conductivities of intact $300 \times 300 \mathrm{~mm}$ specimens and masked $150 \times 150 \mathrm{~mm}$ specimens, with 12.5 and $25 \mathrm{~mm}$ thicknesses..... 63 Table 3.8. Thermal conductivity of intact $300 \times 300 \mathrm{~mm}$ specimens $(\mathrm{k})$ and masked $100 \mathrm{x}$ $100 \mathrm{~mm}$ specimens $\left(\mathrm{k}_{\mathrm{o}}\right), 12.5$ and $25 \mathrm{~mm}$ thick.

Table 3.9. Measured (k) and derived ( $\left.k^{\prime}\right)$ thermal conductivities of intact $300 \times 300 \mathrm{~mm}$ specimens and masked $100 \times 100 \mathrm{~mm}$ specimens, with 12.5 and $25 \mathrm{~mm}$ thicknesses..... 65 Table 3.10. Thermal conductivity of intact $300 \times 300 \mathrm{~mm}$ specimens $(\mathrm{k})$ and masked $50 \mathrm{x}$ $50 \mathrm{~mm}$ specimens $\left(\mathrm{k}_{\mathrm{o}}\right), 12.5$ and $25 \mathrm{~mm}$ thick.

Table 3.11. Measured (k) and derived ( $\left.k^{\prime}\right)$ thermal conductivities of intact $300 \times 300 \mathrm{~mm}$ specimens and masked $50 \times 50 \mathrm{~mm}$ specimens, with 12.5 and $25 \mathrm{~mm}$ thicknesses......... 68 Table 4.1 Thermal conductivity values measured using intact specimens 73 
Table 4.2. Measured and simulated heat flow (q) for specimens with $200 \times 200 \mathrm{~mm}, 25$

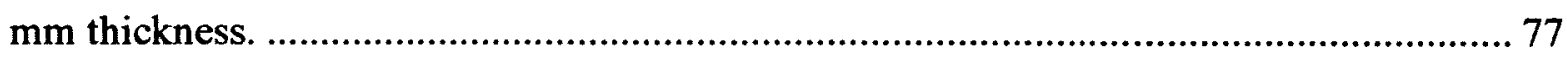

Table 4.3. Measured and simulated heat flow (q) for specimens with $200 \times 200 \mathrm{~mm}, 12.5$

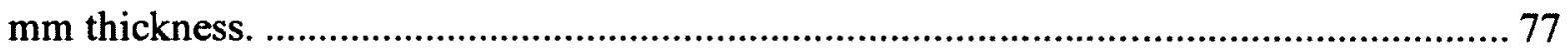

Table 4.4. Measured and simulated heat flow (q) for specimens with $150 \times 150 \mathrm{~mm}, 25$

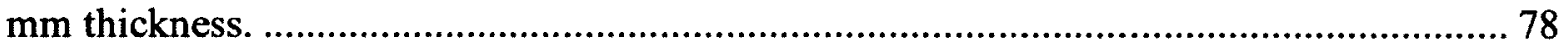

Table 4.5. Measured and simulated heat flow (q) for specimens with $150 \times 150 \mathrm{~mm}, 12.5$

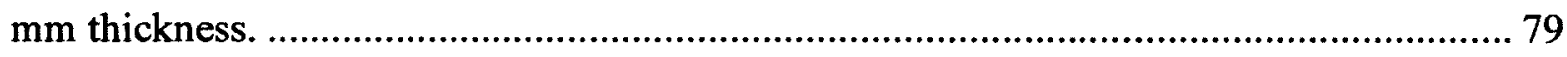

Table 4.6. Measured and simulated heat flow (q) for specimens with $100 \times 100 \mathrm{~mm}, 25$

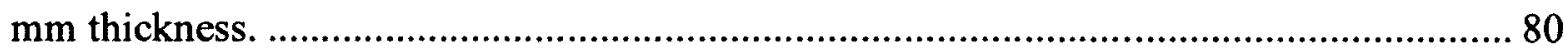

Table 4.7. Measured and simulated heat flow (q) for specimens with $100 \times 100 \mathrm{~mm}, 12.5$

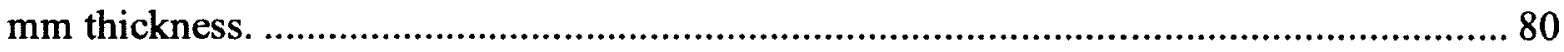
Table 4.8. Measured and simulated heat flow (q) for specimens with $50 \times 50 \mathrm{~mm}, 25 \mathrm{~mm}$

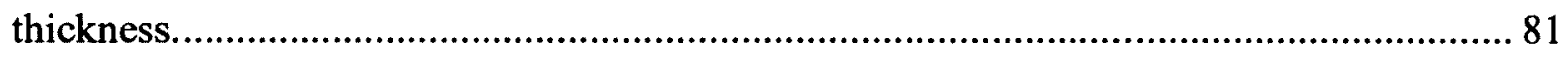

Table 4.9. Measured and simulated heat flow (q) for specimens with $50 \times 50 \mathrm{~mm}, 12.5$

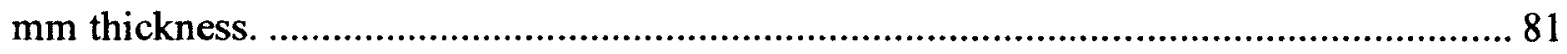




\section{List of Figures}

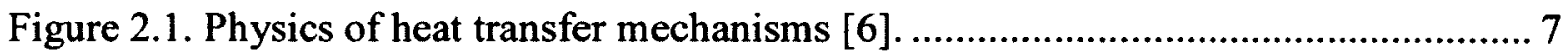

Figure 2.2. Heat loss from a typical house with no insulation [9] ................................... 10

Figure 2.3. Effect of insulation in a typical house [9] ................................................. 11

Figure 2.4. (a) Polystyrene (cellular) insulation [11]; (b) Fiberglass (fibrous) insulation $[8]$.

Figure 2.5. (a) Flake/granular insulation [11]; (b) Reflective insulation [11] ................. 14

Figure 2.6. Schematic diagram showing heat flow through mass insulation [18]........... 17

Figure 2.7. Effect of moisture content on the thermal conductivity of insulation [16] ... 20 Figure 2.8. Comparison of the relative variations of $\mathrm{k}$ with mean operating temperatures [22]. 21

Figure 2.9. Thermal conductivity versus density for various insulation materials [18] .. 22 Figure 2.10. Effect of mass density on thermal conductivity for two values of $\Delta T$ [16].. 23 Figure 2.11. R-values of various insulation materials [3] ............................................... 24

Figure 2.12. Commonly used methods for measuring thermal conductivity [26] ........... 27

Figure 2.13. Schematic diagram of the guarded hot plate apparatus [31] ....................... 30

Figure 2.14. Schematic diagram of the heat flow meter apparatus [35].......................... 31

Figure 2.15. Diagram of Fujino's guarded hot plate apparatus [43]................................ 35

Figure 2.16 Diagram of Muklopadhyaya's heat flow meter apparatus [44]..................... 36

Figure 2.17. Relationship between thermal conductivity measured using intact vs. masked

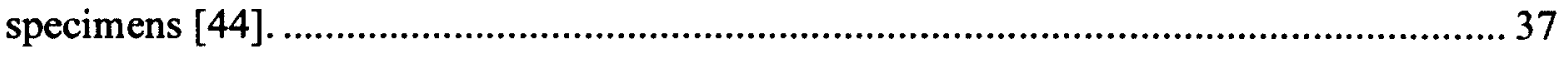

Figure 3.1. Heat flow meter apparatus showing test specimen between two heat flux

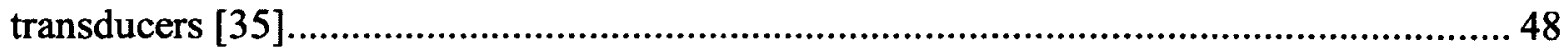

Figure 3.2. Cold and hot plate thermocouple location...................................................... 48

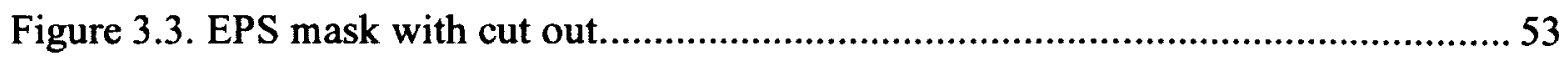




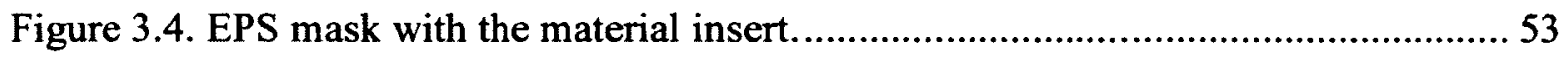

Figure 3.5. Test specimens (LDGF, EPS, XPS, ISO, PUR, HDGF)............................... 54

Figure 3.6. Heat flow meter masked specimen set up. ….................................................... 56

Figure 3.7. Heat flow meter test set up............................................................................ 57

Figure 3.8. Thermal conductivity of masked $200 \times 200 \mathrm{~mm}$ and intact $300 \times 300 \mathrm{~mm}$

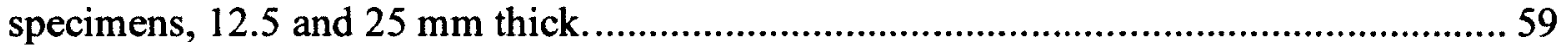

Figure 3.9. Thermal conductivity of masked $150 \times 150 \mathrm{~mm}$ and intact $300 \times 300 \mathrm{~mm}$ samples, 12.5 and $25 \mathrm{~mm}$ thick.

Figure 3.10. Thermal conductivity of masked $100 \times 100 \mathrm{~mm}$ and intact $300 \times 300 \mathrm{~mm}$ samples, 12.5 and $25 \mathrm{~mm}$ thick. 64

Figure 3.11. Thermal conductivity of masked $50 \times 50 \mathrm{~mm}$ and intact $300 \times 300 \mathrm{~mm}$ samples, 12.5 and $25 \mathrm{~mm}$ thick. 66

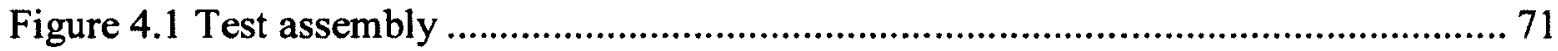

Figure 4.2. Material database library …....................................................................... 71

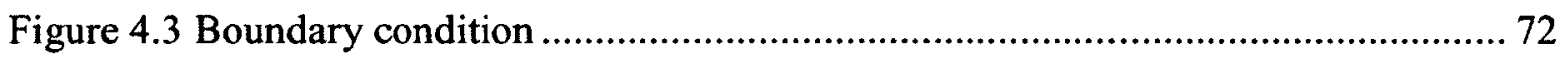

Figure 4.4 Temperature output as shown in the post-processor window. ......................... 74

Figure 4.5 Heat flow output as shown in the post-processor window............................... 74 Figure 4.6. a) Scenario 1: model simulated with no gap and b) Scenario 2: model

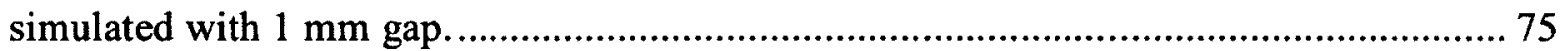

Figure 4.7. a) Scenario 3: model simulated with $0.7 \mathrm{~mm}$ gap and b) Scenario 4: model

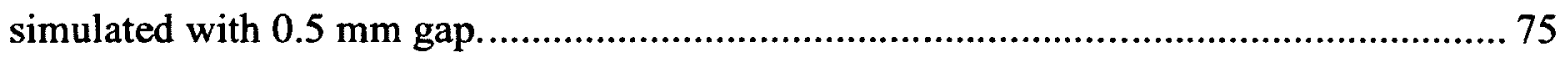




\section{Nomenclature}

$\rho$ - density, $\mathrm{kg} / \mathrm{m}^{3}$

$\mathrm{k}$ or $\lambda,-$ thermal Conductivity, $W /(m K)$

$\sigma$ - Stefan-Boltzmann constant, $5.67 \times 10-8 \mathrm{~W} / \mathrm{m}^{2} \mathrm{~K}^{4}$

$A$ - metering area, $m^{2}$

$A_{\mathrm{t}}$ - total metering area, $m^{2}$

$C$-thermal conductance, $W /\left(m^{2} K\right)$

$\mathrm{Ci}$ - specific heat, $\mathrm{J} / \mathrm{kg} \mathrm{K}$

$E$ - heat flux transducer output, $V$

$\mathrm{k}_{0}$ - thermal conductivity of the reference material, $W /(m K)$

hc - surface coefficient of heat transfer, $W /\left(m^{2} K\right)$

$L$ - separation between the hot and cold plate assemblies during testing, $m$

$L_{0-}$ thickness of the reference material, $m$

$m$ - mass of the specimen, $\mathrm{kg}$

$\mathrm{Q}$ - heat flow rate in the metered area, $W$

$q$ - heat flux (heat flow rate, $\mathrm{Q}$, through area, $A$ ), $W / \mathrm{m}^{2}$

$R$ - thermal resistance, $m^{2} K / W$

$\Delta T$ - temperature difference across the specimen, $T_{h}-T_{c}$

$\mathrm{t}$ - thickness, $m$

$T$ - temperature, ${ }^{\circ} \mathrm{C}$ or $\mathrm{K}$

$T_{\mathrm{h}}$ - hot surface temperature, $K$

$T_{\mathfrak{c}}$ - cold surface temperature, $K$

$T_{\mathrm{m}}$ - mean temperature, $K,\left(T_{h}+T_{c}\right) / 2$

$S$ - calibration factor of the heat flux transducer, $\left(\mathrm{W} / \mathrm{m}^{2}\right) / V$ 


\section{Chapter 1: Introduction}

\subsection{Introduction}

In times of high energy prices and concern about impacts of energy usage on the environment, use of thermal insulation materials to reduce the energy consumption is of particular importance. Thermal insulation is one of the most effective energy conservation measures for cooling and heating buildings, limiting energy consumption by reducing both heat loss or gain and hence the heating and cooling period [1]. Effective insulation improves the conservation of existing energy and allows the use of simpler heating and cooling systems. Therefore, manufacturers and end users are constantly searching for new, more energy-efficient and cost-effective building insulation materials.

Thermal performance of a new insulation product is primarily assessed based on its thermal properties, including thermal conductivity or thermal resistance. Most measurements of thermal conductivity or thermal resistance of building insulations, other than pipe insulation, are now made using a guarded hot plate apparatus or a heat flow meter apparatus [2]. These methods require samples $300-600 \mathrm{~mm}$ in length and width, and 20

- $200 \mathrm{~mm}$ in thickness. When an insulation manufacturer/researcher develops a new product, samples of such sizes are often not available. It is also not feasible to build a new apparatus or modify an existing apparatus every time a different size sample needs to 
be tested. Manufacturers need to acquire data rapidly and with sufficient accuracy to make informed decisions in a timely manner. Consequently, an alternative method of measuring the thermal conductivity of small insulation samples is needed.

The present study tested a new method for measuring thermal conductivity of smaller samples of building insulation materials. Results of the new method were verified to measurements made using larger samples of the same materials, in compliance with ASTM C518, the Standard Test Method for Steady-State Thermal Transmission Properties by Means of the Heat Flow Meter Apparatus. The results were also compared to thermal conductivity of the smaller samples predicted by the modelling software tool, HEAT3. Based on the experimental and modelling results, simplified empirical calculation methods were developed.

\subsection{Study Goals and Specific Objectives}

The goal of the present study is to develop and determine the accuracy of a new method aimed at measuring thermal conductivity of smaller specimens of thermal insulation materials, using the heat flow meter apparatus. Various test materials and samples of different sizes and thicknesses were used. The specific objectives are as follow:

- develop a test method for measuring the thermal conductivity values of small insulation specimens,

- verify the accuracy of the new methodology by comparing the results to measurements made for larger samples of the same materials by the standard test methodology specified in ASTM C518, and 
- evaluate the new methodology by comparing the results to thermal conductivities predicted using a mathematical model based on HEAT3 software.

\subsection{Contribution of the Study}

The methodology proposed for determining thermal conductivity of smaller specimens will be useful by manufacturers developing new insulation materials, particularly foams. The methodology can be used to analyze different types, sizes, and thicknesses of insulation materials that were not examined in the present study.

The experimental tests were validated by using the finite element modelling which is specifically applicable to smaller specimens. The validation extended the use of models for examining thermal properties of insulation materials, and demonstrated that the 3-D heat transfer analysis was accurate for predicting heat transfer at specified temperatures.

\subsection{Organization of Thesis}

This thesis is organized into six chapters.

- Chapter 1 (Introduction): introduces the problem, explains the study goals and objectives.

- Chapter 2 (Background and Literature Review): reviews the literature on thermal properties of insulation materials, with a particular focus on methodologies used for measuring thermal conductivity of composite materials.

- Chapter 3 (Experimental Work): describes the methodology used to determine thermal conductivity of smaller specimens using a heat flow meter apparatus, and re- 
ports on the thermal conductivity values determined for a variety of insulation materials using the new methodology with smaller specimens.

- Chapter 4 (Modelling): describes the HEAT3 modelling tool used, and discusses the results of the scenarios simulated to validate the experimental results.

- Chapter 5 (Conclusion and Recommendations): presents the conclusions from this study and recommendations for future work. 


\section{Chapter 2: Background and Literature Review}

Chapter 2 provides an introduction to thermal insulation, heat transfer mechanisms, and thermal conductivity measurements, and reviews results of previous studies related to thermal conductivity measurement of small specimens.

\subsection{Introduction}

Insulation material is defined as a material, or combination of materials, which provides resistance to the flow of heat [3]. The materials can usually be adapted to a variety of sizes, shapes, and surfaces. Thermal insulation materials are specifically designed to conserve energy by reducing heat loss or gain; to control surface temperatures for personnel protection and comfort; and to increase efficiency of heating, ventilating, and cooling in commercial, residential and industrial installations [3]. To understand the properties of insulation materials and the various approaches to insulating a building, it is necessary to understand the mechanisms of heat transfer.

\subsection{Heat Transfer Mechanisms}

Heat transfer is the transmission of energy from one region to another, as a result of a temperature gradient. For example, a difference of temperature between the interior of a 
building and the exterior environment, or between different parts of a building, will result in a transfer of heat from the warmer to the cooler area. The rate at which heat flows between the two locations is called the rate of heat transfer. The variables that control the rate of heat transfer are temperature difference, material, area, air-flow, air gaps, thickness or distance.

The transfer of heat from a hot to a cold location will continue as long as there is a difference in temperature. Once the two locations reach the same temperature, thermal equilibrium is established, and the heat transfer stops. The rate of heat transfer is directly proportional to the surface area through which the heat is being conducted [4], more heat will be lost from a home through a large window than through a small window of the same composition and thickness. The rate of heat transfer is inversely proportional to the thickness of the wall it is passing through, i.e., heat is transferred more rapidly through a thin wall than through a thick wall when subjected to the same temperature difference [5].

The application of the principles of insulation to building design requires understanding the different modes of heat transfer that influence heat gains and losses in buildings. Three basic mechanisms control the insulating capacity of conventional thermal insulation materials: conduction, convection, and radiation (Figure 2.1). 

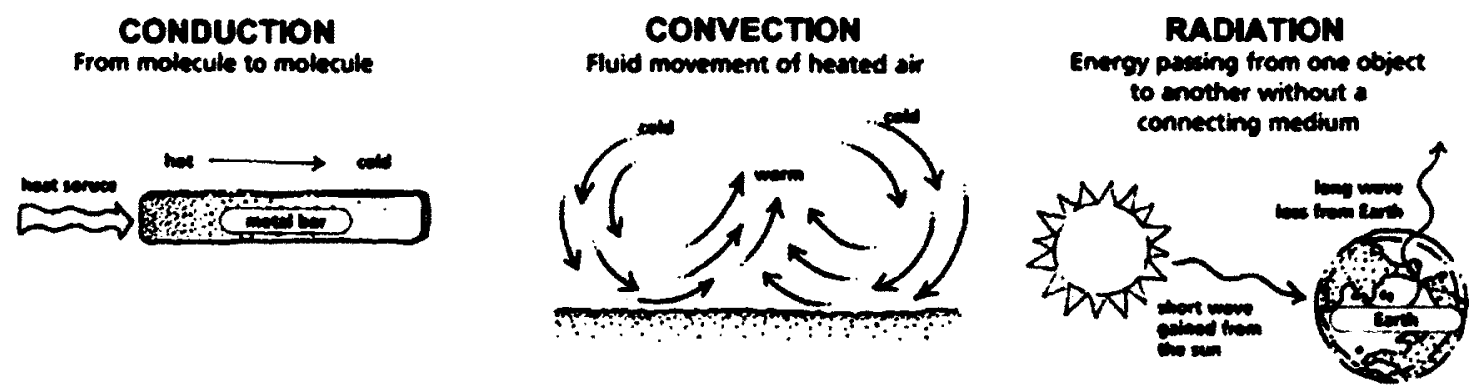

Figure 2.1. Physics of heat transfer mechanisms [6].

\subsubsection{Conduction Heat Transfer}

Conduction is the most significant means of heat transfer in solid materials. Conduction is the process by which heat flows through or along a material, or between two solids materials that are in contact. Conduction occurs as hot, rapidly moving or vibrating atoms and molecules transfer some of their energy as heat to neighboring atoms and molecules [5].

Whenever a temperature gradient exists in a solid medium, heat flows from the higher to the lower temperature region. The rate at which heat is transferred by conduction, $q$ (W), is proportional to the temperature gradient, $\mathrm{dT} / \mathrm{dx}$, times the area, $\mathrm{A}\left(\mathrm{m}^{2}\right)$, through which heat is transferred,

$$
\dot{q} \propto A \frac{d T}{d x}
$$

where $\mathrm{T}$ is the local temperature in Kelvin $(\mathrm{K})$, and $\mathrm{x}$ is the distance, in meters $(\mathrm{m})$, in the direction of heat flow in watts (W). The actual rate of heat flow depends on the thermal conductivity, $\mathrm{k}(\mathrm{W} / \mathrm{mK})$, which is a physical property of the medium. For conduction 
through a homogeneous medium, the rate of heat transfer is calculated using Equation 2.1, known as Fourier's law.

$$
q=-k A \frac{d \mathrm{~T}}{d x}
$$

\subsubsection{Convection Heat Transfer}

Heat transfer by convection occurs in liquids and gases. Differences in density, due to variations in temperature cause movement of the liquid or gas resulting in the transfer of heat. There has to be a temperature difference, or no heat transfer occurs. Convection heat also transfer occurs at the surfaces of walls, floors, and roofs, when the surface is warmer or cooler than the adjacent air. The rate of transfer increases, if air movement is enhanced, for example, by wind or a fan [6]. The rate of heat transfer by convection between a surface and a fluid can be calculated from Equation 2.2.

$$
\dot{q}_{c}=h_{c} A \Delta T
$$

Where $q_{c}$ is the rate of heat transfer by convection in watts (W), $A$ is the heat transfer

area in square meters $\left(\mathrm{m}^{2}\right), \Delta \mathrm{T}$ is the difference between the surface temperature and a temperature of the fluid at some specified location, $(\mathrm{K})$, and $\bar{h}_{c}$ is the surface coefficient of heat transfer, $\left(\mathrm{W} / \mathrm{m}^{2} \mathrm{~K}\right)$.

\subsubsection{Radiation Heat Transfer}

In heat transfer by radiation, heat is emitted from a body and transmitted through space as energy. All bodies emit radiant energy, and the rate of emission depends on the 
temperature of the body and on the nature of its surface. Radiation is the only form of heat transfer that can occur in the absence of a medium, i.e., in a vacuum. Thermal radiation is based on the emission of electromagnetic radiation, which carries energy away from a surface [7]. The quantity of energy leaving a surface as radiant heat depends on the absolute temperature and the nature of the surface. A perfect radiator or blackbody emits radiant energy from its surface at a rate $\dot{q}$ given by Equation 2.3 .

$$
\dot{q}=\sigma A_{s}\left(T_{s}^{4}\right)
$$

Where $\dot{q}$ is the heat transfer per unit time (W), $\sigma$ is the Stefan-Boltzmann constant, and is equal to $5.670310-8\left(\mathrm{~W} / \mathrm{m}^{2} \mathrm{~K}^{4}\right), \mathrm{T}$ is the temperature in Kelvin $(\mathrm{K})$, and $\mathrm{A}$ is the area $\left(\mathrm{m}^{2}\right)$ of the emitting body.

\subsection{Thermal Performance and Insulating Material}

Thermal insulation is used to minimize radiative, convective, and conductive heat transfer. Insulation helps to maintain a comfortable indoor living environment by maintaining steady temperatures and, at the same time, reducing energy consumption [8]. The main purpose of insulation is to create a thermal barrier around the building, over the roof, on the walls, and beneath the floor to resist heat transfer. This helps to reduce the amount of heat gained on a warm day and the amount of heat loss on a cold day. Figure 2.2 , illustrates the different ways heat air is lost in a house. Since the majority of heat is lost or gained through the roof and the exposed walls, these areas are the most fundamental places to insulate in order to create a comfortable and energy efficient home. 


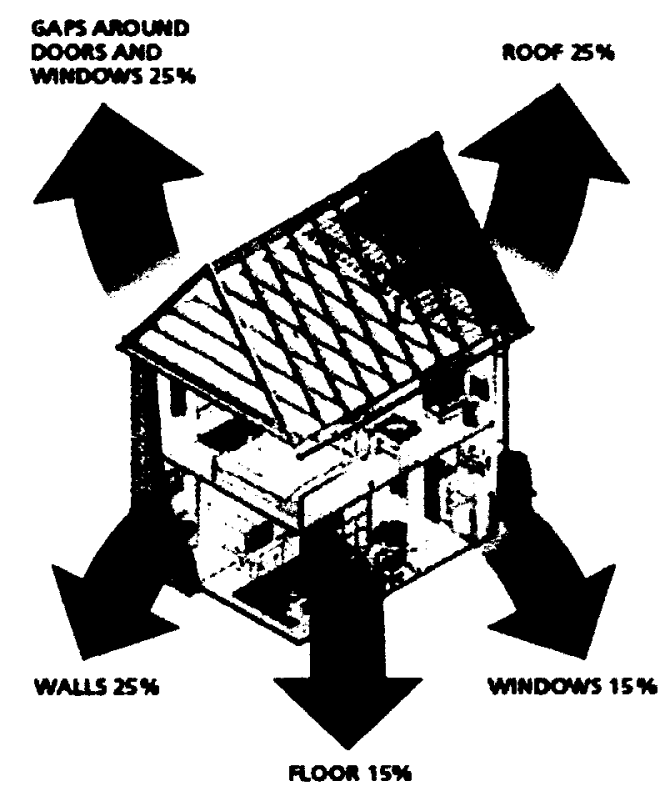

Figure 2.2. Heat loss from a typical house with no insulation [9].

In a house with insulation, heat flow through its boundaries is limited to an extent that depends on the capacity of the material to conduct heat. Effective insulation prevents heat from being transmitted through the roof and walls. The interior remains relatively cool in the summer and warm in the winter, compared to the exterior environment, because most heat transfer is blocked by the insulation barrier. Thus, the interior temperature can be kept comfortable with less heating and cooling energy [10].

On a hot day, the temperature of the roof and walls increases, until they start to emit heat to the interior of the building. Materials with the capacity to store heat, such as concrete and brick, can remain warm during the night, continuing to make the building inte- 
rior uncomfortably hot. The opposite happens during cold weather where heat from the interior of the house is absorbed by the roof and walls and emitted to the exterior environment, so that the interior temperature can eventually match the cold exterior temperature.

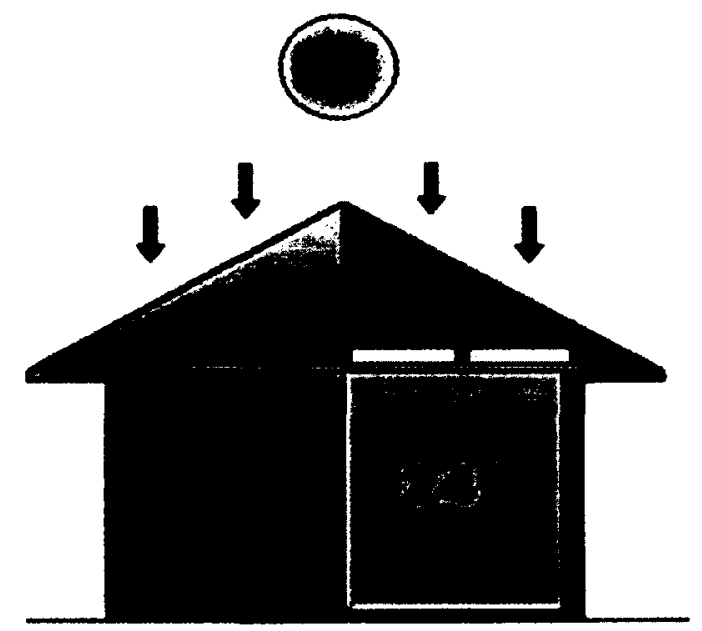

Figure 2.3. Effect of insulation in a typical house [9].

The effectiveness of insulation as a heat barrier is determined by many factors, most importantly by its thermal conductivity. This value denotes the resistance against heat transfer across the material. Thermal conductivity is the property used in the industry to compare different types of insulation. However, other factors, such as cost, safety, and feasibility of the product are also considered in choosing insulation for a specific use $[10]$. 


\subsubsection{Thermal Insulation Materials}

A variety of insulation materials is available, with different applications, and can be divided into four main groups [11]:

- cellular insulation,

- fibrous insulation,

- flake/granular insulation, and

- reflective insulation.

\section{Cellular Insulation}

Cellular insulation is composed of small individual cells either closed-cell or opencell. The material is in the form of extended flexible or rigid boards, and is used in roofs, walls, and under floors. Cellular insulation has the advantage of low density, low heat capacity, and relatively high compressive strength. Examples of cellular insulations are polystyrene, polyisocyanurate (polyiso), polyurethane, and foam rubber [11]. All of these materials are produced in rigid sheet form (Figure 2.4a), and some can be sprayed into the cavities of walls.

\section{Fibrous Insulation}

Fibrous insulation, such as rock wool, sheep's wool, and glass fiber (Figure 2.4b) is commonly used for insulating attics and walls. These materials are generally manufactured in blanket rolls or rigid sheets. Fibrous insulations are composed of small diameter 
fibers that finely divide the air space. The fibers might be perpendicular or parallel to the surface being insulated, and might or might not be bonded together. Fibrous materials have high porosity ( $90 \%$ ). Mineral wool is a common fibrous insulation used at temperatures below $700^{\circ} \mathrm{C}$, and fiberglass is often used at temperatures below $200^{\circ} \mathrm{C}$ [12].
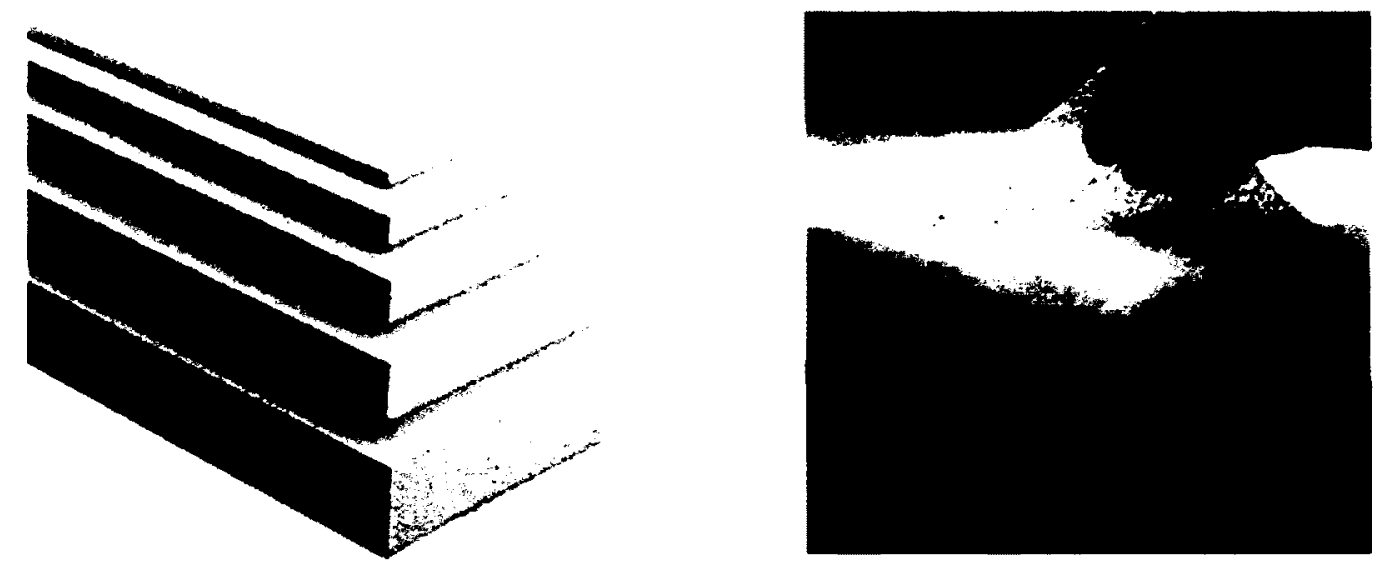

Figure 2.4. (a) Polystyrene (cellular) insulation [11]; (b) Fiberglass (fibrous) insulation [8].

\section{Granular/Flake Insulation}

Granular/flake insulation is an open cell material, consisting of small nodules containing air pockets, or small flakes that divide the air, and is commonly used in attics (Figure 2.5a). Granular/flake insulation is not considered to be true cellular material, as gas can be transferred between the spaces. This insulation is produced in the form of loose fill/pourable material, which can be combined with a binder and fibers to make rigid insulation. Examples are expanded vermiculite, perlite, and cellulose [12]. 
Reflective Insulation

Reflective insulation is a thermal insulating coating that provides a radiant barrier (Figure 2.5b). Instead of reducing conductive heat flow, it reduces radiant heat flow. Reflective insulation only works when there is an air gap between the heat source and the reflective surface because when an air gap exists in a building's shell, heat moves across the gap via radiation [12]. This type of insulation is added to surfaces, such as ceilings, to lower heat transfer to and from those surfaces.
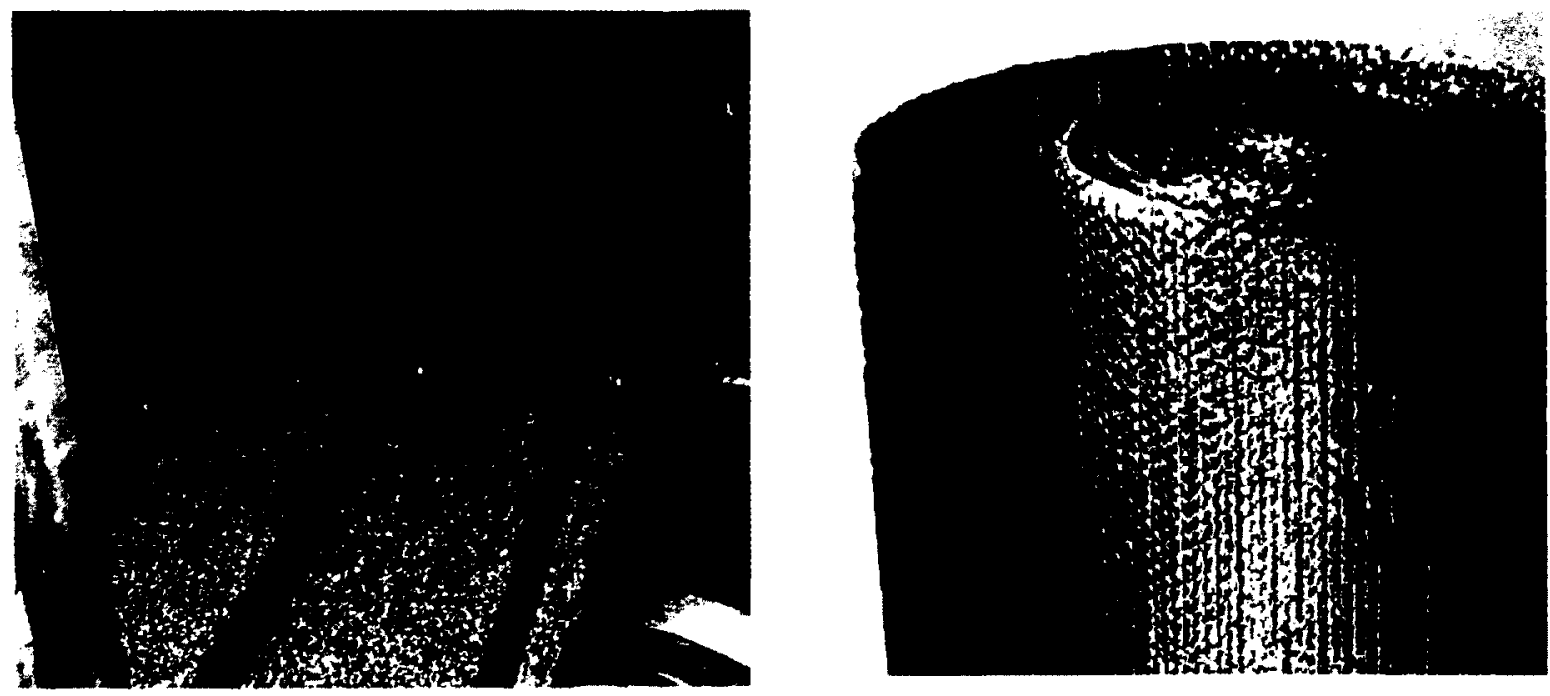

Figure 2.5. (a) Flake/granular insulation [11]; (b) Reflective insulation [11].

Thermal insulation materials are heterogeneous in nature, so some variation in properties must be expected. The primary goal is to ensure that the material performs at the level it was originally designed for, based on the assumption that all properties remain 
unchanged. However, actual performance can be affected by the manufacturing process, packing, handling, transportation, installation, time, and the environment.

Characteristics of three types of insulation and their associated properties such as density, and thermal conductivity are shown in Table 2.1 .

Table 2.1. Characteristics of common insulation materials [13].

\section{Property}

Density $\rho\left(\mathrm{kg} / \mathbf{m}^{3}\right)$

Thermal Conductivity (W/mK)

\section{Cellular}

Expanded polystyrene

$16-35$

$0.032-0.037$

Extruded polystyrene

$20-33$

0.024-0.026

Polyisocyanurate

$24-55$

$0.021-0.027$

Polyurethane

$27-49$

$0.021-0.033$

\section{Fibrous}

Low density glass fiber

$$
12-56
$$

0.033-0.040

High density glass fiber

$66-150$

0.031-0.043

Rockwool

$40-200$

$0.036-0.045$

\section{Granular/fake}

Vermiculite

$64-130$

0.063-0.068

Perlite

$32-176$

0.040-0.060 


\subsection{Thermal Conductivity (k)}

All materials have thermodynamic properties which are used in the evaluation of the materials and in heat energy calculations [15]. Thermal conductivity is the property that determines the ability of a material to transfer heat. The heat conduction equation is directly used to determine the thermal conductivity of materials, according to Fourier's law [14], Equation 2.1, thermal conductivity $(\mathrm{W} / \mathrm{mK})$ is defined in Equation 2.4 .

$$
k=\frac{Q \Delta_{x}}{A \Delta_{T}}
$$

Thermal conductivity is a measure of the rate at which heat flows through a material when there is a temperature difference between its surfaces, i.e., the quantity of heat passing through the material, per unit of time, per unit area, at a temperature difference. Thermal conductivity is expressed as watts per metre thickness of material for a temperature gradient of one Kelvin (W/mK).

The thermal conductivity value depends on the medium and varies with aging effects, density, moisture content, and temperature [16].

\section{Structure of Insulation}

Most insulation materials presently used in buildings have two basic structures: a continuous body of gas that contains a dispersion of solid particles or fibres; and a con- 
tinuous matrix of solid material with a random dispersion of gas-filled cavities [17] (Figure 2.6).

When a small amount of opaque solid material is distributed throughout an air space, it inhibits heat transfer by convection and radiation while contributing little to conduction, thereby raising the value of the thermal resistance of the space. Solids such as glass, rock and plastic that provide little resistance to heat flow can be used in this way to produce good insulation [19].
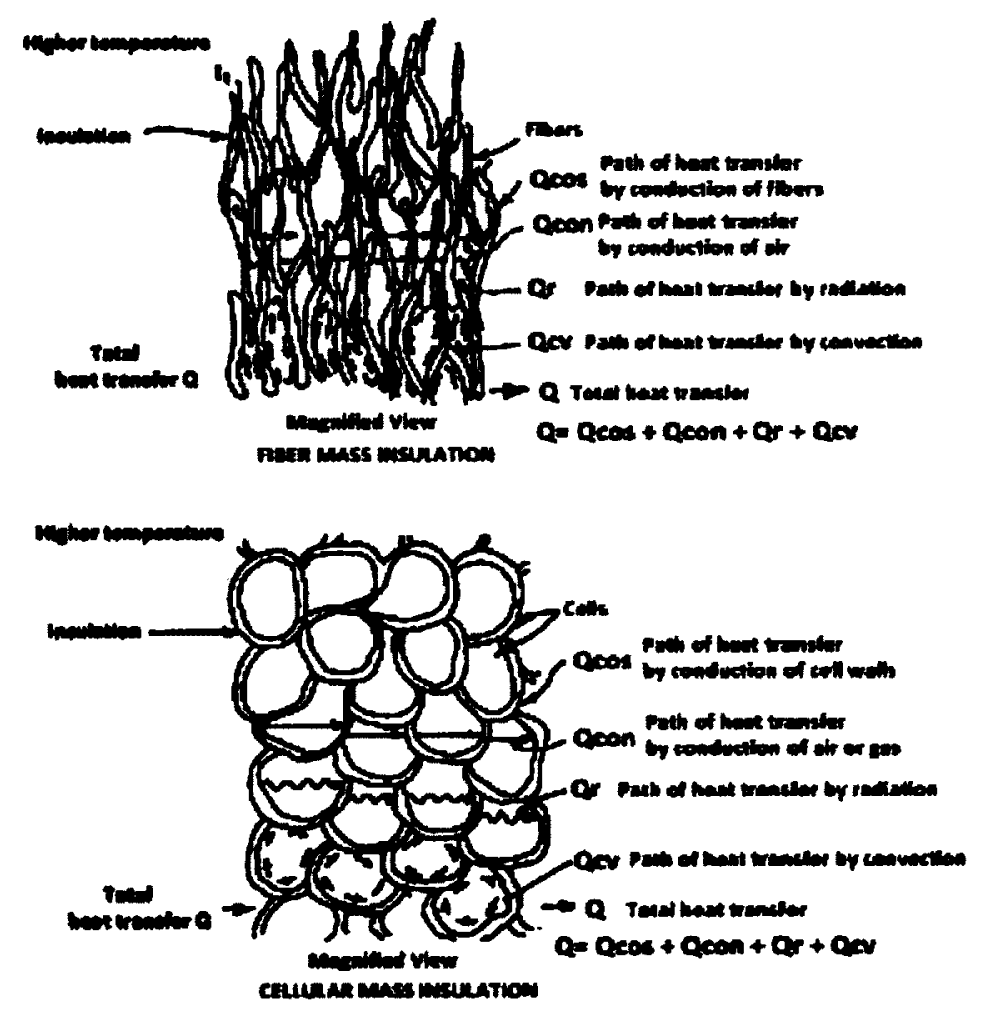

Figure 2.6. Schematic diagram showing heat flow through mass insulation [18]. 
The closed-cell type of insulation can have gases other than air in the cells and thus can have resistances higher than are possible for air-filled materials. The closed-cells are filled up by the captive gaseous blowing agent(s) during the manufacturing process of the foam [20]. The thermal conductivity of the blowing agent is usually lower than air. In effect, the presence of blowing agents inside the closed-cell reduces the air conduction component of thermal conductivity significantly depending on the type of blowing agent used in the closed-cell foam insulation [20] (Table 2.2).

Table 2.2. Blowing Agent types [20]

\begin{tabular}{cc}
\hline Blowing Agent & Thermal Conductivity $\left[\mathrm{k}_{\text {gas }} @ 25\left({ }^{\circ} \mathrm{C}\right) \mathrm{mW} / \mathrm{mK}\right]$ \\
\hline CFC-11 & 8.7 \\
HCFC-22 & 11 \\
HFC - 134a & 12 \\
Hydrocarbon c- C5 & 15 \\
Air & 26 \\
\hline
\end{tabular}

Aging Effects

Thermal conductivity of the closed-cell foam insulation, due to the presence of captive blowing agents inside the close-dell, increases over time as air diffuses into and blowing agents(s) diffuses out of the closed-cells [17].

The rate at which this diffusion (also called aging) occurs depends on a number of parameters such as properties of foam, geometry and structure of the cells, expose con- 
ditions, density of material, and manufacturing process. Gases with large molecules such as Freon-11 may take years to diffuse out of high quality urethane foam, but carbon dioxide can diffuse out of the same foam in only a few days and air may diffuse into the cells in a matter of weeks [20]. This aging process slows down with the time and almost reaches to an equilibrium state after a certain time. The fully aged value of resistance should be used for buildings expected to have a life span of many decades [20]. Open cell insulations contain only air and are not subject to this aging effect.

\section{Moisture}

Moisture in a material is usually measured by weight and expressed as a percentage of the weight of the material when completely dry, or as a percentage of the weight of the saturation content the maximum amount that the material can hold. The higher the moisture content of the material, the greater the thermal conductivity value (Figure 2.7).

The saturation moisture content and the percentage increase in the $\mathrm{k}$ value due to saturation, vary considerably for different materials. Thermal insulation is typically advertised using its thermal conductivity in a dry state. In practice, however, thermal conductivity values should be relevant to the range of moisture content that is likely to predominate in the material when used in a structure. The thermal conductivity value is usually determined for material stored at $22^{\circ} \mathrm{C}$ under normal atmospheric conditions. Thermal conductivity values of insulation materials are typically below $0.060 \mathrm{~W} / \mathrm{m} . \mathrm{K}$ at $10^{\circ} \mathrm{C}$. The 
lower the thermal conductivity value, the better the insulation performance of the material $[21]$.

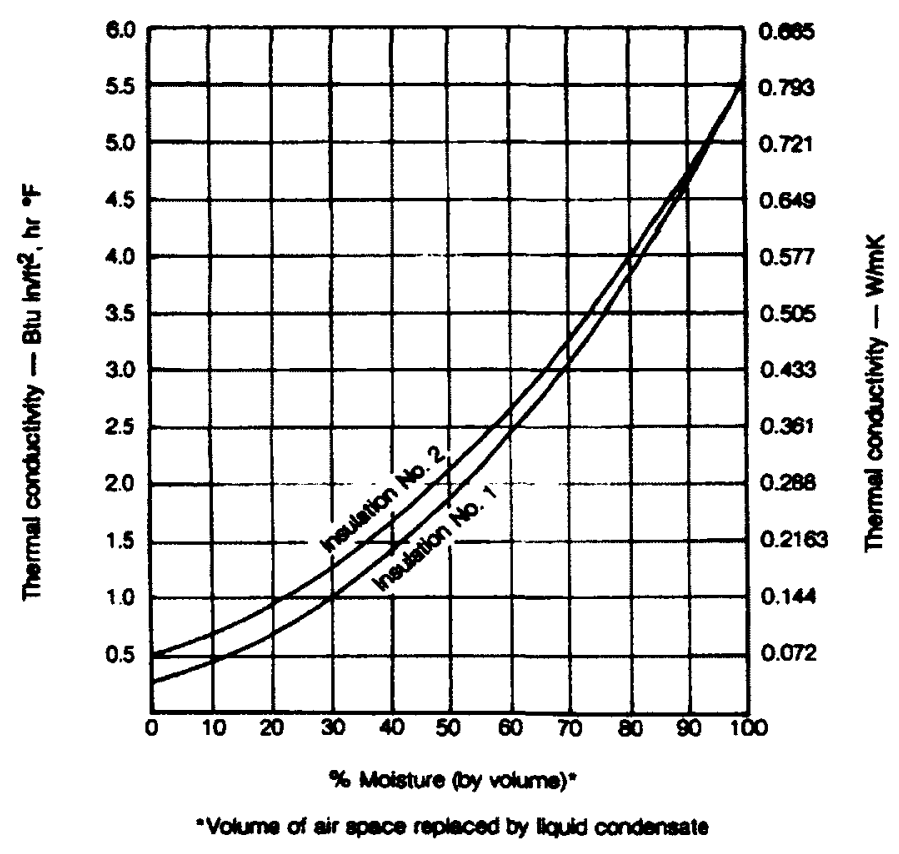

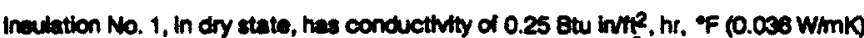
invulation No. 2, in ory state, has conductuty of 0.5 Btu int? hr, $\%$ (0.072 W/mK)

Figure 2.7. Effect of moisture content on the thermal conductivity of insulation [16].

\section{Temperature}

Temperature is another factor influencing the rate of heat flow through a material. The conductivity of a material changes with variation in mean temperature, temperature difference, and direction of heat flow. All of these factors must be considered in the determination of the thermal conductivity of an insulating material. Thermal conductivities can be considerably greater at high temperatures than at low temperatures [22], however; the variation in thermal conductivity over the range of temperatures commonly occurring 
in buildings is comparatively small and the values measured at normal atmospheric temperatures are generally used when considering structural insulation.

A comparison of the relative variations of thermal conductivity with mean operating temperatures for different samples of insulation materials is illustrated in Figure 2.8. It can be seen that the thermal conductivity values of all insulation materials are affected in varying degrees with operating temperature. In all cases, however, a higher temperature leads to higher thermal conductivity values [22].

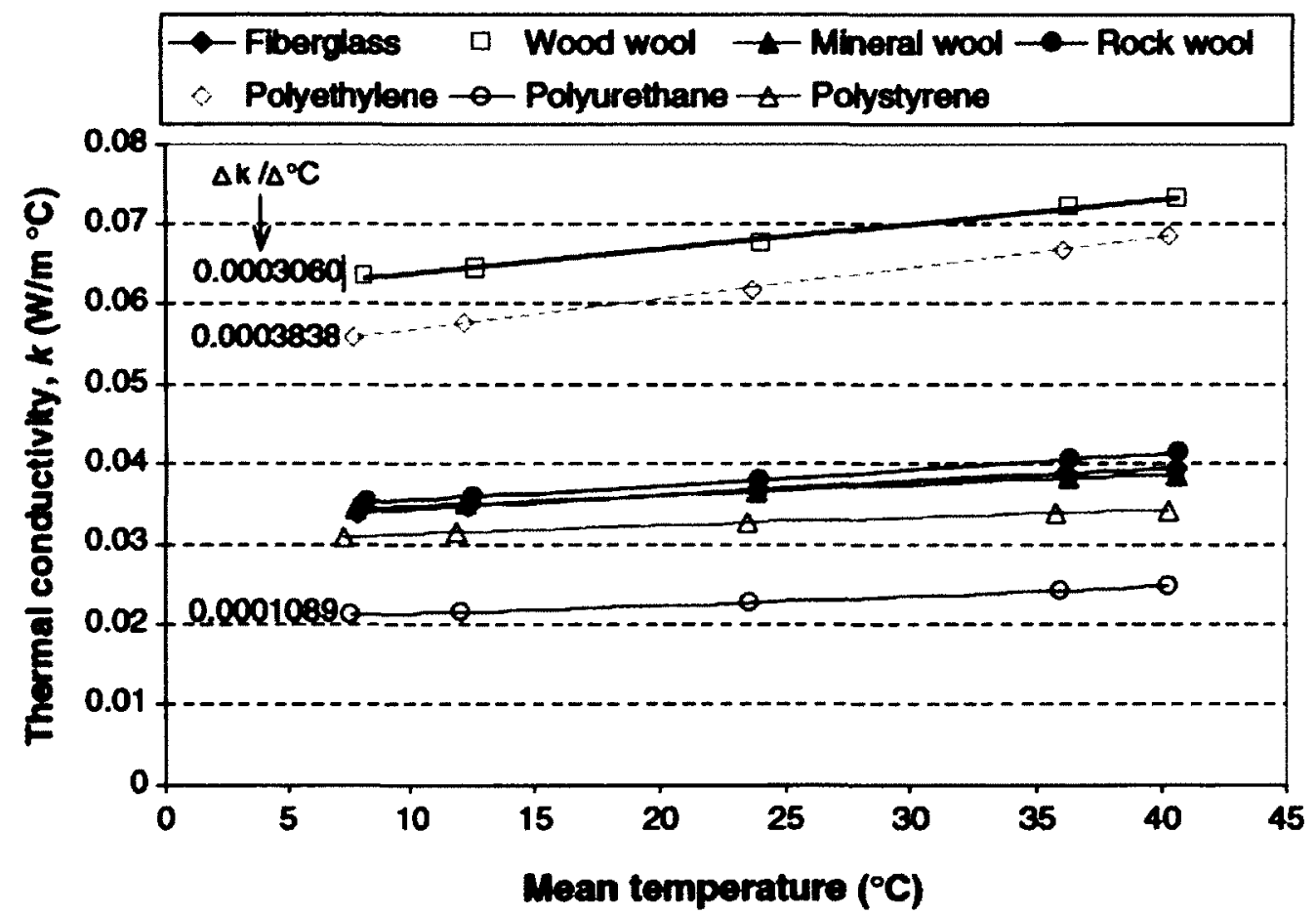

Figure 2.8. Comparison of the relative variations of $k$ with mean operating temperatures [22]. 


\section{Density}

Density of the material affects its thermal conductivity. Dense materials generally have higher thermal conductivity and, therefore, are poor insulators compared to lightweight materials [18] (Figure 2.9). The thermal conductivity (k) of Glass Fiber A decreases sharply from 0.4 to 0.25 when the density increases from 8 to $16 \mathrm{~kg} \mathrm{~m}^{-3}$. However, when the density reaches $24 \mathrm{~kg} \mathrm{~m}^{-3}$ the density does not have a big effect on the thermal conductivity value. Glass Fiber B exhibits a similar, but more gradual, change in thermal conductivity as the density increases. In contrast, density has only a small effect on the thermal conductivity of Cellulosic, and no significant effect on the thermal conductivity of Extruded Polystyrene or the Polyurethane.

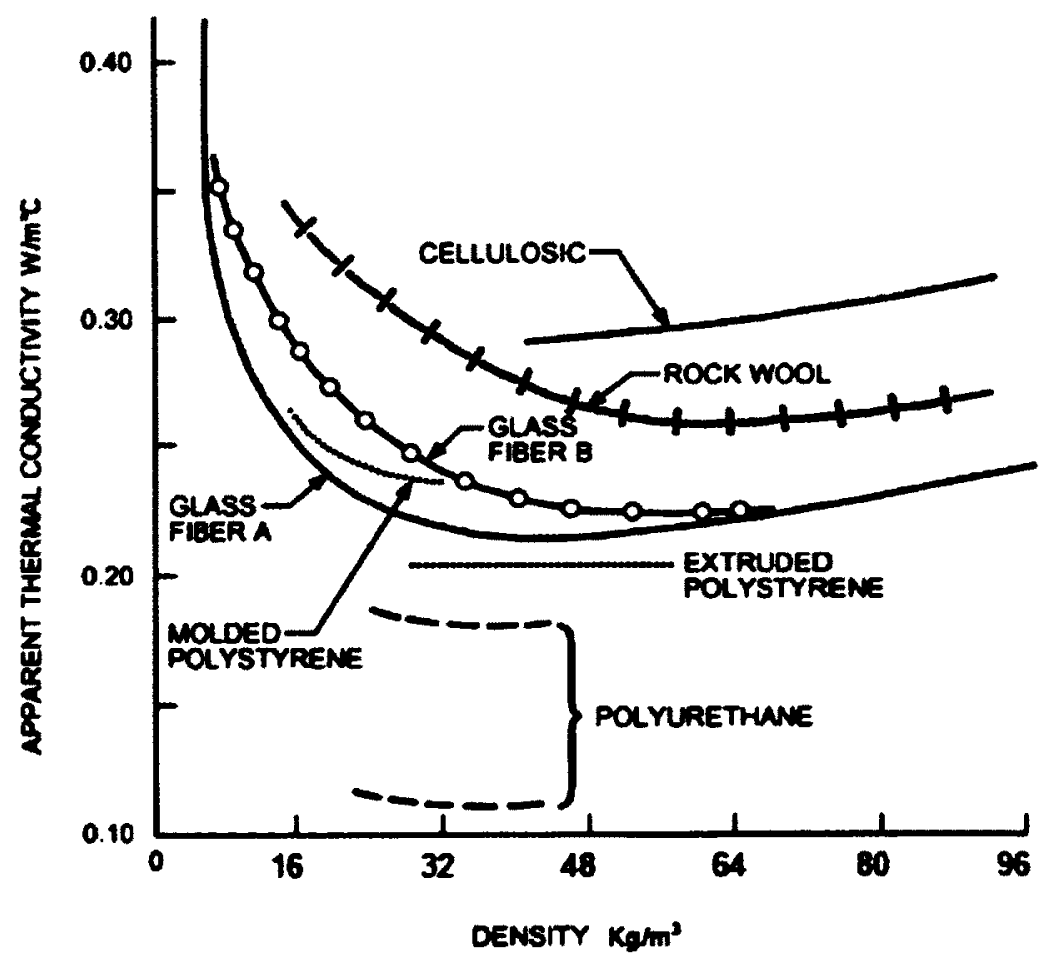

Figure 2.9. Thermal conductivity versus density for various insulation materials [18]. 
Heat is more easily transferred across a flake or fiber insulation containing a few large air spaces than across a material with many small air spaces. Thus, for a given mean temperature and temperature difference, there is an optimum density at which a material is most efficient in reducing heat flow [19]. Therefore, conductivity decreases with increasing density until the lowest conductivity is reached, then increases with further increases in density as per Figure 2.10. The density at which conductivity is lowest depends on temperature. Therefore, determining the mass density and temperature at which the minimum thermal conductivity is achieved is important in selecting the insulation material.
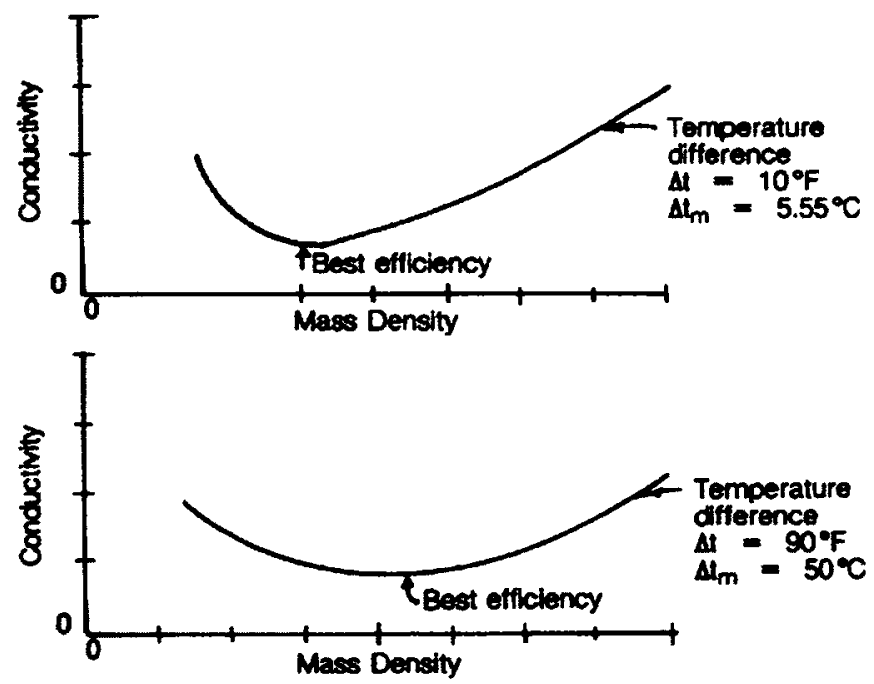

Figure 2.10. Effect of mass density on thermal conductivity for two values of $\Delta T[16]$. 


\subsubsection{Thermal Resistance}

Thermal resistance is the ability of a specific insulation material to resist heat transfer at a given thickness, and is expressed as an R-value in the building and construction industry. The R-value is the most effective measure for comparing the performance of different materials and thicknesses. The higher the R-value the more effective the insulation (Figure 2.11).

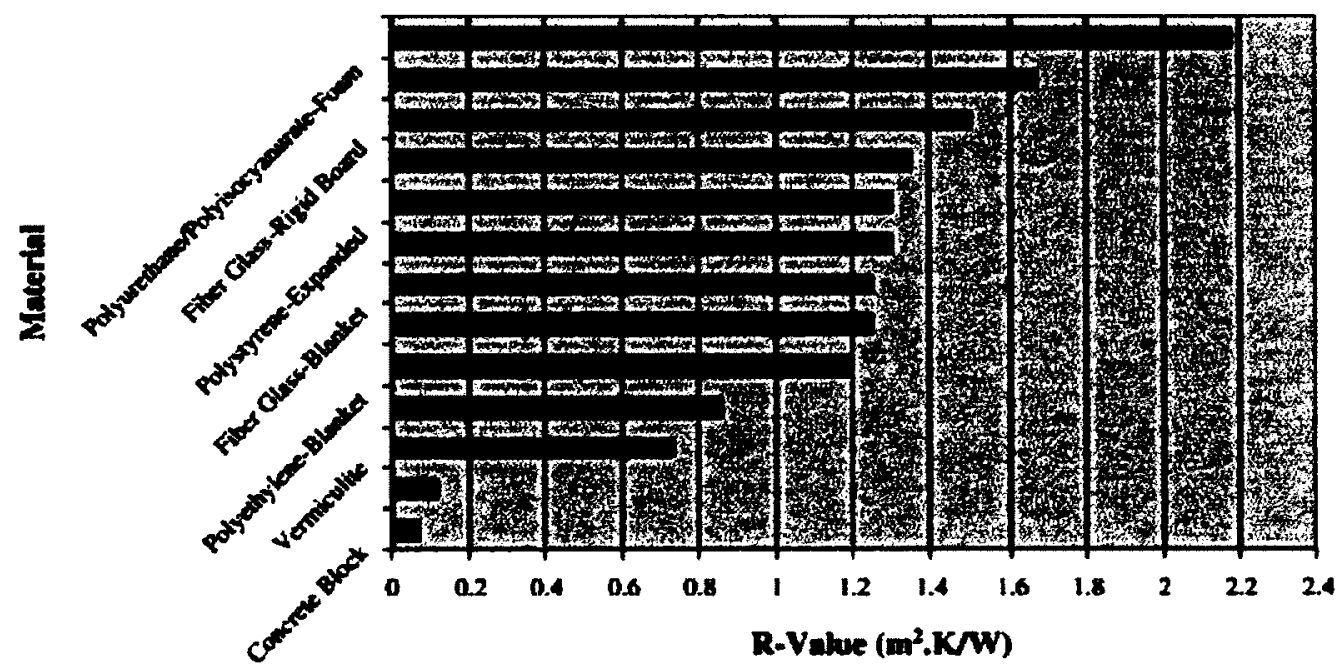

Figure 2.11. R-values of various insulation materials [3].

Increasing thickness provides a proportional increase in thermal resistance. The thermal resistance of a material is calculated as per Equation 2.5.

$$
R=\frac{\mathbf{t}}{\mathbf{k}}
$$

where $t$ is the thickness $(m)$, and $k$ is the thermal conductivity $(\mathrm{W} / \mathrm{m} . \mathrm{K})$. 


\subsubsection{Thermal Conductivity Measurement}

Standard measurements of thermal conductivity were initiated in the late 1920 s and early 1930s, but methods of determining thermal conductivity were first developed during the $19^{\text {th }}$ century. Zarr and Kumaran [23] summarized the work of early thermal conductivity researchers, such as Péclet, Forbes, Christiansen, Hencky. Péclet proposed three methods for determining thermal conductivity, using a sphere, pipe section, or vertical slab. Forbes developed a slab method for determining negative temperatures, by measuring the thickness of the ice layer formed on one surface of the specimen, while the other side was exposed to a freezing mixture. Christiansen built a comparative instrument that was later developed into a heat flow meter (HFM) apparatus. It contained three relatively thick copper plates with drilled holes for thermometers. Two specimens were placed between the plates - a reference material with known thermal conductivity and a test material for which thermal conductivity was to be measured. Thermal conductivity, $k$, of the test specimen was calculated using Equation 2.6.

$$
k=k_{0} \frac{L\left(T_{3}-T_{2}\right)}{L_{0}\left(T_{2}-T_{1}\right)}
$$

where $k_{0}=$ thermal conductivity of the reference material, $\mathrm{L}$ and $\mathrm{L}_{\mathrm{o}}=$ thicknesses of the test and reference materials, respectively, and, $T_{3}, T_{2}, T_{1}=$ temperatures of copper plates, starting from the hot plate. 
Schmidt measured thermal conductivity using a heat flow transducer with low thermal resistance and compensating rubber strips of approximately the same resistance as the transducer [23]. Hencky modified the design by adding a layer with thermal resistance comparable to that being measured. The same technique is being used eighty years later, because the physical principles involved remain practically unchanged. However, more precise instruments have been developed to improve the precision and accuracy for a wider range of materials and testing conditions.

\subsubsection{Techniques for Thermal Conductivity Measurement}

Today, a number of methods and types of equipment are used to evaluate thermal transmission properties. The methods can be categorized as either steady-state or transient (dynamic) methods [24]. In general, thermal conductivity is measured by steady-state techniques, which apply to situations where the temperature of the material remains constant over time. Steady state signals are constant, so analysis is straightforward [24]. Under steady-state conduction, the quantity of heat passing into an object is equal to that being released. Some transient techniques can also be modified for measuring thermal conductivity $[25]$.

Thermal properties range widely, so no single measurement method can be used to characterize all materials (Figure 2.12). The type of material, range of thermal properties, sample size and shape, and operational temperature range determine the method and equipment used. The heat flow meter and guarded hot plate are usually used to measure k-values of low conductivity materials [25], such as insulations and foams. Other meth- 
ods, such as the laser flash, give more accurate results for highly conductive ceramics, metals, or diamond composites [25].

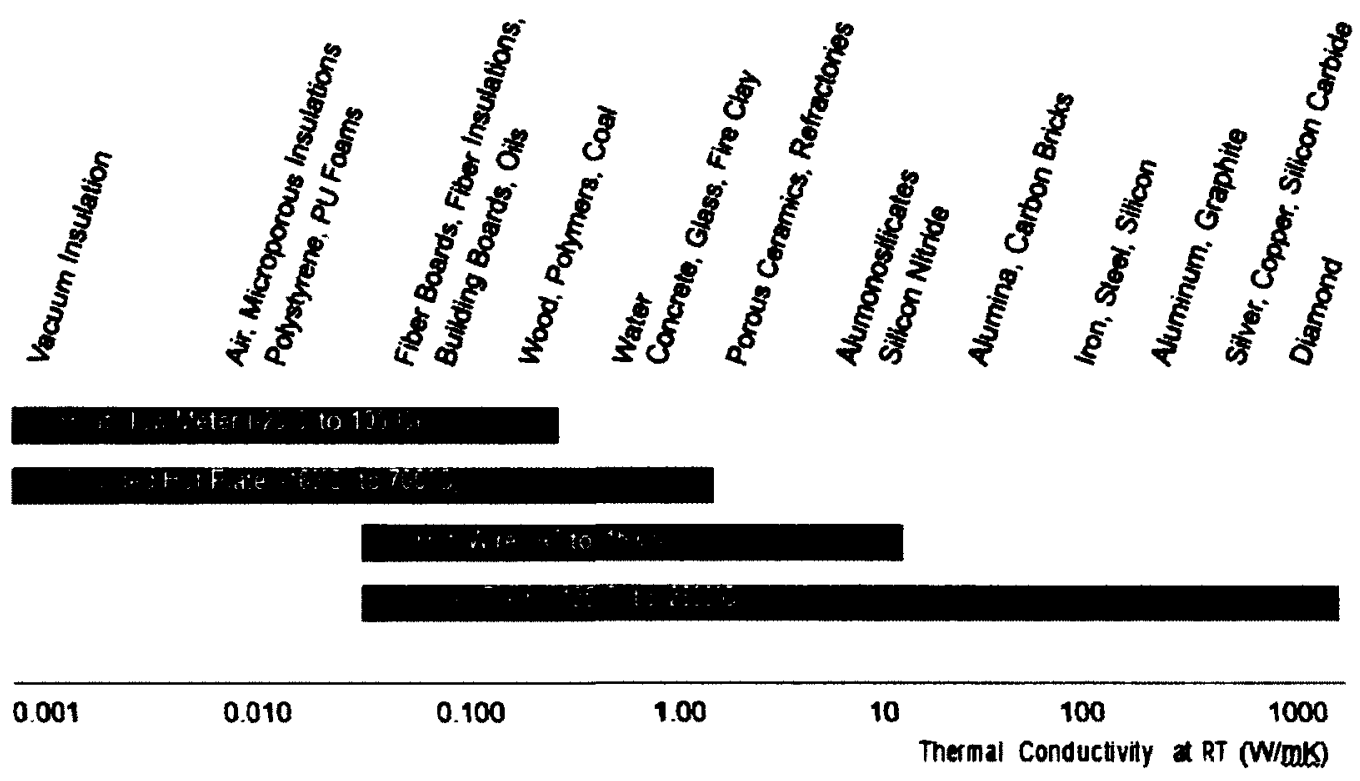

Figure 2.12. Commonly used methods for measuring thermal conductivity [26].

There are two types of guarded hot plate techniques used to measure thermal conductivity of insulation materials, and the standards used to measure thermal conductivity of insulation materials are summarized in Table 2.3.

The first type, represented by ASTM C177 [27], ISO 8302:1991 [28], DINEN 12939 [29], and JIS A 1412-1 [30] is an absolute method, where the apparatus is constructed so that thermal conductivity is directly obtained from measurement of electrical power, temperatures, and sample dimensions [31]. The other type, represent- 
ed by ASTM C518 [32], ISO 8301:1991 [33], and DINEN 12667 [34], incorporates one or more heat flux meters in a stack of plates calibrated against standard samples.

Table 2.3. Standard techniques for measuring thermal conductivity.

Standard Description

ASTM C177 Standard Test Method for Steady-State Heat Flux Measurements and Thermal Transmission Properties by Means of the Guarded-Hot-Plate Apparatus

ASTM C518 Standard Test Method for Steady-State Thermal transmission Properties by Means of the Heat Flow Meter Apparatus

DINEN

$12667 / 12939$ European Standard for Measurements of Insulating Materials Using the Heat Flow Meter Method or the Guarded Hot Plate Technique

ISO 8301/8302 Standard Test Technique for Measurements of Insulating Materials Using the Heat Flow Meter/Guarded Hot Plate Method

JIS A 1412-1:1999 Test Method For Thermal Resistance And Related Properties Of Thermal Insulations - Guarded Hot Plate 


\subsubsection{Use of the Guarded Hot Plate Apparatus to Measure Thermal Conductivity}

The guarded hot plate apparatus is used to determine the steady state heat transfer properties, thermal conductivity, and thermal resistance of flat slab specimens, in accordance with International Standards (ISO) 8302 and ASTM C-177 [31]. It is designed for use in test laboratories, manufacturing processes, and quality control procedures, for a wide range of materials with low and intermediate thermal conductivity, including rubber, plastics, mineral and glass fibers, cellular rubber, polyurethane, and polystyrene.

The guarded hot plate apparatus consists of a flat, electrically heated, metering section, surrounded on all sides by a guard. The heater, controlled using differential thermocouples, supplies a planar heat source over the hot face of the specimen. The most common measurement configuration is a symmetrical arrangement, where the heater assembly is sandwiched between two specimens. The schematic diagram of the guarded hot plate is shown in Figure 2.13. In the single-sided configuration, the heat flow passes through one specimen, and the back of the main heater acts as a guard plate, creating an adiabatic environment [36]. 


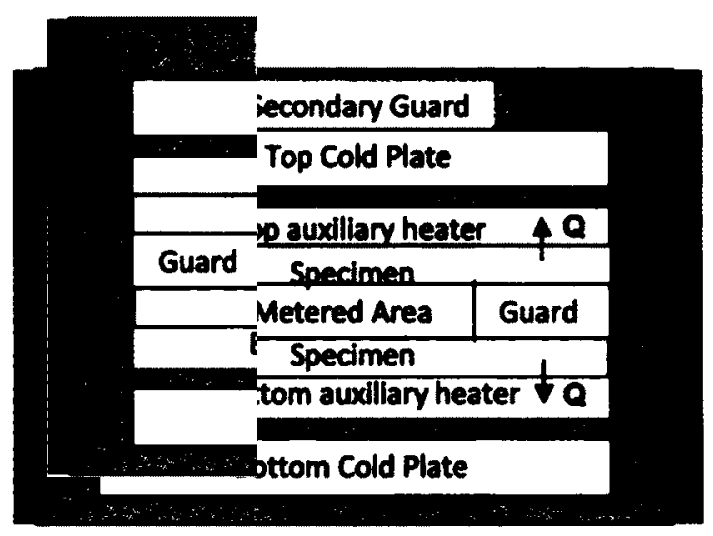

Figure 2.13. Schematic diagram of the guarded hot plate apparatus [31].

\subsubsection{Use of Heat Flow meter Apparatus to Measure Thermal Conductivity}

The heat flow meter apparatus is a widely used and versatile method of measuring steady state thermal transmission. The method is based on a simple operation and provides accurate results for flat, homogeneous materials with low thermal conductivities under moderate temperature conditions [35]. The heat flow meter apparatus consists of two isothermal plate assemblies, and one or more heat flux transducers. The sample is sandwiched between the hot and cold surface assemblies, which provide steady-state, one-dimensional heat flux through the specimens (Figure 2.14). The metered section is defined by ASTM C518 as the portion of the test specimen (or auxiliary insulation) through which the heat input flows under ideal conditions [37]. The heat transferred through the specimen is equal to the power supplied to the metered section. Temperature 
is monitored at each surface, using thermocouples. Steady-state is achieved when temperature and voltage readings become constant.

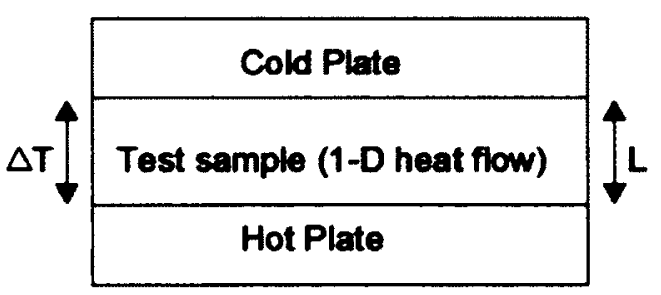

Figure 2.14. Schematic diagram of the heat flow meter apparatus [35].

The heat flow meter apparatus is usually located in an environmentally controlled chamber, and is used to determine the thermal conductivity of thermal insulations used in building construction.

Deviations from the idealized measurements using the heat flow meter apparatus can be considerable, due to non-homogeneity of specimens, temperature differences between the metered section and the guard, and temperature differences between the outer edge of the assembly, and the surrounding controlled environment. Any heat propagating routes that result in lateral heat flow within the apparatus, rather than heat flow through the specimen along the direction of temperature gradient, affect the results. Specific configurations for standardized measurements with maximum accuracy are recommended by the ASTM C518. The linear dimension of the metered section must be precisely determined, and the temperature along the surface plate of the hot surface assembly in the lateral direction must be constant, with less than $2 \%$ temperature variation across the specimen 
[38]. The gap between the metered section and the primary guard must be not more than $5 \%$ of the metered section area, to provide lateral thermal resistance. Despite these precautions, experimental error can be considerable, because thermal properties are sensitive to many environmental factors, such as temperature, moisture, and pressure [38]. The results can also vary significantly among tests using apparatuses with different specifications. Thus, each apparatus must be calibrated periodically.

\subsection{Measuring Thermal Conductivity of Smaller Specimens}

In the late 1990s, Flynn and Gorthala designed a small guarded hot plate apparatus for determining the thermal conductivity of smaller specimens, 100 to $300 \mathrm{~mm}^{2}$ in area, and up to $13 \mathrm{~mm}$ thick [39][40]. The apparatus was intended to be useful to manufacturers for characterizing insulation materials and polymers, particularly experimental products that are only available in very small sample sizes. The work was conducted under a Small Business Innovative Research (SBIR) Phase I contract from the National Institute of Standards and Technology (NIST). The goal was a single-sided guarded hot plate that was much smaller than any other device available, for measuring materials with very low thermal conductivity. Flynn and Gorthala favored an absolute measurement approach and noted the general lack of calibration standards for highly insulating materials. The meter and guard on the cold plate side of the small guarded hot plate apparatus were designed to incorporate a heat flux meter. Ceramic materials, including $\mathrm{BeO}, \mathrm{AlN}, \mathrm{Si}$, or polycrystalline diamond, were considered for the meter and guard plates to provide electrical insula- 
tion. The surfaces of the plates were to be treated, so that they had high emittance or matched emittance corresponding to the end use of the material being tested. The apparatus was designed to cover a temperature range of at least -40 to $10^{\circ} \mathrm{C}$, in an environment of air, selected gases, or vacuum. The primary conductivity range was designed to be from 0.02 to $0.05 \mathrm{~W} / \mathrm{mK}$, and if possible, from less than 0.005 to $0.35 \mathrm{~W} / \mathrm{mK}$. The design goals were less than $5 \%$ error in accuracy $\left(<2 \%\right.$ near $\left.25^{\circ} \mathrm{C}\right)$, and less than $2 \%$ error in repeatability $\left(<0.5 \%\right.$ near $\left.25^{\circ} \mathrm{C}\right)$.

Flynn and Gorthala $[39,40]$ noted that constructing a small guarded hot plate apparatus required serious correction, especially regarding heat flow across the gap. The sample thickness should be scaled down in proportion to the lateral dimensions which was an apparent contradiction to the stated goal of allowing samples up to $13 \mathrm{~mm}$ thick. They also expressed skepticism about using air as a calibration standard. The prototype was to be built, if a Phase II SBIR contract was awarded. However, there is no evidence in the literature to indicate that the apparatus was actually built and tested.

Miller et al. [41] developed a hot plate method using air as a standard reference material, for the steady-state measurement of the thermal conductivity of small samples with thermal conductivity on the order of air. Heat flow through the test sample was designed to be essentially one-dimensional, but no attempt was made to use heated guards to block the flow of heat from the hot plate to the surroundings. Miller et al. stated that, since large correction factors must be applied to account for guard imperfections when sample di- 
mensions are small, it was preferable to simply measure and correct for heat that flows from the heater disc to directions other than into the sample. Experimental measurements made with a prototype apparatus, combined with extensive computational modelling of heat transfer in the apparatus, showed that sufficiently accurate measurements could be obtained to allow determination of the thermal conductivity of low thermal conductivity materials. The technique required a standard reference material with relatively low thermal conductivity, such as Glass Fiberboard SRM 1450c, which has a thermal conductivity of about $0.033 \mathrm{~W} / \mathrm{mK}$ at room temperature. The thickness of this material is $25 \mathrm{~mm}$; however, its layered structure might not lend itself to machining into small, wellcharacterized samples. Expanded polystyrene, EPS SRM 1453 [42], is another standard reference material with similar thermal conductivity and similar problems for machining into samples $\sim 4 \mathrm{~mm}$ in thickness.

Fujino [43] developed a guarded hot plate apparatus [43] for measuring the thermal conductivity of polymer specimens smaller $(\leq 200 \mathrm{~mm})$ and thicker than recommended by the JIS [30] and ASTM C-177 [20], within 10\% accuracy (Figure 2.15).

The thermal conductivity of such polymers ranges from 0.2 to $0.6 \mathrm{~W} / \mathrm{mK}$. Three experimental apparatuses were built, appropriate for specimens $50 \times 50,100 \times 100$, and 200 x $200 \mathrm{~mm}^{2}$ in area. The major concerns were the influence of specimen size, the difference in temperature between the main and guard heaters, and effect of the gap on thermal conductivity measurements. In a test apparatus suitable for specimens of $50 \mathrm{~mm} \times 50$ 
$\mathrm{mm}^{2}$, the gap affects the measurement of thermal conductivity, and the temperature difference of the heat source, $\Delta \mathrm{Tg}$, has a direct influence on deviation in the thermal conductivity data. Fujino compared results from his apparatus with results from the standard apparatus, and found thermal conductivity measurements within $4 \%$ of the standard results. A $50 \times 50 \mathrm{~mm}^{2}$ in area specimen was sufficient to determine thermal conductivity ranging from 0.2 to $0.6 \mathrm{~W} / \mathrm{mK}$. However, the gap did affect the measurement, and the long term effect of thermal contact resistance considerably increased thermal conductivity.

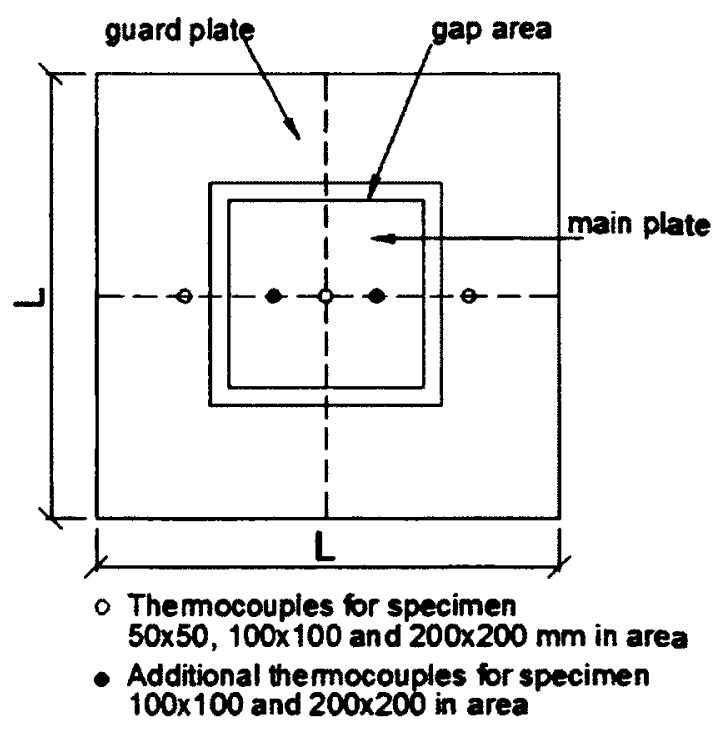

Figure 2.15. Diagram of Fujino's guarded hot plate apparatus [43].

Mukhopadhyaya et al. [44] developed a method, using an existing heat flow meter apparatus and following ASTM C518, to assess the thermal conductivity of new biobased polyurethane (PU), closed-cell, foam insulations using smaller size samples. The size of the foam specimen was $70 \times 70 \times 12 \mathrm{~mm}$. The heat flow meter had a metering area of 150 
$\mathrm{x} 150 \mathrm{~mm}$, and the smaller specimen was masked with a larger piece of insulation (Figure 2.16). Standard size specimens ( $300 \mathrm{~mm} \times 300 \mathrm{~mm}$ ) are called "intact", and smaller specimens are "masked".
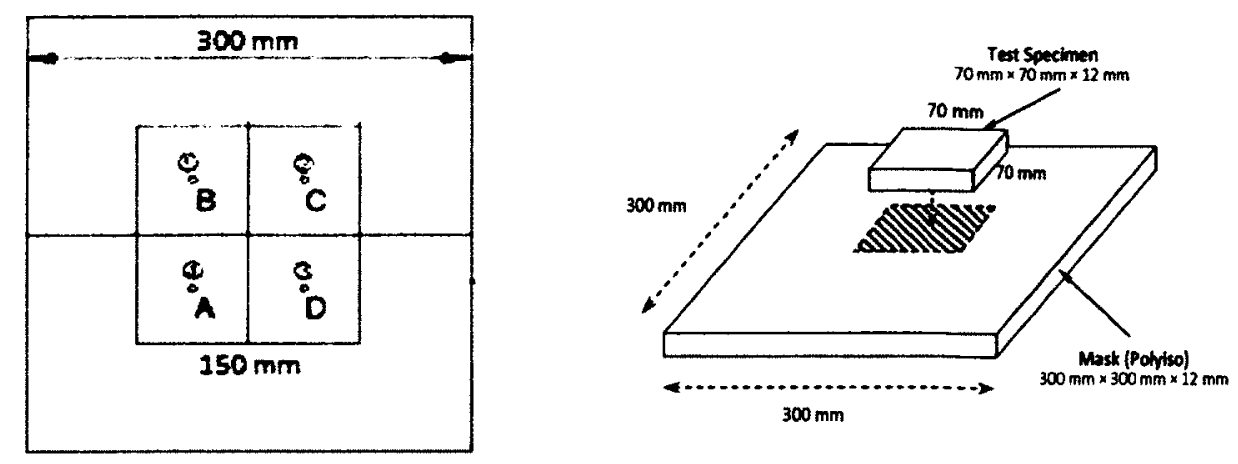

Figure 2.16 Diagram of Muklopadhyaya's heat flow meter apparatus [44].

The results showed close correlation between the new method and the standard method with $300 \times 300 \mathrm{~mm}$ specimens (Figure 2.17) [44]. The range of the thermal conductivity was $0.024-0.028 \mathrm{~W} / \mathrm{m} . \mathrm{K}$ for the masked specimens versus $0.025-0.04 \mathrm{~W} / \mathrm{m} . \mathrm{K}$ for the intact specimens. This relationship could be used to derive the thermal conductivity of biofoam materials from masked thermal conductivity measurements with small specimens. 


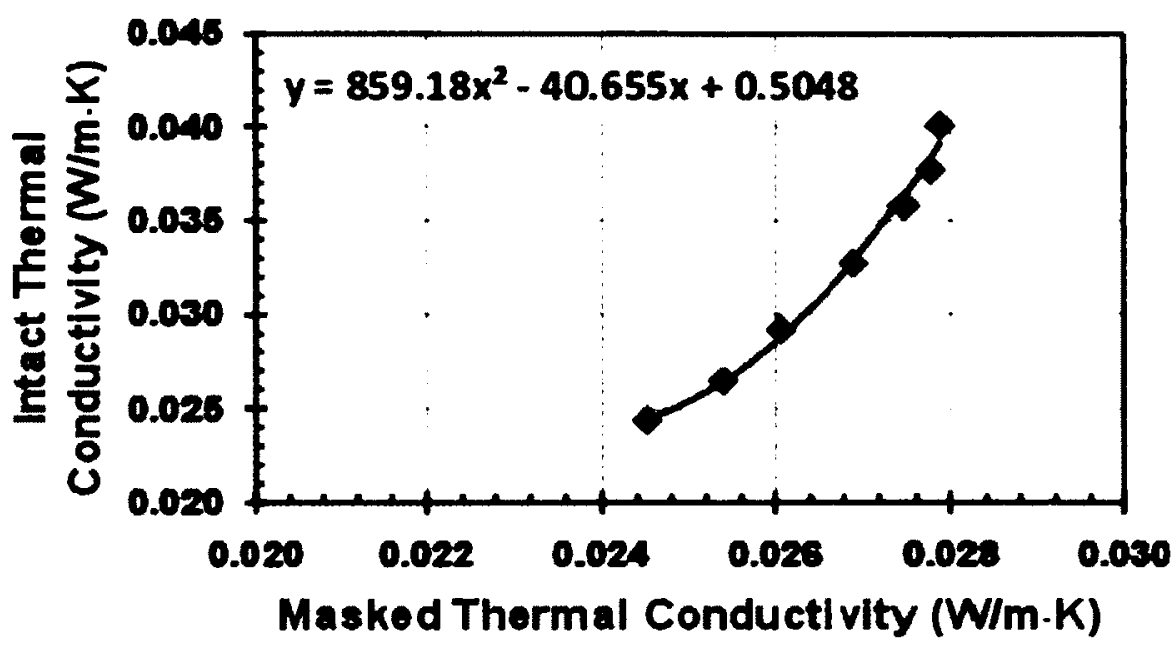

Figure 2.17. Relationship between thermal conductivity measured using intact vs. masked specimens [44].

Masson et al. [45] developed a rapid method for measuring thermal conductivity of new foams, using temperature-modulated differential scanning calorimetry (MDSC) . The method determines thermal conductivity values from heat capacity measurements on cylindrical samples $\leq 2 \mathrm{~g}$ in weight, and is the basis for ASTM E1952, "Thermal Conductivity and Thermal Diffusivity by Modulated Differential Scanning Calorimetry" (MDSC) [46]. ASTM E1952 methods were applied to thermal insulating foams used in construction applications, and the results demonstrated that MDSC provides excellent repeatability and good reproducibility. However, a comparison of established values of thermal conductivity for six insulating foams to values determined by ASTM E1952 showed that the ASTM E1952 method was inaccurate. Two sources of errors were identified: 1) the use of nitrogen as a purge gas, and 2) the use of an equation that inaccurately 
relates the measured heat capacity to thermal conductivity. The method needs to be tested using purge gases with lower thermal conductivity and other numerical models.

\subsection{Thermal Modelling}

The term, model, from Latin modulus or measure is a representation of reality that retains its salient features [47]. Modelling often involves approximating the real geometry as an ideal geometry, e.g., assuming perfect planar, cylindrical, or spherical surfaces; fitting a set of points to a given interpolation function and its domain; approximating material properties, such as constant values, isotropic values, reference material values, extrapolated values. In the case of heat transfer equations, modeling involves neglecting some contributions, linearizing some terms, assuming the media are a continuum, and discretization [47].

Modelling material properties introduces uncertainties, because density, thermal conductivity, thermal capacity, emissivity, and so on, depend on the base materials, their impurity contents, applied bulk and surface treatments, actual temperatures, effects of aging, etc. Most of the times, material properties are modelled as uniform in space and constant in time for each material, but, the worthiness of this model and the right selection of the constant-property values, requires insight [48].

Thermal problems are mathematically stated as a set of restrictions that the model solution must verify. Some of the restrictions are given explicitly, such as data; some are implicit, including assumed data and equations [49]. Both the explicit boundary condi- 
tions and the implicit equations (algebraic, differential, or integral) are subject to uncertainties from the assumed geometry, material properties, and external interactions [49]. In modeling a physical system, numerical methods are not just approximations based on differential equations; they are approximations of real behaviour. There is no exact model or an exact solution to a physical problem, just an attempt at sufficient accuracy to achieve the purpose [48].

Numerical solutions are generally used to solve practical heat transfer problems, as well as mass and momentum transfer problems, because analyses using partial differential equations are not solvable analytical, except for very simple configurations [49]. Numerical methods transform the continuous problem to a discrete problem. Thus, rather than providing a continuous solution that is valid for every point in space and time, and every value of the parameters, numerical methods yield discrete solutions that are valid for discrete points in space and time, and for discrete values of the parameters [50]. Despite these limitations, the numerical approach has two crucial advantages.

- It can provide a solution to any practical problem, however complicated, not just steady, one-dimensional, constant-property ideal models.

- The discretization can be refined as much as is desired, although there are costs in computing time and required memory.

Numerical approaches transform the continuous problem, which can be written as $P D E(T)=F$, indicating that a partial differential operator applied to the temperature field should equal the force-field imposing the thermal non-equilibrium, to a discrete problem. 
For each time step, there is a set of $N$ algebraic equations, involving unknown temperatures at $N$ selected points in the system, a set of known applied stimuli at $N$ points, and a set of $N^{*} N$ coefficients [49]. Numerical methods differ in the way they resolve this system of algebraic equations, but follow a general baseline. The problem can be generally stated in Equation 2.7.

$$
P D E(T(\vec{x}, t))=0, B C\left(T\left(\vec{x}_{0}, t\right)\right)=0, I C\left(T\left(\vec{x}_{0}, t\right)\right)=0
$$

where $P D E, B C$ and $I C$ represent functionals related to the partial differential equation, boundary conditions, and initial conditions, respectively.

Several numerical methods have been developed, each with its own advantages and complexities. Simple methods like the finite difference method, can be developed from scratch for every new problem, but become too cumbersome in complex cases. The standard finite element method demands more effort to develop, but can be routinely applied to a variety of complex cases.

The most common numerical method is the differential method. Differential methods solve the heat equation, rather than the integral energy equation, and are used for the numerical analysis of heat transfer. The most commonly used differential methods are:

- Finite differences,

- Finite elements, and

- Boundary elements. 


\section{Finite Difference Method (FDM)}

In the finite difference method (FDM), invented by Courant et al. in 1929 [50], the partial differential equation (PDE) is discretized term by term, substituting each derivative with its truncated Taylor expansion [50]. The minimum order for time derivatives is a linear approach, usually advanced in time as per Equation 2.8 .

$$
\partial T / \partial t \approx T((t+\Delta T)-T(t) / \Delta T)
$$

The FDM can be also viewed as a discretized mesh, with the PDE integrated at each finite volume. A nodal point is assigned to each finite volume, and an unknown temperature is attributed to each nodal point [50]. The FDM yields a highly structured system of equations, particularly when a regular mesh is used, which has advantages and disadvantages. The main advantage is the simple formulation of the method - it is the most basic numerical method for solving PDEs. The disadvantage is that FDM demands a simple geometry with a structured grid, and becomes complicated in systems with nonrectangular, non-cylindrical, or non-spherical geometries.

FDM starts by establishing a mesh of nodes in the domain, i.e., a set of points in space, where the function is to be computed. There should be a node where the function is sought; at least one node at each boundary or singularity, plus a few others for better resolution [51]. Although not mandatory, it is advisable to use a regular mesh to simplify the coding. A material element and a thermal inertia are ascribed to each node. A thermal conductance is assigned to each pair of nodes. The finite difference discretization of the 
PDE provides the energy balance for every generic (internal) node. The energy balance must be set aside for each special (interface) node, which are the most characteristic data in a problem. A regular spatial mesh is used, such as a square mesh of size $h$ in 2D, and derivatives are approximated by finite differences, centred in the node, or from one side (forward or backward) [51]. For example, the Laplace operator is approximated at every standard internal node (marked by its $x$-step position, $i$, and its $y$-step position, $j$ ), using centred differences as per Equation 2.9.

$$
\nabla^{2} T_{i, j} \approx \frac{1}{h^{2}}\left(T_{i-1, j}+T_{i+1, j}+T_{i, j-1}+T_{i, j+1}-4 T_{i, j}\right)
$$

This simple discretization becomes cumbersome when applied to boundary nodes, if the geometry is not rectangular. Thus, for boundary nodes that have only a fraction $f$ of an $h$-step in the North-South-East-West neighbour, the Laplace operator should be approximated as per Equation 2.10.

$$
\nabla^{2} T_{i, j} \approx \frac{2}{h^{2}}\left(\frac{1 / f_{W}}{f_{W}+f_{E}} T_{i-1, j}+\frac{1 / f_{E}}{f_{w}+f_{E}} T_{i+1, j}+\frac{1 / f_{s}}{f_{s}+f_{N}} T_{i, j-1}+\frac{1 / f_{N}}{f_{s}+f_{N}} T_{i, j+1}-\frac{f_{s} f_{N}+f_{W} f_{E}}{f_{s} f_{N} f_{W} f} \Delta T_{i, j}\right)
$$

This becomes even more awkward, because for a regular mesh in an irregular domain, a mesh refinement does not include all previous nodes in the boundary.

\section{Finite Elements}

The finite elements method (FEM), also known as finite element analysis (FEA) was invented by Courant in 1943. FEM is based on the premise that an approximate solution 
to any complex engineering problem can be reached by subdividing the problem into smaller, more manageable, finite elements [51]. Using finite elements, complex partial differential equations that describe the behaviour of structures can be reduced to a set of linear equations that are easily solved using the standard techniques of matrix algebra.

In the simplest FEM formulation, 2D spatial domains are discretized in triangles, and the base functions are chosen as linear unitary local functions, i.e., zero outside of their associated element [51]. The subsystem in FEM is a mass between nodal points at the corners, in contrast to the subsystem in FDM, which is a mass around the nodal point.

Standard algorithms exist for meshing any irregular domain. The procedure is well developed because the approximation is by integration, which with suitable base functions, can be done locally in each element without any directionality, rather than by differentiation, which is a directional operation based on all neighbour elements. The task is massive, but simple, which is ideal for computers. Thus, FEM is the preferred numerical method for non-singular engineering problems, particularly for multidisciplinary computations, such as mechanical, thermal, fluid-dynamic, or electrical [52].

Typical commercial FEM packages include ABAQUS, ANSYS, FEMLAB, HEAT3, and MSC/NASTRAN. These packages usually cover a wide spectrum of possibilities, e.g., material properties and heat sources that vary with time. 


\section{Boundary Elements}

Because a given set of boundary and initial conditions uniquely defines the solution in the domain, the value of the function at any point in the interior can be expressed as a sole contribution of boundary values. This is achieved mathematically by the GreenStokes-Gauss-divergence theorem [52], which is the foundation of the boundary elements method (BEM). In BEM, first the full solution of the function and derivatives at the boundary points are computed by a kind of finite-element method, in which the base functions are the fundamental solutions of the PDE at the boundary nodes. A set of algebraic equations are then solved at the nodes. Finally, if needed, the value at any internal point is directly computed by a quadrature, without interpolation. The problem with the boundary element method is that local integration within the boundary is more involved than in standard FEM, because there are singular points that require more elaborate computations [53] other drawback is that the BEM only applies to regions of constant properties. The great advantage of BEM is that, for bulky domains, the number of nodes significantly decreases which explains its frequent use in external fluidmechanics and geomechanics [53].

\subsection{Summary}

Rising energy prices and increasing pressure to conserve energy and protect the environment emphasize the importance of developing innovative thermal insulating foams for building applications [11]. This goal requires a rapid and accurate method for measur- 
ing thermal conductivity of new products. Most measurements of the thermal conductivity or thermal resistance of building insulations are currently made using a guarded hot plate apparatus or heat flow meter apparatus. Both methods are applicable to a wide variety of materials, but require specimens around 300-600 $\mathrm{mm}$ in length and width, and 20$200 \mathrm{~mm}$ in thickness. Such large samples are often unavailable for innovative insulations in the process of development.

The present study used an alternative method for rapidly measuring thermal conductivity of smaller insulation samples. Using smaller specimens, rather than standard size, might provide more rapid and less costly measurements of thermal conductivity. The new method tested and reported herein uses a heat flow meter apparatus, and is based on methodology developed by Mukhopadhyaya et al. [44]. The experimental results were validated by numerical modelling, using the HEAT3 software. 


\section{Chapter 3: Experimental Work}

The objective of this research was to develop and test new methodology for determining the thermal conductivity of smaller insulation specimens. Thermal conductivity tests were conducted on six insulation materials using the standard heat flow meter apparatus (300 mm x $300 \mathrm{~mm}$ ) following ASTM Standard test method C518, and results from the new methodology with smaller specimens were verified with the results obtained from full-size specimens.

\subsection{Test Materials}

Six types of aged insulation materials of two different thicknesses that are commonly used for residential, commercial, and industrial applications were procured from the storage of National Research Council Canada (NRC). The aged (about 5 years or more) insulations were used in this study to isolate the aging effect from the experimental results.

The density and thickness of insulation materials used in this study are shown in Table 3.1. It is to be noted that insulation materials have the same density for both thicknesses except for high density glass fibre where two slightly different density boards. 
Table 3.1. Type, density and thickness of insulation materials.

\begin{tabular}{lcc} 
& Specimen Thickness & Density \\
\hline \multicolumn{1}{c}{ Insulation Material } & $\mathrm{mm}$ & $\rho\left(\mathrm{kg} / \mathrm{m}^{3}\right)$ \\
\hline Expanded Polystyrene (EPS) & $12.5 / 25$ & 22 \\
Extruded Polystyrene (XPS) & $12.5 / 25$ & 25 \\
Polyurethane (PUR) & $12.5 / 25$ & 39 \\
Polyisocyanurate (ISO) & $12.5 / 25$ & 29 \\
High Density Glass Fiber (HDGF) & 25 & 135 \\
High Density Glass Fiber (HDGF) & 12.5 & 118 \\
Low Density Glass Fiber (LDGF) & $12.5 / 25$ & 11 \\
\hline
\end{tabular}

\subsection{Test Apparatus and Methods}

\subsubsection{Heat Flow Meter Apparatus}

The heat flow meter at the NRC laboratory was used to measure the thermal conductivity of the insulation materials. The heat flow meter measures the steady state thermal transmission by establishing steady state heat flux in one dimension through a flat slab test specimen held between two parallel plates at constant, but different, temperatures. The plate assemblies are rigid to maintain flatness and uniform thickness of the specimens. Figure 3.1, shows the test specimen between two plates (hot and cold) embedded with heat flux transducers. The Top plate is the cold surface, and the bottom plate is the hot surface. Fluid baths are connected to the plates to maintain the desired temperatures. The plate assemblies provide isothermal surfaces in contact with both sides of the speci- 
men, and a heat flux transducer is attached to both plate assemblies to measure heat flow through specimen surfaces.

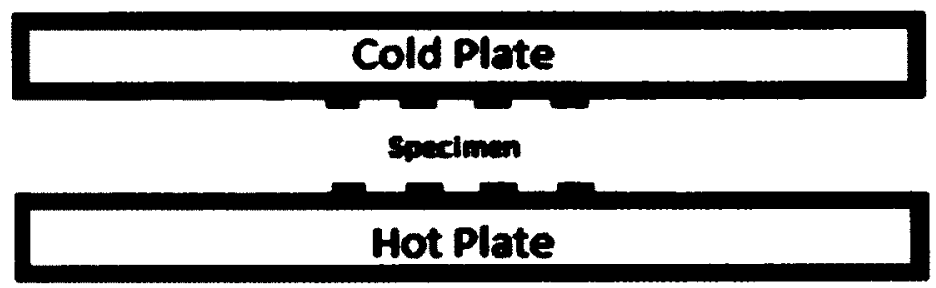

- - Heat Flux Transducers

Figure 3.1. Heat flow meter apparatus showing test specimen between two heat flux transducers [35].

The plates are $300 \times 300 \mathrm{~mm}$ in width and length. Figure 3.2 shows the metering area, $150 \times 150 \mathrm{~mm}$, defined by the sensor of the heat flux transducer, and the location of the thermocouples. The remainder of the plates is the guard area. The metering area of the heat flow meter is usually not more than $25 \%$ of the total plate surface area [35].

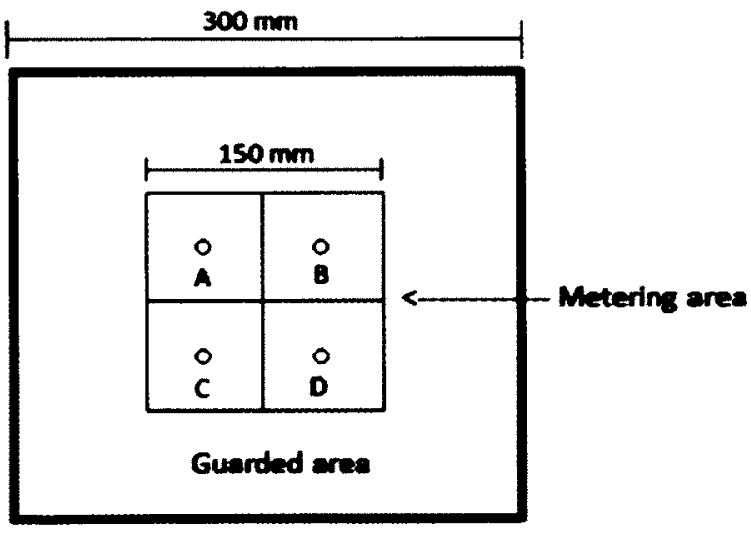

o Thermocouples

Figure 3.2. Cold and hot plate thermocouple location. 


\subsubsection{Thermal Conductivity Measurements Using the Heat Flow Meter}

The conventional heat flow meter technique assumes one-dimensional heat conduction. The method works well for determining thermal conductivity of thin thermal insulators, as long as the requirement that one-dimensional heat flow with negligible lateral losses is maintained [38]. Heat flow is perpendicular to the plate surfaces. The test specimen of given thickness is sandwiched between the hot and cold plates. The plates are maintained at different constant temperatures, giving a temperature difference of $\Delta T(K)$. A thin heat flux transducer, with negligible thermal resistance, relative to that of the specimen, is placed in series with the test specimen at the hot and/or cold plate. At equilibrium condition, the heat flux transducer output $Q(V)$, is measured and the apparent thermal conductivity, $\mathbf{k}_{\mathrm{app}}$, is calculated using Equation 3.1 .

$$
\mathbf{k}_{\mathrm{app}}=\mathrm{NQ} 1 / \Delta \mathrm{T}
$$

where $\mathrm{N}$ is a calibration factor for a particular set of conditions $\left(\mathrm{W} \mathrm{m} \mathrm{m}^{-2} \mathrm{~V}^{-1}\right) . \mathrm{N}$ is obtained by calibrating the apparatus with an appropriate transfer standard of known thermal resistance, measured under the same conditions used for the test specimen.

As described in Chapter 2, the heat flow meter method uses Fourier's law of heat conduction to calculate thermal conductivity and thermal resistance. Equation 3.2 represents the heat conduction equation, as outlined in the standard test method (ASTM C518), for practical applications as, 


$$
\mathbf{k}_{\mathrm{app}}=\mathrm{q} \times 1 /(\Delta \mathrm{T})
$$

Where $k_{\mathrm{app}}=$ apparent thermal conductivity, a function of the average temperature of the test specimen $(\mathrm{W} / \mathrm{m} . \mathrm{K}), \mathrm{q}=$ heat flow rate $(\mathrm{W}), \mathrm{l}=$ thickness of test specimen $(\mathrm{m}), \Delta \mathrm{T}$ $=$ hot surface temperature - cold surface temperature $(\mathrm{K})$.

\subsubsection{Calibration of the Heat Flow Meter Apparatus}

One of the challenges of measuring heat flow across a material is to accurately calibrate the heat flux transducer. Accurate measurement of the thickness of the material is also of particular concern, especially for light materials and/or smaller specimens. These factors are important, because lateral heat losses or gains can be significant under all testing conditions, even under identical conditions of a plate temperature, temperature gradient, specimen thickness, heat flow direction, and apparatus orientation. In the present study, the heat flow meter was routinely calibrated by the NRC personnel following the standard practice described in ASTM C518 (section 6) [32].

\subsubsection{Data Acquisition System}

Data from the heat flow meter were collected and analyzed, according to the following routine.

1) Data acquisition is done using the Keithley Scanner [54] and the software, Agilent HP-Vee Pro, version 8.0 [55], a graphical dataflow programming software development for automated test, measurement, data analysis and reporting. 
2) Based on the scan interval configured in the application (e.g., 2 min between scans), the software cues the Keithley 706 Scanner, to "begin scanning" the configured contacts.

3) The Scanner is a type of multi-plexer, which closes and opens the contacts of individual electrical circuits, consisting of sets of electrical contacts. Each of the 20 circuits is located on one of the ten Model 7064 20-Channel $L_{0}$ Voltage Scanner "I/O Cards," located in the back of the scanner chassis.

4) The lead wires of the resistance temperature detectors (RTD), thermocouple, or heat flux transducer measurement instrument, located in the heat flow-meter plates, are attached to one of the contact pairs of the $\mathrm{I} / \mathrm{O}$ "channel" that corresponds to the contact pair in the scanner/card. When a specific circuit is closed, an electrical path is opened between the appropriate set of electrical contacts and the respective measurement instrument.

5) Upon contact closure of a particular circuit, the corresponding set of contacts passes either an electrical resistance or an electrical voltage, representing the temperature at the surface of the plate, or the flux of heat passing through the test specimen, to the other side of the contact pair, i.e., opens the I/O channel.

6) One set of ends of each of the 20 contact pairs is connected together, forming one wire that is connected to one measurement terminal of the digital multi-meter (2000 DMM). The other set of ends is also connected together, forming one wire that is connected to the 2000 DMM's other measurement terminal. 
7) The progression of contact closures is configured by the data acquisition program and executed by the scanner. Electrical values representing resistances, e.g. temperatures measured by RTDs, or voltages provided by the thermocouples and the heat flux transducer, are read in rapid succession. The Agilent HP-Vee Pro software records the thermal measurements at the configured scan rate and reports the results as averages.

\subsubsection{Environmental Conditions}

The selected test specimens of the various insulation materials were kept in a humidity and temperature controlled room at $22^{\circ} \mathrm{C}$ temperature and $50 \% \mathrm{RH}$ for over 24 hours prior to the test as prescribed in the ASTM C518 test method. Tests were conducted in a room with controlled temperature around $22 \pm 1^{\circ} \mathrm{C}$.

\subsubsection{Specimen Preparation}

Full size $(300 \times 300 \mathrm{~mm})$ specimens were tested to establish the thermal resistance of each material. Thereafter, smaller specimens were cut from the center of the tested sample (Figure 3.3). 

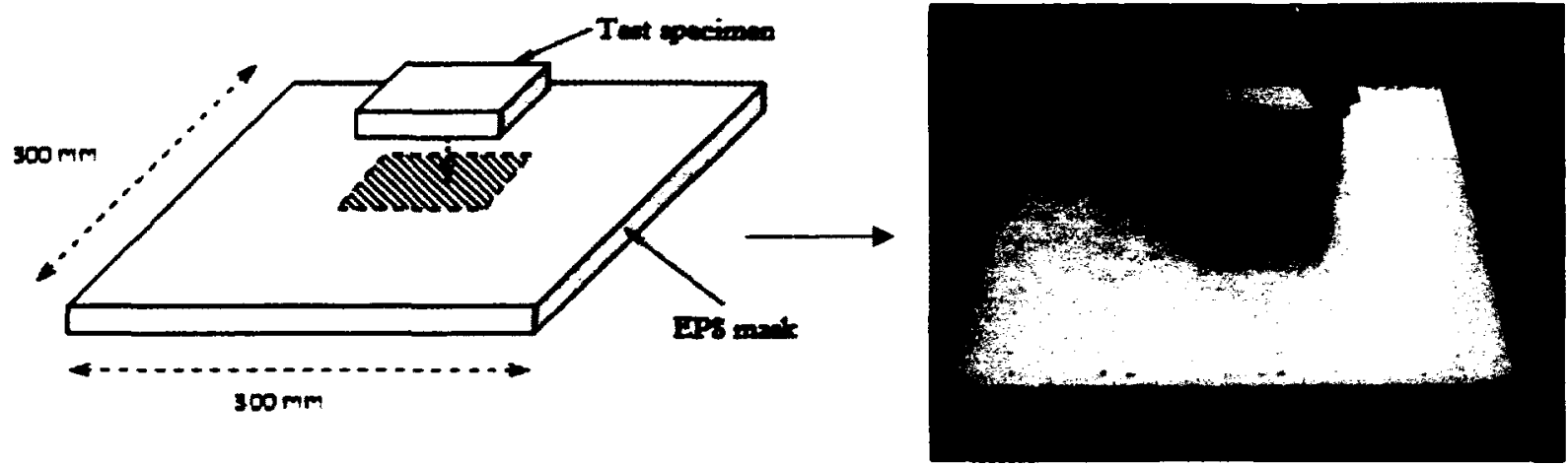

Figure 3.3. EPS mask with cut out.

Expanded polystyrene or EPS $(300 \times 300 \times 12.5$ and $25 \mathrm{~mm})$ was used as mask to measure the thermal conductivity of smaller specimens. EPS board is a material sufficiently homogeneous and stable. EPS board is also used as a standard reference material for calibration of heat flow meter. To reduce, or eliminate, lateral flow (2-D flow), it is recommended that the physical and thermal properties of the mask material should be as similar as those of the test specimen (masked specimen). Figure 3.4 shows the EPS mask with the material insert.

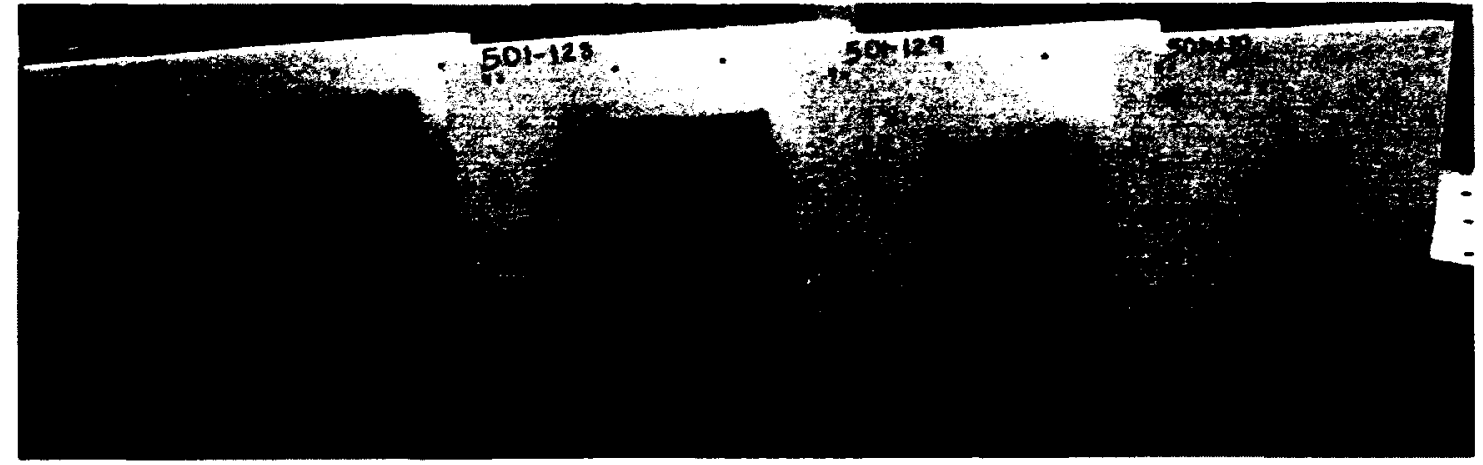

Figure 3.4. EPS mask with the material insert. 
A total of 144 samples were used in this study. Three parameters were investigated in the experimental tests: material type, thickness and size. The number of specimens and the materials tested are shown in

Table 3.2. Three specimen sizes were within the metering area $(150 \times 150 \mathrm{~mm})$ of the heat flow meter and one specimen size $(200 \times 200 \mathrm{~mm})$ was beyond the metering area of the heat flow meter. Figure 3.5, shows the specimens sizes.

Table 3.2. Number of samples tested for each sample size, per thickness.

\begin{tabular}{cccccc}
\hline \multicolumn{7}{c}{ \# of Samples per thickness - Size (mm) } \\
\hline Material & $300 \times 300$ & $200 \times 200$ & $150 \times 150$ & $100 \times 100$ & $50 \times 50$ \\
\hline EPS & 8 & 1 & 1 & 1 & 1 \\
XPS & 8 & 1 & 1 & 1 & 1 \\
PUR & 8 & 1 & 1 & 1 & 1 \\
ISO & 8 & 1 & 1 & 1 & 1 \\
HDGF & 8 & 1 & 1 & 1 & 1 \\
LDGF & 8 & 1 & 1 & 1 & 1 \\
\hline Total & 48 & 6 & 6 & 6 & 6 \\
\hline
\end{tabular}

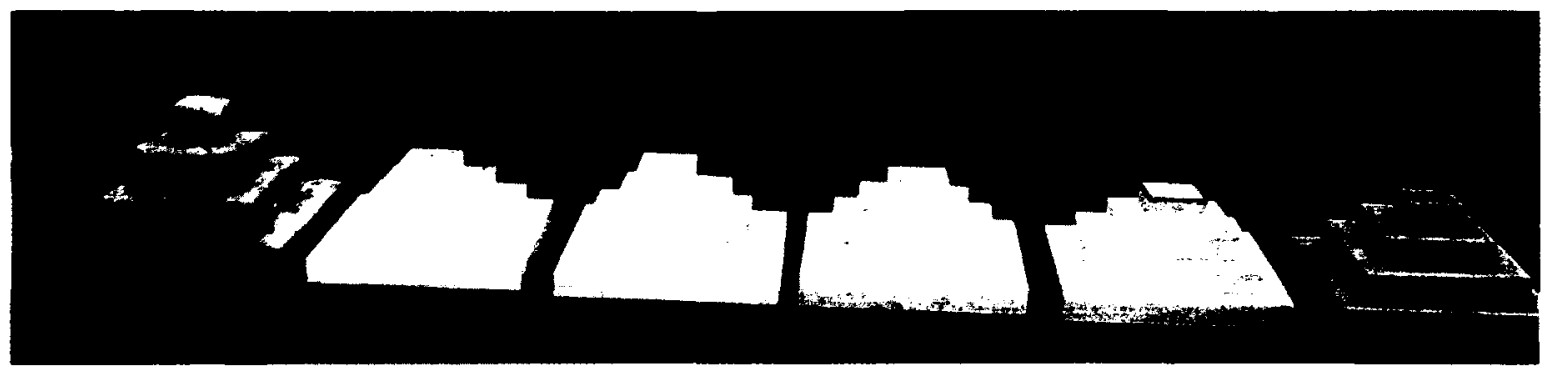

Figure 3.5. Test specimens (LDGF, EPS, XPS, ISO, PUR, HDGF). 


\subsubsection{Sensitivity Analysis}

Sensitivity analysis was conducted to determine the number of specimens to be tested for each parameter under investigation. As per Section 7.2.1 of ASTM C518 [32], one specimen can be used to measure thermal characteristics of insulation materials. Nevertheless, tests were conducted on multiple specimens using Polyurethane (PUR), which belongs to the foam insulation family, and High Density Glass Fiber (HDGF) from the fibrous insulation family. Three $200 \times 200 \times 25 \mathrm{~mm}$ and three $150 \times 150 \times 25 \mathrm{~mm}$ specimens of PUR and HDGF were tested. The results showed a variance less than $1 \%$ between $200 \times 200 \mathrm{~mm}$ HDGF specimens, and less than $2 \%$ between $150 \times 150 \mathrm{~mm}$ specimens (Table 3.3). The variance for PUR specimens of both sizes was less than $2 \%$. These variance values are in compliance with Section 10 (Precision and Bias) of ASTM C518. The standard states that, "The accuracy of a test result refers to the closeness of agreement between the observed value and an accepted reference value." In the present case, the accepted variance value would be $2.8 \%$ for High Density Glass Fiber, and $\pm 5 \%$ for foams. Therefore, only one specimen was tested for each case considered in the present study.

Table 3.3 Repeatability of thermal conductivity tests

\begin{tabular}{lcccc}
\hline \multicolumn{4}{c}{ Thermal conductivity (W/m.k) } \\
\hline Specimen & $200 \times 200 \mathrm{~mm}$ & $150 \times 150 \mathrm{~mm}$ & $200 \times 200 \mathrm{~mm}$ & $150 \times 150 \mathrm{~mm}$ \\
\hline R1 & 0.0260 & 0.0274 & 0.0343 & 0.0348 \\
R2 & 0.0262 & 0.0275 & 0.0343 & 0.0342 \\
R3 & 0.0257 & 0.0265 & 0.0340 & 0.0337 \\
\hline
\end{tabular}




\subsubsection{Test Procedure}

The procedure for determining thermal resistance of the specimens followed the standard specified by ASTM C518.

1) Remove the specimen from the humidity room and measure its thickness.

2) Insert the intact sample in the heat flow meter.

3) Measure the distance between the plates.

4) Adjust the temperature, so the temperatures of the plates are maintained within 22 ${ }^{\circ} \mathrm{C}$ for these measurements.

5) Measure thermal resistance after steady state conditions is reached.

Figure 3.6 shows the specimen set up in the HFM and Figure 3.7 shows the final heat flow meter set up.

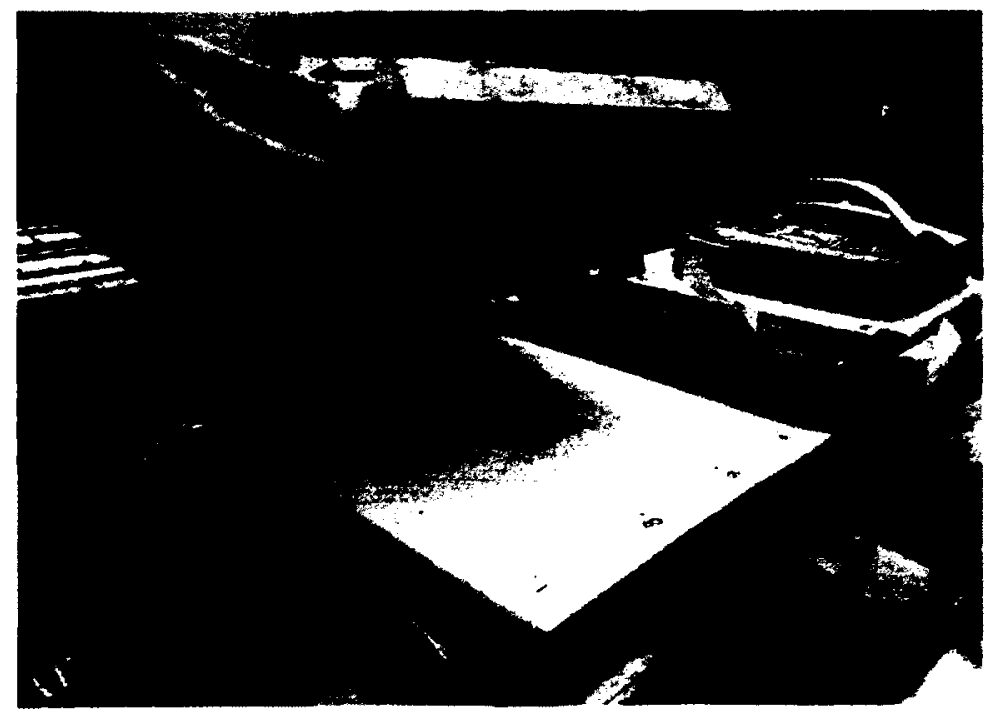

Figure 3.6. Heat flow meter masked specimen set up. 

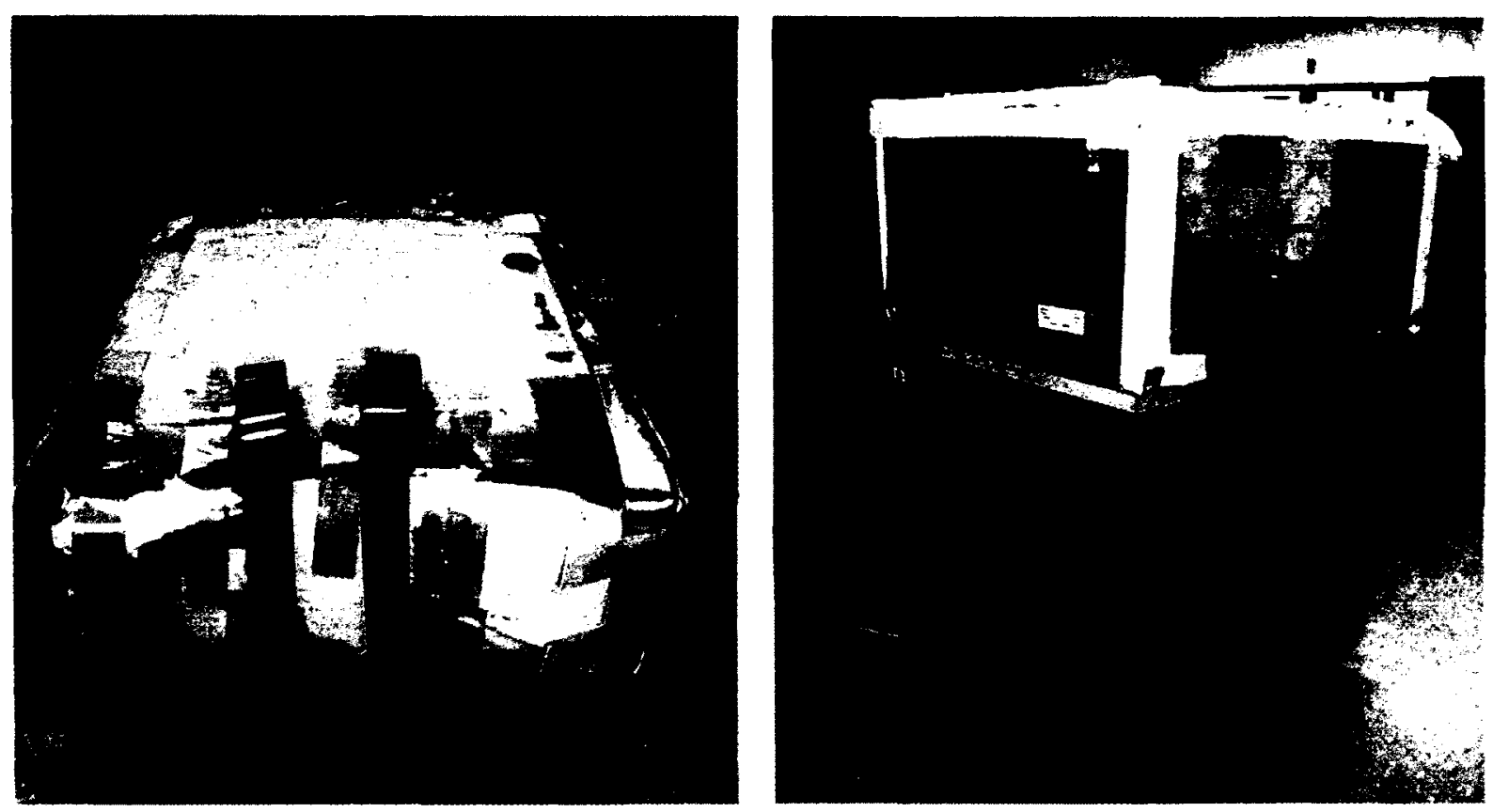

Figure 3.7. Heat flow meter test set up.

\subsection{Tests Results and Discussion}

Thermal conductivities were compared for intact $(k)$ and smaller masked samples $\left(k_{0}\right)$ (Figures 3.8-3.11). The results were used to generate empirical equations relating intact and masked samples, which were then used to calculate derived thermal conductivities ( $\left.k^{\prime}\right)$ (Table 3.4-3.1). It is to be noted that the equations derived from this study are different from the previous similar study done by Mukhophyaya el al. primarily due to the change of mask material (ISO to EPS). 


\subsection{1 $200 \times 200 \mathrm{~mm}$ Specimens}

Thermal conductivities were compared for masked $200 \times 200 \mathrm{~mm}$ specimens and intact $300 \times 300 \mathrm{~mm}$ specimens, with 12.5 and $25 \mathrm{~mm}$ thicknesses (Figure 3.8, Table 3.4). Regression analysis was used, rather than a straight line approach, to investigate the relationship between the thermal conductivities and find the equation that fits the data. The curve was selected based on the $R^{2}$ value that best fit the data including only the experimental data point, and excluding the points at $x=0$ and $y=0$. A Regression analysis showed a significant correlation between the thermal conductivities of masked and intact samples for both thicknesses: $y=9.31 x^{2}+0.4493 x+0.0083\left(R^{2}=0.9963\right)$ for specimens with $12.5 \mathrm{~mm}$ thickness, and $y=-8.4251 \mathrm{x}^{2}+1.4907 \mathrm{x}+0.0066\left(\mathrm{R}^{2}=0.9978\right)$ for specimens with $25 \mathrm{~mm}$ thickness. The equation shown on Figure 3.8, for specimens with $25 \mathrm{~mm}$ thickness, has a negative sign for the $\mathrm{x}^{2}$ coefficient (Example: $-\mathbf{8 . 4 2 5} \mathrm{x}^{2}$ ); it is negative due to the polynomial curve been concave. The difference between the thermal conductivities of masked $\left(\mathrm{k}_{0}\right)$ and intact $(\mathrm{k})$ specimens of ISO and LDGF was $1.34 \%$ and $1.3 \%$, respectively (Table 3.4). The difference between thermal conductivities of masked and intact specimens of HDGF was $1.05 \%$. The thermal conductivities of masked and intact specimens were similar for XPS, EPS and HDGF, with variances less than $1 \%$. When measuring thermal conductivity when the same material is used as the intact part and the mask, it is expected that the variance should be zero. However, in the case of EPS (Table 3.4) the calculated value of the variance, $0.02 \%$ and $-0.53 \%$, is due to the gap between the sample and the mask 
$200 \times 200 \mathrm{~mm}$ sample : $12.5 \mathrm{~mm}$ and $25 \mathrm{~mm}$ thickness

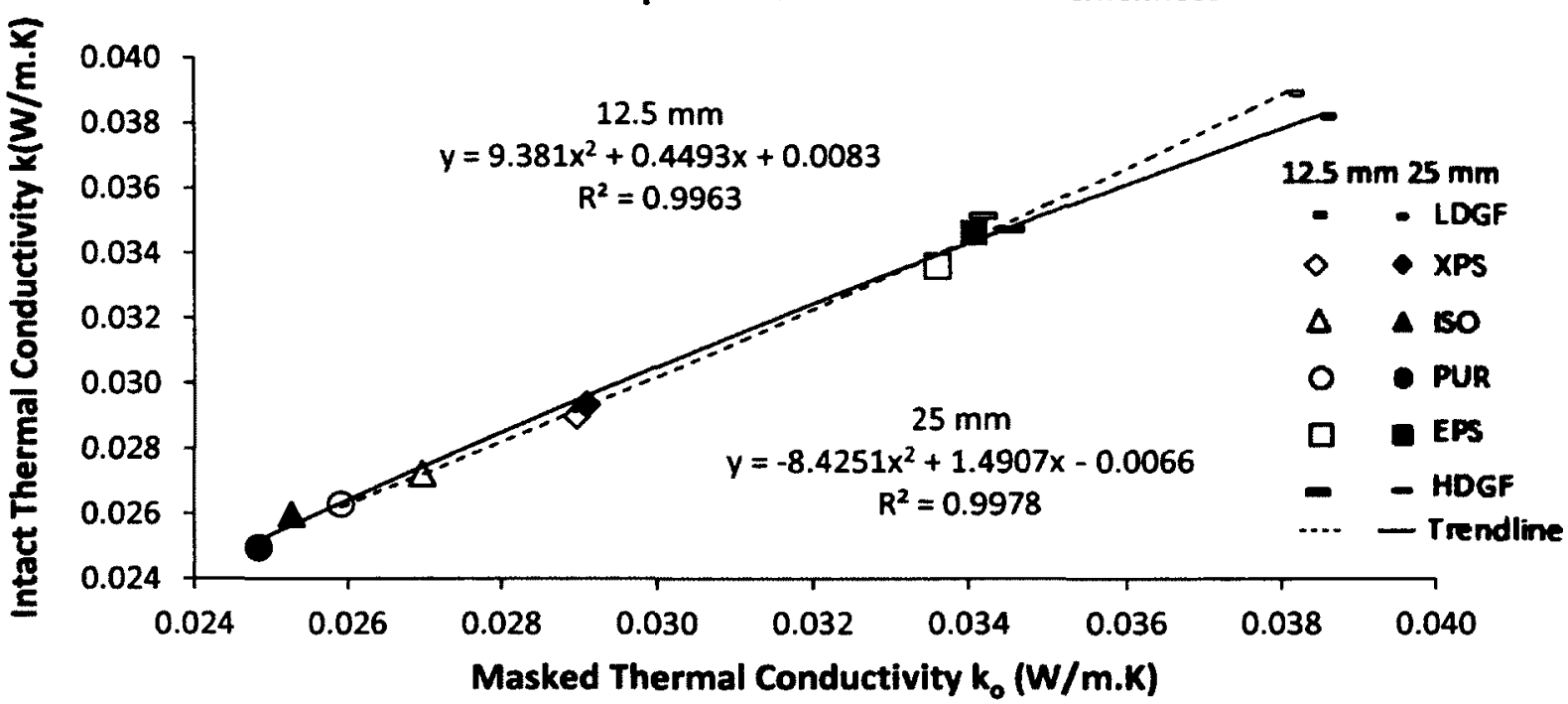

Figure 3.8. Thermal conductivity of masked $200 \times 200 \mathrm{~mm}$ and intact $300 \times 300 \mathrm{~mm}$ specimens, 12.5 and $25 \mathrm{~mm}$ thick.

Table 3.4. Thermal conductivity of intact $300 \times 300 \mathrm{~mm}$ specimens (k) and masked $200 \times$ $200 \mathrm{~mm}$ specimens $\left(\mathbf{k}_{\mathbf{0}}\right), 12.5$ and $25 \mathrm{~mm}$ thick.

\begin{tabular}{cccccccc}
\hline & \multicolumn{5}{c}{ Thermal conductivity (W/m.k) } \\
\cline { 2 - 4 } \cline { 6 - 8 } Size $(\mathrm{mm})$ & $300 \times 300$ & \multicolumn{2}{c}{$200 \times 200$} & & $300 \times 300$ & \multicolumn{3}{c}{$25 \mathrm{~mm}$ thickness } \\
Material & $\mathrm{k}$ & $\mathrm{k}_{0}$ & Variance $\%$ & $\mathrm{k}$ & $\mathrm{k}_{0}$ & Variance \% \\
\hline EPS & 0.03360 & 0.03360 & 0.02 & & 0.03473 & 0.03455 & -0.53 \\
XPS & 0.02897 & 0.02896 & -0.01 & & 0.02935 & 0.02910 & -0.85 \\
PUR & 0.02723 & 0.02697 & -0.95 & & 0.02574 & 0.02536 & -1.47 \\
ISO & 0.02629 & 0.02591 & -1.44 & & 0.02599 & 0.02526 & -2.80 \\
HDGF & 0.03514 & 0.03420 & -2.67 & & 0.03463 & 0.03407 & -1.62 \\
LDGF & 0.03894 & 0.03812 & -2.09 & & 0.03823 & 0.03853 & 0.79 \\
\hline
\end{tabular}


Thermal conductivity values (k') for $200 \times 200 \mathrm{~mm}$ masked specimens were derived from the empirical equation and the thermal conductivity of intact specimens (k) (Table 3.5). The variance between the derived values and measured values for intact $300 \times 300$ mm specimens ranged from $-1.43 \%$ to $1.18 \%$ for $12.5 \mathrm{~mm}$ thick materials, and from $1.18 \%$ to $1.08 \%$ for $25 \mathrm{~mm}$ thick materials. EPS, HDGF, and LDGF had smaller variances for specimens with $25 \mathrm{~mm}$ thickness than XPS, PUR, and ISO. The ISO specimen with $25 \mathrm{~mm}$ thickness had the highest variance (1.18\%), and LDGF had the lowest (0.27\%). For $12.5 \mathrm{~mm}$ thick specimens, HDGF had the highest variance $(1.43 \%)$, and PUR had the lowest $(0.06 \%)$. The difference in variances between 12.5 and $25 \mathrm{~mm}$ thicknesses was $1 \%$ for PUR and ISO, and less than $1 \%$ for the other materials. HDGF was the only material with slightly different densities, and the variance differed by $0.78 \%$ between the two thicknesses. Thus, there was a correlation between the values derived from the empirical formula and values from experimental observations.

Table 3.5. Measured (k) and derived ( $k^{\prime}$ ) thermal conductivities of intact $300 \times 300 \mathrm{~mm}$ specimens and masked $200 \times 200 \mathrm{~mm}$ specimens, with 12.5 and $25 \mathrm{~mm}$ thicknesses.

\begin{tabular}{|c|c|c|c|c|c|c|}
\hline \multicolumn{7}{|c|}{ Thermal conductivity $(\mathrm{W} / \mathrm{m} . \mathrm{k})$} \\
\hline \multirow{3}{*}{$\begin{array}{c}\text { Size }(\mathrm{mm}) \\
\text { Material }\end{array}$} & \multicolumn{3}{|c|}{$12.5 \mathrm{~mm}$ thickness } & \multicolumn{3}{|c|}{$25 \mathrm{~mm}$ thickness } \\
\hline & \multirow{2}{*}{$\begin{array}{c}300 \times 300 \\
k\end{array}$} & \multicolumn{2}{|c|}{$200 \times 200$} & \multirow{2}{*}{$\begin{array}{c}300 \times 300 \\
\mathbf{k}\end{array}$} & \multicolumn{2}{|c|}{$200 \times 200$} \\
\hline & & Variance $\%$ & $\mathbf{k}^{\prime}$ & & Variance $\%$ & $\mathbf{k}^{\prime}$ \\
\hline EPS & 0.03360 & 1.18 & 0.03400 & 0.03473 & 0.31 & 0.03484 \\
\hline XPS & 0.02897 & 0.74 & 0.02919 & 0.02935 & 1.02 & 0.02964 \\
\hline PUR & 0.02723 & 0.06 & 0.02724 & 0.02574 & 1.12 & 0.02546 \\
\hline ISO & 0.02629 & -0.18 & 0.02624 & 0.02599 & -1.18 & 0.02567 \\
\hline HDGF & 0.03514 & -1.43 & 0.03464 & 0.03463 & -0.65 & 0.03441 \\
\hline LDGF & 0.03894 & 0.32 & 0.03907 & 0.03823 & 0.27 & 0.03833 \\
\hline
\end{tabular}




\subsubsection{0 x $150 \mathrm{~mm}$ Specimens}

Thermal conductivities were compared for masked $150 \times 150 \mathrm{~mm}$ specimens and intact $300 \times 300 \mathrm{~mm}$ specimens, with 12.5 and $25 \mathrm{~mm}$ thicknesses (Figure 3.9, Table 3.6). Regression analysis showed a significant correlation between the thermal conductivities of masked and intact samples for both thicknesses. For specimens with $12.5 \mathrm{~mm}$ thickness $y=32.572 x^{2}-9469 x+0.0288\left(R^{2}=0.9912\right)$, and for specimens with $25 \mathrm{~mm}$ thickness $y=8.8317 x^{2}+0.5726 x+0.0046\left(R^{2}=0.9947\right)$. The difference between variances for the two thicknesses was highest for LDGF (1.31\%), indicating that thickness affected results for the masked samples. The other insulation materials had small differences between variances of the two thicknesses.

$150 \times 150 \mathrm{~mm}$ sample : 12.5 and $25 \mathrm{~mm}$ thickness

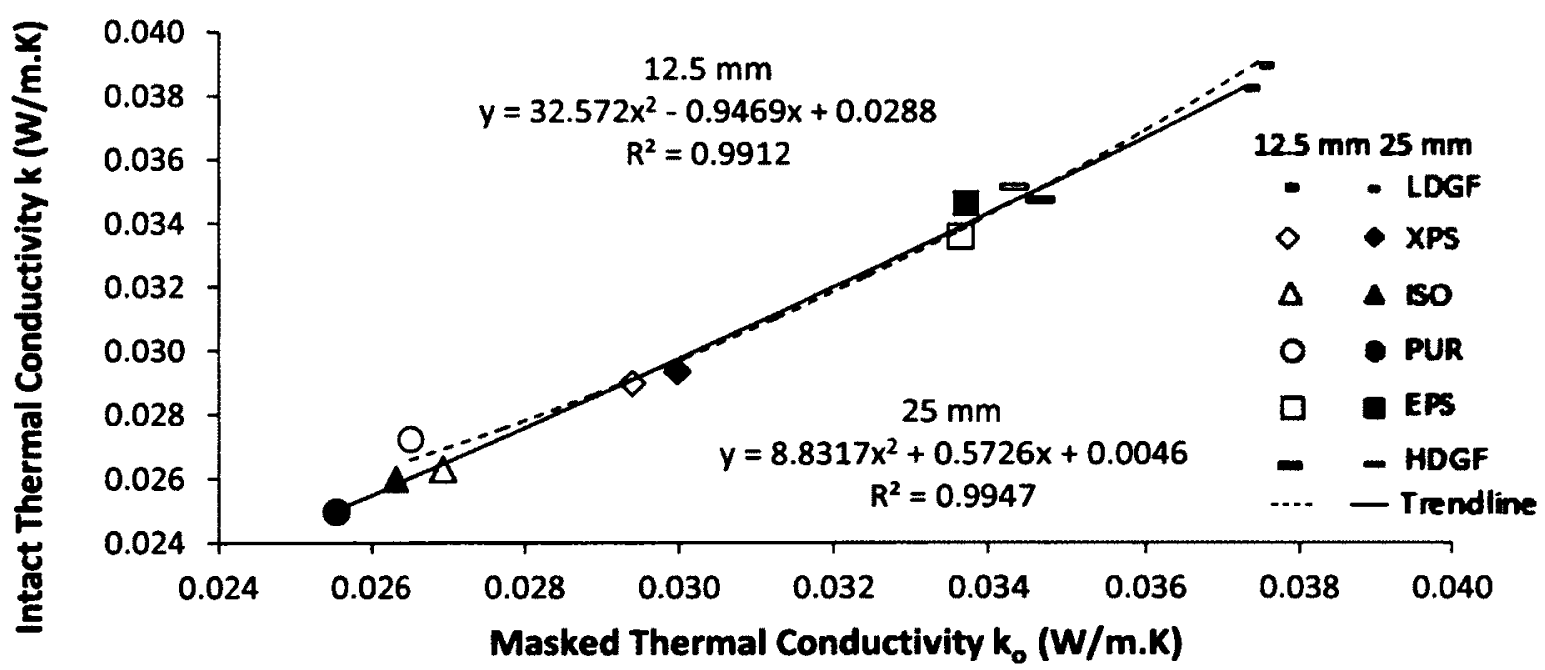

Figure 3.9. Thermal conductivity of masked $150 \times 150 \mathrm{~mm}$ and intact $300 \times 300 \mathrm{~mm}$ samples, 12.5 and 25 mm thick. 
Table 3.6. Thermal conductivity of intact $300 \times 300 \mathrm{~mm}$ specimens $(\mathrm{k})$ and masked $150 \times$ $150 \mathrm{~mm}$ specimens $\left(k_{0}\right), 12.5$ and $25 \mathrm{~mm}$ thick.

\begin{tabular}{|c|c|c|c|c|c|c|}
\hline \multicolumn{7}{|c|}{ Thermal conductivity (W/m.k) } \\
\hline \multirow{3}{*}{$\begin{array}{c}\text { Size }(\mathrm{mm}) \\
\text { Material }\end{array}$} & \multicolumn{3}{|c|}{$12.5 \mathrm{~mm}$ thickness } & \multicolumn{3}{|c|}{$25 \mathrm{~mm}$ thickness } \\
\hline & \multirow{2}{*}{$\begin{array}{c}300 \times 300 \\
k\end{array}$} & \multicolumn{2}{|c|}{$150 \times 150$} & \multirow{2}{*}{$\begin{array}{c}300 \times 300 \\
k\end{array}$} & \multicolumn{2}{|c|}{$150 \times 150$} \\
\hline & & $\mathbf{k}_{\mathrm{o}}$ & Variance $\%$ & & $\mathbf{k}_{\mathbf{0}}$ & Variance \% \\
\hline EPS & 0.03360 & 0.0336 & 0.12 & 0.03473 & 0.03467 & -0.18 \\
\hline XPS & 0.02897 & 0.0294 & 1.46 & 0.02935 & 0.02998 & 2.15 \\
\hline PUR & 0.02723 & 0.0265 & -2.62 & 0.02574 & 0.02654 & -3.09 \\
\hline ISO & 0.02629 & 0.0269 & 2.47 & 0.02599 & 0.02632 & 1.26 \\
\hline HDGF & 0.03514 & 0.0343 & -2.26 & 0.03463 & 0.03371 & -2.65 \\
\hline LDGF & 0.03894 & 0.0375 & -3.71 & 0.03823 & 0.03731 & -2.41 \\
\hline
\end{tabular}

Thermal conductivity values (k') for $150 \times 150 \mathrm{~mm}$ masked specimens were derived from the empirical equation and the thermal conductivity of intact specimens (k) (Table 3.7). The variance between the derived values and measured values for intact $300 \times 300$ $\mathrm{mm}$ specimens ranged from $-2.32 \%$ to $0.61 \%$ for $12.5 \mathrm{~mm}$ thick materials, and $-2 \%$ to $1.22 \%$ for $25 \mathrm{~mm}$ thick materials. EPS, XPS, and LDGF specimens with $12.5 \mathrm{~mm}$ thickness had variances less than $1 \%$. EPS, PUR, and LDGF specimens with $25 \mathrm{~mm}$ thickness had variances as low as $1 \%$. The difference in variances between 12.5 and $25 \mathrm{~mm}$ thicknesses was highest for PUR and ISO $-2.97 \%$ and $1.67 \%$ respectively, indicating that thickness slightly affected predicted thermal conductivity. HDGF was the only material with slightly different densities, and the variance differed by $0.74 \%$ between the two thicknesses, indicating no significant effect on thermal conductivity predictions. Thus, there was a very close correlation between the values derived from the empirical formula and values from experimental observations. 
Table 3.7. Measured (k) and derived (k') thermal conductivities of intact $300 \times 300 \mathrm{~mm}$ specimens and masked $150 \times 150 \mathrm{~mm}$ specimens, with 12.5 and $25 \mathrm{~mm}$ thicknesses.

\begin{tabular}{|c|c|c|c|c|c|c|}
\hline \multicolumn{7}{|c|}{ Thermal conductivity (W/m.k) } \\
\hline \multirow{3}{*}{$\begin{array}{c}\text { Size }(\mathrm{mm}) \\
\text { Material }\end{array}$} & \multicolumn{3}{|c|}{$12.5 \mathrm{~mm}$ thickness } & \multicolumn{3}{|c|}{$25 \mathrm{~mm}$ thickness } \\
\hline & \multirow{2}{*}{$\begin{array}{c}300 \times 300 \\
k\end{array}$} & \multicolumn{2}{|c|}{$150 \times 150$} & \multirow{2}{*}{$\begin{array}{c}300 \times 300 \\
k\end{array}$} & \multicolumn{2}{|c|}{$150 \times 150$} \\
\hline & & $\mathbf{k}^{\prime}$ & Variance $\%$ & & $\mathbf{k}^{\prime}$ & Variance $\%$ \\
\hline EPS & 0.03360 & 0.03381 & 0.61 & 0.03473 & 0.03506 & 0.95 \\
\hline XPS & 0.02897 & 0.02911 & 0.47 & 0.02935 & 0.02970 & 1.22 \\
\hline PUR & 0.02723 & 0.02659 & -2.32 & 0.02574 & 0.02557 & 0.65 \\
\hline ISO & 0.02629 & 0.02693 & 2.45 & 0.02599 & 0.02579 & -0.78 \\
\hline HDGF & 0.03514 & 0.03470 & -1.26 & 0.03463 & 0.03394 & -2.00 \\
\hline LDGF & 0.03894 & 0.03909 & 0.38 & 0.03823 & 0.03825 & 0.07 \\
\hline
\end{tabular}

\subsection{3 $100 \times 100 \mathrm{~mm}$ Specimens}

Thermal conductivities were compared for masked $100 \times 100 \mathrm{~mm}$ specimens and intact $300 \times 300 \mathrm{~mm}$ specimens, with 12.5 and $25 \mathrm{~mm}$ thicknesses (Figure 3.10, Table 3.8).. PUR had the highest variation between thermal conductivity of masked and intact specimens of both thicknesses, followed by LDGF and ISO. The respective variances were $4.81 \%, 4.41 \%$ and $2.12 \%$. For XPS, ISO and HDGF, the variances were less than $2 \%$. Regression analysis showed a significant correlation between the thermal conductivities of masked and intact samples for both thicknesses: $y=454.3 x^{2}-27.176 x+0.4327$ $\left(R^{2}=0.9906\right)$ for specimens with 12.5 mm thickness; $y=-20.498 x^{2}+3.50561 x-0.0619$ $\left(\mathrm{R}^{2}=0.9927\right)$ for specimens with $25 \mathrm{~mm}$ thickness. The line fit to data for specimens with $12.5 \mathrm{~mm}$ thickness was somewhat curved, but the line fit to data for $25 \mathrm{~mm}$ thick specimens was linear. Despite the relatively high variances of PUR, ISO, XPS, the high $\mathrm{R}^{2}$ 
values indicated strong correlations between measured and predicted thermal conductivity for both thicknesses.

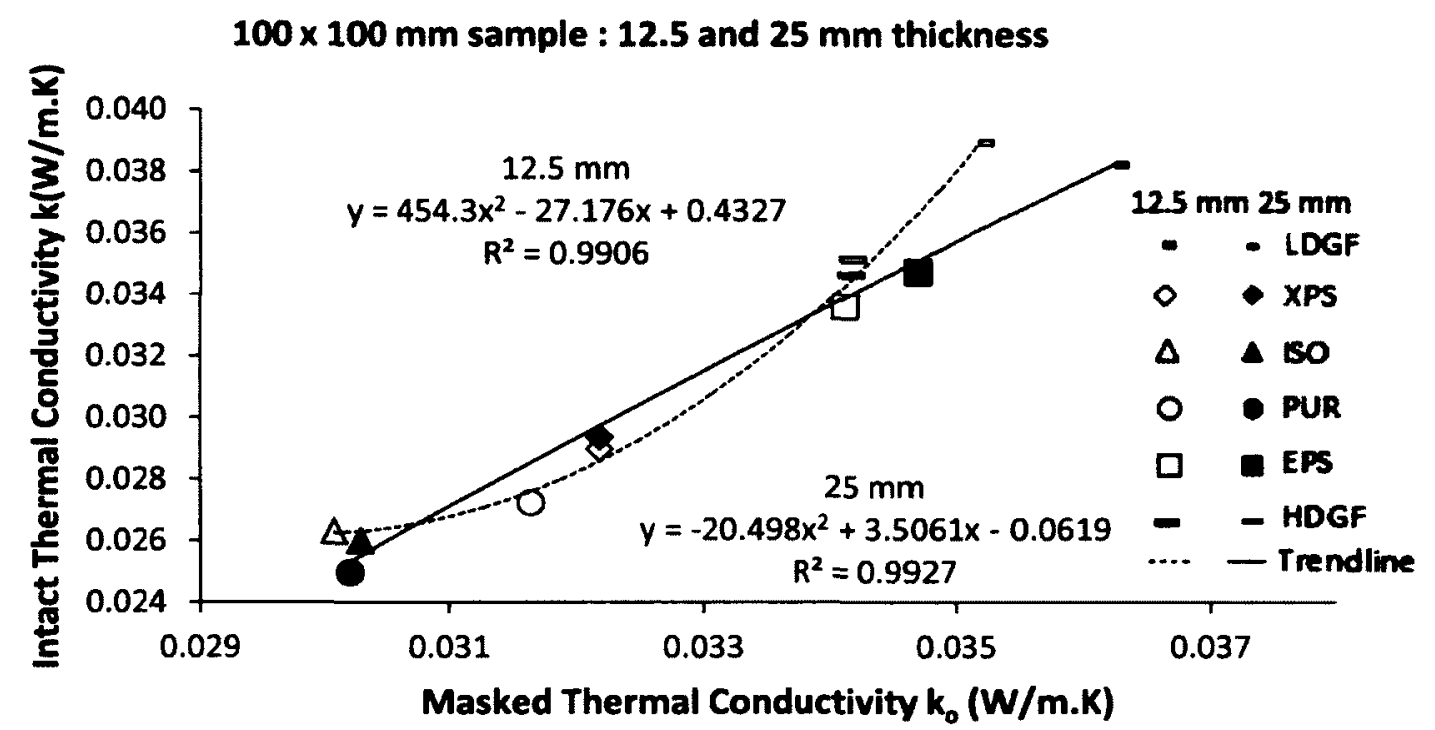

Figure 3.10. Thermal conductivity of masked $100 \times 100 \mathrm{~mm}$ and intact $300 \times 300 \mathrm{~mm}$ samples, 12.5 and $25 \mathrm{~mm}$ thick.

Table 3.8. Thermal conductivity of intact $300 \times 300 \mathrm{~mm}$ specimens (k) and masked $100 \times$ $100 \mathrm{~mm}$ specimens $\left(k_{\mathbf{o}}\right), 12.5$ and $25 \mathrm{~mm}$ thick.

\begin{tabular}{|c|c|c|c|c|c|c|}
\hline \multicolumn{7}{|c|}{ Thermal conductivity $(\mathrm{W} / \mathrm{m} . \mathrm{k})$} \\
\hline \multirow{3}{*}{$\begin{array}{r}\text { Size }(\mathrm{mm}) \\
\text { Material } \\
\end{array}$} & \multicolumn{3}{|c|}{$12.5 \mathrm{~mm}$ thickness } & \multicolumn{3}{|c|}{$25 \mathrm{~mm}$ thickness } \\
\hline & \multirow{2}{*}{$\begin{array}{c}300 \times 300 \\
k\end{array}$} & \multicolumn{2}{|c|}{$100 \times 100$} & \multirow{2}{*}{$\begin{array}{c}300 \times 300 \\
\mathbf{k} \\
\end{array}$} & \multicolumn{2}{|c|}{$100 \times 100$} \\
\hline & & $\mathbf{k}_{0}$ & Variance $\%$ & & $\mathbf{k}_{0}$ & Variance $\%$ \\
\hline EPS & 0.03360 & 0.03412 & 1.57 & 0.03473 & 0.03469 & -0.09 \\
\hline XPS & 0.02897 & 0.03218 & 11.08 & 0.02935 & 0.03218 & 9.65 \\
\hline PUR & 0.02723 & 0.03163 & 16.19 & 0.02574 & 0.03020 & 21.00 \\
\hline ISO & 0.02629 & 0.03007 & 14.41 & 0.02599 & 0.03028 & 16.53 \\
\hline HDGF & 0.03514 & 0.03418 & -2.72 & 0.03463 & 0.03417 & -1.33 \\
\hline LDGF & 0.03894 & 0.03519 & -9.61 & 0.03823 & 0.03624 & -5.20 \\
\hline
\end{tabular}


The variance between derived thermal conductivity values $\left(k^{\prime}\right)$ for $100 \times 100 \mathrm{~mm}$ masked specimens and thermal conductivity of intact specimens $(\mathrm{k})$ ranged from $-1.94 \%$ to $1.34 \%$ for $25 \mathrm{~mm}$ thick samples, and from $-1.58 \%$ to $2.28 \%$ for $12.5 \mathrm{~mm}$ thick samples (Table 3.9). The variance for EPS and LDGF specimens with $25 \mathrm{~mm}$ thickness was less than $1 \%$. ISO and HDGF had the highest variance for specimens with $25 \mathrm{~mm}$ thickness (1.9\%). ISO and LDGF had variances as low as $0.1 \%$ for specimens with $12.5 \mathrm{~mm}$ thickness, and EPS had the highest variance for specimens with $12.5 \mathrm{~mm}$ thickness (2.28\%). XPS and ISO had variances of $2.4 \%$ and $1.99 \%$, respectively, for both thicknesses. As for larger masked samples, HDGF was the only material with slightly different densities between thicknesses, and the variance differed by $0.33 \%$, indicating no significant effect on thermal conductivity predictions. Thus, there was a close correlation between the values derived from the empirical formula and values from experimental observations.

Table 3.9. Measured ( $k$ ) and derived (k') thermal conductivities of intact $300 \times 300 \mathrm{~mm}$ specimens and masked $100 \times 100 \mathrm{~mm}$ specimens, with 12.5 and $25 \mathrm{~mm}$ thicknesses.

\begin{tabular}{|c|c|c|c|c|c|c|}
\hline \multicolumn{7}{|c|}{ Thermal conductivity (W/m.k) } \\
\hline \multirow{3}{*}{$\begin{array}{c}\text { Size }(\mathrm{mm}) \\
\text { Material }\end{array}$} & \multicolumn{3}{|c|}{$12.5 \mathrm{~mm}$ thickness } & \multicolumn{3}{|c|}{$25 \mathrm{~mm}$ thickness } \\
\hline & \multirow{2}{*}{$\begin{array}{c}300 \times 300 \\
\mathrm{k}\end{array}$} & \multicolumn{2}{|c|}{$100 \times 100$} & \multirow{2}{*}{$\begin{array}{c}300 \times 300 \\
\mathrm{k}\end{array}$} & \multicolumn{2}{|c|}{$100 \times 100$} \\
\hline & & $\mathbf{k}^{\prime}$ & Variance \% & & $\mathbf{k}^{\prime}$ & Variance $\%$ \\
\hline EPS & 0.03360 & 0.03437 & 2.28 & 0.03473 & 0.03508 & 0.99 \\
\hline XPS & 0.02897 & 0.02863 & -1.19 & 0.02935 & 0.02970 & 1.21 \\
\hline PUR & 0.02723 & 0.02764 & 1.53 & 0.02574 & 0.02529 & 1.34 \\
\hline ISO & 0.02629 & 0.02630 & 0.05 & 0.02599 & 0.02548 & -1.94 \\
\hline HDGF & 0.03514 & 0.03459 & -1.58 & 0.03463 & 0.03397 & -1.91 \\
\hline LDGF & 0.03894 & 0.03898 & 0.10 & 0.03823 & 0.03824 & 0.04 \\
\hline
\end{tabular}




\subsubsection{0 x 50 mm Specimens}

The predicted thermal conductivities of masked $50 \times 50 \mathrm{~mm}$ specimens of $25 \mathrm{~mm}$ thick materials were fairly well correlated with thermal conductivity measurements for intact specimens (Figure 3.11): $y=-2339.1 x^{2}+167.44 x-2.9585\left(R^{2}=0.94\right)$. However, predicted and measured values were poorly correlated for $12.5 \mathrm{~mm}$ thick samples: $y=491.59 x^{2}-29.659 x+0.4731\left(R^{2}=0.53\right)$. The latter correlation was not strong enough to provide reliable values. Variance between measured thermal conductivity of masked $\left(\mathrm{k}_{0}\right)$ and intact (k) samples were highest for XPS, PUR and ISO samples of both thicknesses. When both thicknesses were compared, the difference between variances was $15.78 \%$, $5.74 \%$, and $3.36 \%$ for PUR, HDGF, and ISO, respectively (Table 3.10). The difference between variances was less than $1.6 \%$ for EPS, XPS and LDGF.

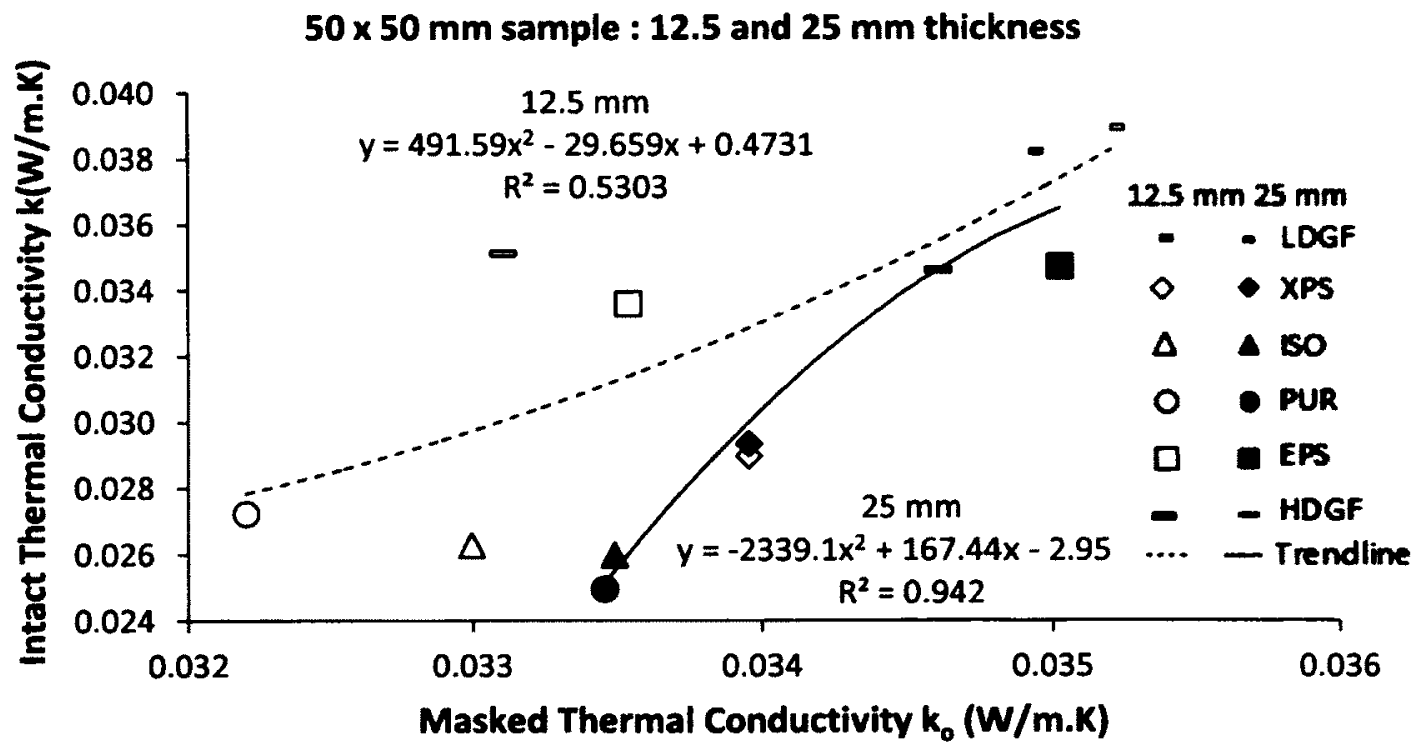

Figure 3.11. Thermal conductivity of masked $50 \times 50 \mathrm{~mm}$ and intact $300 \times 300 \mathrm{~mm}$ samples, 12.5 and $25 \mathrm{~mm}$ thick. 
Table 3.10. Thermal conductivity of intact $300 \times 300 \mathrm{~mm}$ specimens (k) and masked $50 \times$ $50 \mathrm{~mm}$ specimens $\left(\mathbf{k}_{\mathbf{0}}\right)$, 12.5 and $25 \mathrm{~mm}$ thick.

\begin{tabular}{|c|c|c|c|c|c|c|}
\hline \multicolumn{7}{|c|}{ Thermal conductivity (W/m.k) } \\
\hline \multirow{3}{*}{$\begin{array}{c}\text { Size }(\mathrm{mm}) \\
\text { Material }\end{array}$} & \multicolumn{3}{|c|}{$12.5 \mathrm{~mm}$ thickness } & \multicolumn{3}{|c|}{$25 \mathrm{~mm}$ thickness } \\
\hline & \multirow{2}{*}{$\begin{array}{c}300 \times 300 \\
k\end{array}$} & \multicolumn{2}{|c|}{$50 \times 50$} & \multirow{2}{*}{$\begin{array}{c}300 \times 300 \\
k\end{array}$} & \multicolumn{2}{|c|}{$50 \times 50$} \\
\hline & & $\mathbf{k}_{0}$ & Variance $\%$ & & $\mathbf{k}_{\mathrm{o}}$ & Variance \% \\
\hline EPS & 0.03360 & 0.03354 & -0.18 & 0.03473 & 0.03502 & 0.85 \\
\hline XPS & 0.02897 & 0.03395 & 17.21 & 0.02935 & 0.03395 & 15.69 \\
\hline PUR & 0.02723 & 0.03220 & 18.26 & 0.02574 & 0.03346 & 34.04 \\
\hline ISO & 0.02629 & 0.03300 & 25.50 & 0.02599 & 0.03349 & 28.86 \\
\hline HDGF & 0.03514 & 0.03311 & -5.78 & 0.03463 & 0.03461 & -0.05 \\
\hline LDGF & 0.03894 & 0.03520 & -9.60 & 0.03823 & 0.03492 & -8.65 \\
\hline
\end{tabular}

Variance between derived thermal conductivity values ( $\left.k^{\prime}\right)$ and values measured for intact $300 \times 300 \mathrm{~mm}$ specimens (k) are shown in ranged from $-14.64 \%$ to $13.21 \%$ for $12.5 \mathrm{~mm}$ thick materials, and from $-5.35 \%$ to $5.35 \%$ for $25 \mathrm{~mm}$ thick materials (Table 3.11). For specimens with $25 \mathrm{~mm}$ thickness, EPS had the highest variance $(5.35 \%)$, and HDGF had the lowest $(0.23 \%)$. HDGF had the highest variance for $12.5 \mathrm{~mm}$ thick specimens (14.64\%), and LDGF had the lowest (-1.86\%). XPS, ISO and HDGF had variances of more than $12 \%$ when both thicknesses were compared, but the same variances were less than $3.5 \%$ for the other materials. HDGF was the only material with slightly different densities between the two thicknesses, and the variance difference was $14.41 \%$. From these observations, it is evident that thermal conductivity measurements using $50 \times 50$ mm specimens were more reliable for materials with $25 \mathrm{~mm}$ thickness than with 12.5 thicknesses. 
Table 3.11. Measured (k) and derived (k') thermal conductivities of intact $300 \times 300 \mathrm{~mm}$ specimens and masked 50 x 50 mm specimens, with 12.5 and 25 mm thicknesses.

\begin{tabular}{|c|c|c|c|c|c|c|}
\hline \multicolumn{7}{|c|}{ Thermal conductivity (W/m.k) } \\
\hline \multirow{3}{*}{$\begin{array}{c}\text { Size (mm) } \\
\text { Material }\end{array}$} & \multicolumn{3}{|c|}{$12.5 \mathrm{~mm}$ thickness } & \multicolumn{3}{|c|}{$25 \mathrm{~mm}$ thickness } \\
\hline & \multirow{2}{*}{$\begin{array}{c}300 \times 300 \\
k\end{array}$} & \multicolumn{2}{|c|}{$50 \times 50$} & \multirow{2}{*}{$\begin{array}{c}300 \times 300 \\
k\end{array}$} & \multicolumn{2}{|c|}{$50 \times 50$} \\
\hline & & $\mathbf{k}^{\prime}$ & Variance $\%$ & & $\mathbf{k}^{\prime}$ & Variance $\%$ \\
\hline EPS & 0.03360 & 0.03134 & 6.72 & 0.03473 & 0.03659 & 5.35 \\
\hline XPS & 0.02897 & 0.03280 & 13.21 & 0.02935 & 0.03007 & 2.48 \\
\hline PUR & 0.02723 & 0.02778 & 2.05 & 0.02574 & 0.02521 & 1.01 \\
\hline ISO & 0.02629 & 0.02968 & 12.91 & 0.02599 & 0.02558 & -1.57 \\
\hline HDGF & 0.03514 & 0.03000 & -14.64 & 0.03463 & 0.03471 & 0.23 \\
\hline LDGF & 0.03894 & 0.03822 & -1.86 & 0.03823 & 0.03620 & -5.31 \\
\hline
\end{tabular}

\subsubsection{Summary}

The correlations varied more as specimens became smaller, but the relationships were still highly significant, indicating that it is possible to accurately derive the thermal conductivity value $\left(\mathrm{k}^{\prime}\right)$ from the value measured using the masked sample $\left(\mathrm{k}_{\mathrm{o}}\right)$. In general, thermal conductivity measurements for masked specimens $200 \times 200 \mathrm{~mm}$, $150 \times 150 \mathrm{~mm}$, and $100 \times 100 \mathrm{~mm}$ were closely correlated with measurements for intact $300 \times 300 \mathrm{~mm}$ specimens of the same materials.

Measurements using the smallest masked specimens tested $(50 \times 50 \mathrm{~mm})$ did not provide reliable results, particularly for the thinner materials (Figure 3.11), because the thermal conductivity measurements were more representative of the mask material than the sample material. Thus, $50 \times 50 \mathrm{~mm}$ is too small a sample size for accurate assessment of thermal conductivity using the heat flow meter with a metering area $150 \times 150 \mathrm{~mm}$. 
It is also recommended that this test methodology may not be applicable for any new specimens with unknown thermal conductivity beyond the range of thermal conductivity data $(0.025 \mathrm{~W} / \mathrm{mK}-0.034 \mathrm{~W} / \mathrm{mK})$ that were used to generate the best fit curve in this study. 


\section{Chapter 4: Modelling}

Chapter 4 presents a three-dimensional analysis, using HEAT3, version 6.1 [56], of heat transfer through different size specimens of the six experimental insulation materials. HEAT3 is a finite element-based, finite volume method for solving transient and steady-state heat conduction. In the present study, numerical simulations were compared to experimental results.

\subsection{Data Input}

Several types of data were entered into the HEAT3 program to simulate the test conditions and calculate heat flows. Data input included, but was not limited to:

\section{Geometrical definition}

The test assembly was described with three different materials (Figure 4.1):

- The mask (Area I)

- The air gap (Area II)

- The test specimen (Area III) 


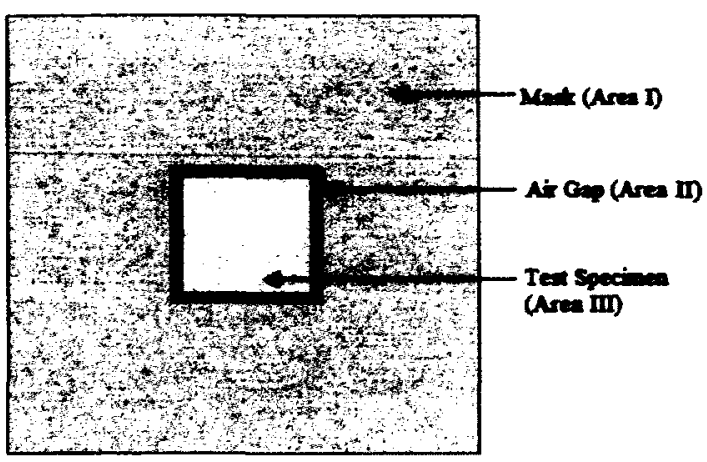

Figure 4.1 Test assembly

Type of Material

Materials were selected from the material database library (Figure 4.1).

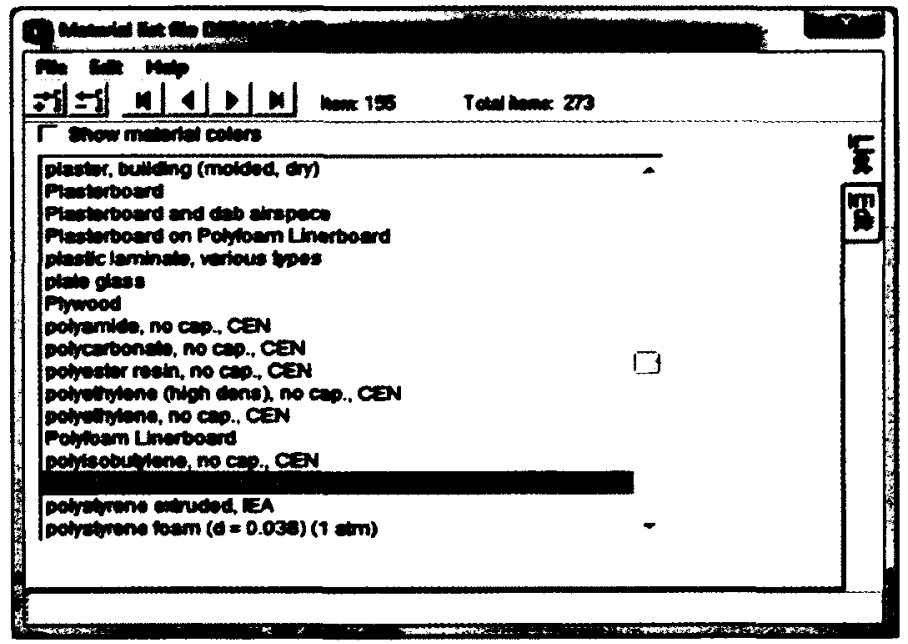

Figure 4.2. Material database library 
Boundary Conditions

Boundary conditions were the temperatures of the cold and hot plates $\left(13^{\circ} \mathrm{C}\right.$ and $35^{\circ} \mathrm{C}$, respectively), and heat flow at the four edges of the specimen. All the four edges were considered to be completely insulated, so heat flow was assumed to be zero (Figure 4.3).

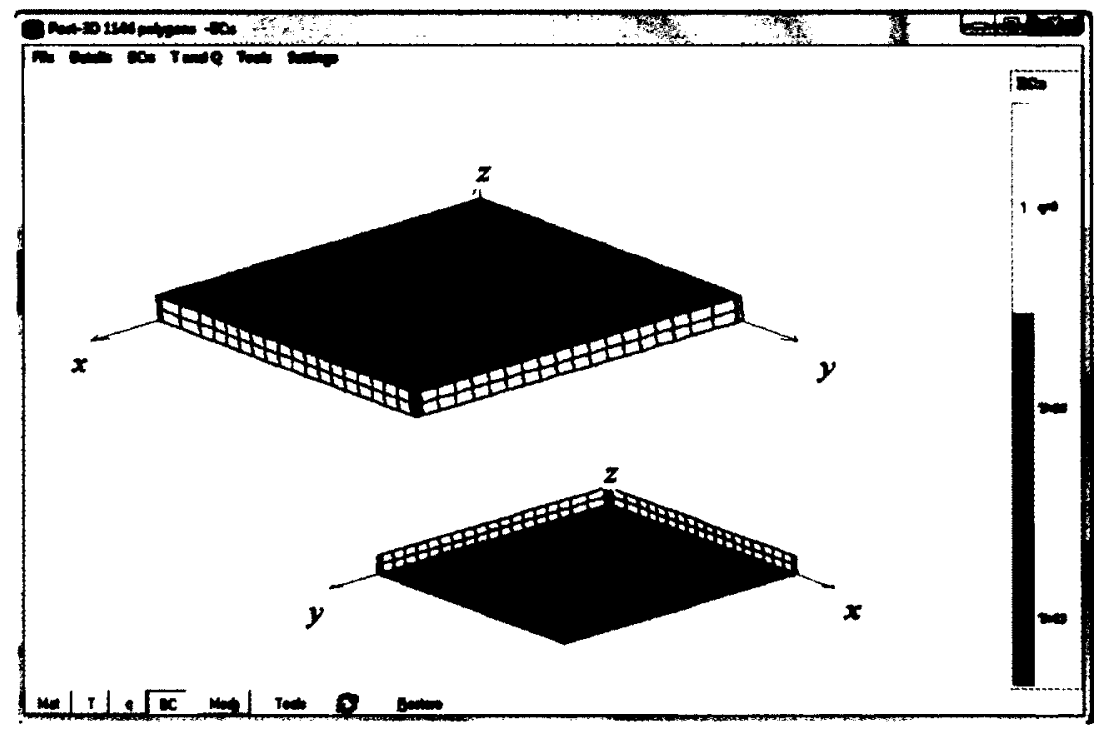

Figure 4.3 Boundary condition

\section{Thermal Conductivity of Material}

The experimentally determined thermal conductivity values of intact $300 \times 300 \mathrm{~mm}$ mask and these thermal conductivity values were used as input (Table 4.1), The thermal conductivity of the air $(0.024 \mathrm{~W} / \mathrm{mk})$ is also required as input. 
Table 4.1 Thermal conductivity values measured using intact specimens

\begin{tabular}{ccc}
\cline { 2 - 3 } & \multicolumn{2}{c}{ Size sample $300 \times 300 \mathrm{~mm}$} \\
\cline { 2 - 3 } Material & $\mathrm{k}(\mathrm{W} / \mathrm{mK})$ & $\mathrm{k}(\mathrm{W} / \mathrm{mK})$ \\
\hline EPS & 0.03360 & 0.03473 \\
XPS & 0.02897 & 0.29350 \\
PU & 0.02723 & 0.02574 \\
PI & 0.02629 & 0.02599 \\
HDGF & 0.03514 & 0.03462 \\
LDGF & 0.03894 & 0.03823 \\
AIR & 0.00240 & 0.00240 \\
\hline
\end{tabular}

Mesh

The FEM divides a continuum into discrete elements. This subdivision is called discretization. In FEM, the individual elements are connected by a topological map, usually called a mesh. The finite element interpolation functions are built on the mesh, which ensures compatibility of the interpolation. The mesh used in the HEAT3 model had the smallest cell dimensions $(\mathrm{dx}=0.0002 \mathrm{~m}, \mathrm{dy}=0.0005 \mathrm{~m}, \mathrm{dz}=0.0023 \mathrm{~m})$. The total number of computational cells was 183,001 .

\subsection{Simulation Output}

The simulation output is: Heat flow $\left(\mathrm{W} / \mathrm{m}^{2}\right)$ and Surface temperature $\left({ }^{\circ} \mathrm{C}\right)$. The Typical post-processor output is shown in Figure 4.4, and Figure 4.5. 


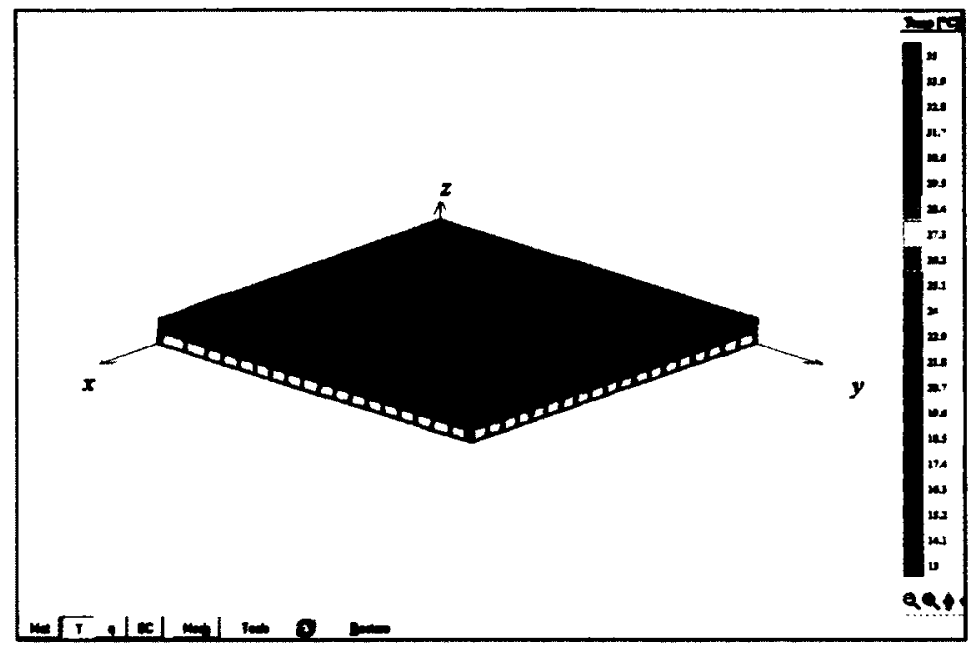

Figure 4.4 Temperature output as shown in the post-processor window.

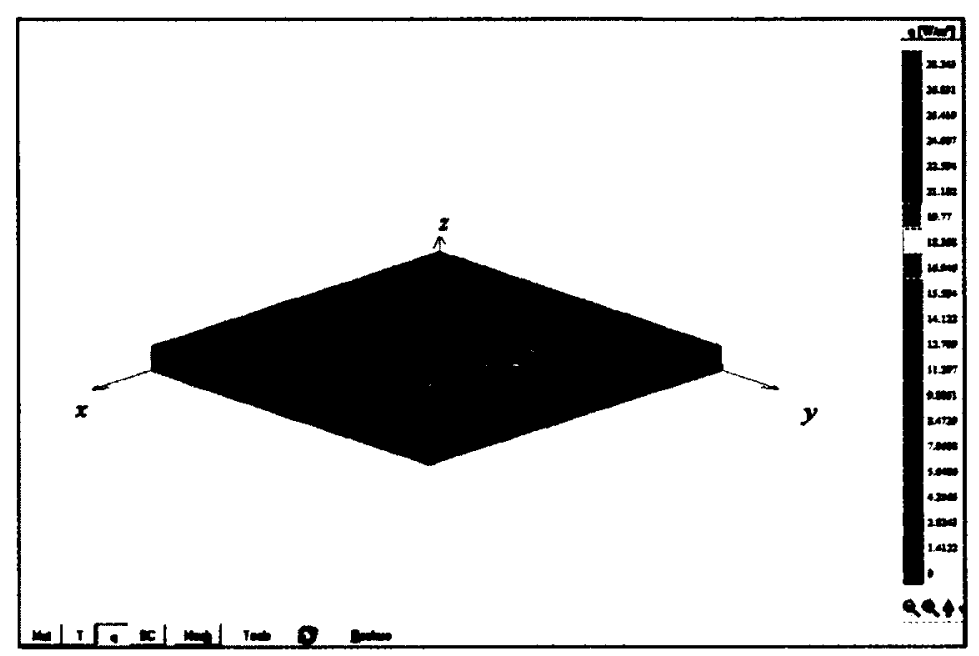

Figure 4.5 Heat flow output as shown in the post-processor window.

\subsection{Sensitivity Analysis}

Four scenarios were used to validate the results of model simulations, using thermal conductivities measured for masked smaller specimens of the six types of insulation (Figure 4.6 and Figure 4.7). 
- Scenario 1 assumed that there was no gap between the specimen and the EPS mask.

- Scenario 2 assumed a $1 \mathrm{~mm}$ gap between the specimen and the mask.

- Scenario 3 assumed a $0.7 \mathrm{~mm}$ gap between the specimen and the mask.

- Scenario 4 assumed a $0.5 \mathrm{~mm}$ gap between the specimen and the mask.
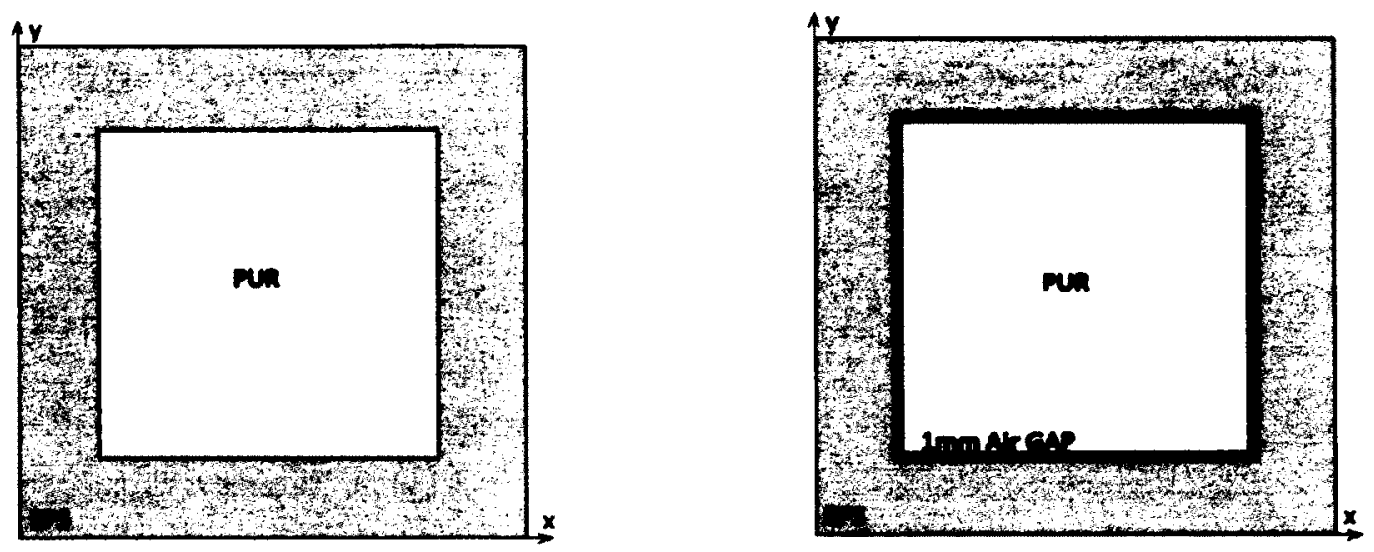

Figure 4.6. a) Scenario 1: model simulated with no gap and b) Scenario 2: model simulated with $1 \mathrm{~mm}$ gap.
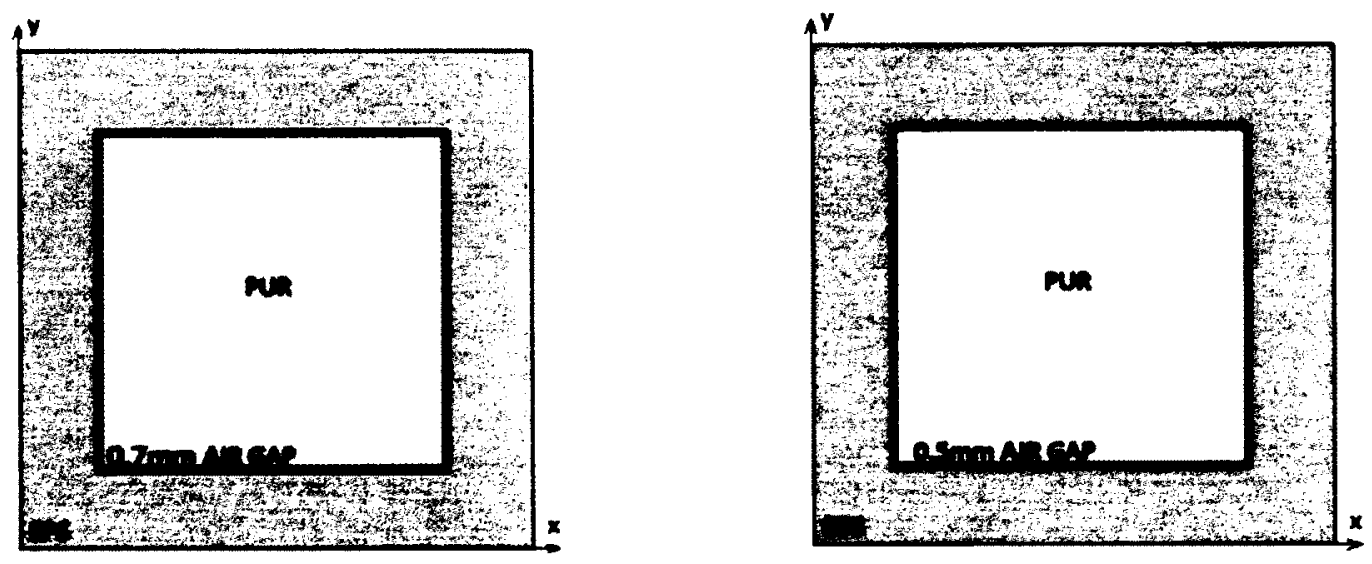

Figure 4.7. a) Scenario 3: model simulated with $0.7 \mathrm{~mm}$ gap and b) Scenario 4: model simulated with $0.5 \mathrm{~mm}$ gap.

This study was aimed to optimize the air gap size between the mask and test specimen. One hundred ninety-two steady-state simulations were carried out using HEAT3, 
based on the four scenarios, four sample sizes $(200 \times 200 \mathrm{~mm}, 150 \times 150 \mathrm{~mm}, 100 \times 100$ $\mathrm{mm}$, and $50 \times 50 \mathrm{~mm}$ ), and two thicknesses of the six insulation materials.

\subsection{Results and Discussion}

Heat flows predicted using HEAT3 with the four scenarios were compared to heat flows measured using masked small specimens of the six insulation materials (Table 4.2$4.9)$.

\subsection{1 $200 \times 200 \mathrm{~mm}$ Specimens}

As per Equation 2.4 the heat flow $(\mathrm{Q})$ for specimen $12.5 \mathrm{~mm}$ thickness should be double of specimens with $25 \mathrm{~mm}$ thickness. However, in few cases, it was noticed that surface resistance of the material affected this correlation. LDGF had the highest variance of the six materials (Table 4.2 and Table 4.3). Variance between experimental and simulated measurements was less than $1 \%$ for EPS, XPS, PUR, ISO, and HDGF in all gap scenarios. Although variance increased with increasing the gap size, differences between scenarios were small, indicating that a gap up to $1 \mathrm{~mm}$ does not have a significant effect on heat flow measurements using masked $200 \times 200 \mathrm{~mm}$ samples. 
Table 4.2. Measured and simulated heat flow (q) for specimens with $200 \times 200 \mathrm{~mm}, 25$ mm thickness.

\begin{tabular}{|c|c|c|c|c|c|c|c|c|c|}
\hline \multirow{3}{*}{ 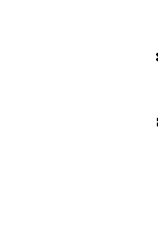 } & \multirow{3}{*}{ Measured } & \multicolumn{8}{|c|}{ Simulated - HEAT3 } \\
\hline & & \multicolumn{2}{|c|}{ No Gap } & \multicolumn{2}{|c|}{$0.5 \mathrm{~mm}$ Gap } & \multicolumn{2}{|c|}{$0.7 \mathrm{~mm}$ Gap } & \multicolumn{2}{|c|}{$1 \mathrm{~mm}$ Gap } \\
\hline & & $\left(\mathrm{W} / \mathrm{m}^{2}\right)$ & $\begin{array}{c}\text { Variance } \\
(\%)\end{array}$ & $\left(\mathrm{W} / \mathrm{m}^{2}\right)$ & $\begin{array}{c}\text { Variance } \\
(\%)\end{array}$ & $\left(\mathrm{W} / \mathrm{m}^{2}\right)$ & $\begin{array}{c}\text { Variance } \\
(\%)\end{array}$ & $\left(\mathrm{W} / \mathrm{m}^{2}\right)$ & $\begin{array}{c}\text { Variance } \\
(\%)\end{array}$ \\
\hline EPS & 29.56 & 29.78 & 0.75 & 29.79 & 0.79 & 29.81 & 0.87 & 29.84 & 0.94 \\
\hline XPS & 25.13 & 25.06 & -0.20 & 25.07 & -0.23 & 25.07 & -0.25 & 24.89 & -0.96 \\
\hline PUR & 21.85 & 21.78 & -0.31 & 21.92 & 0.33 & 21.77 & -0.34 & 21.74 & -0.49 \\
\hline ISO & 21.80 & 21.84 & 0.17 & 21.77 & -0.15 & 21.76 & -0.20 & 21.72 & -0.38 \\
\hline HDGF & 29.08 & 29.15 & 0.24 & 29.17 & 0.30 & 29.20 & 0.40 & 28.96 & -0.42 \\
\hline LDGF & 33.92 & 34.02 & 0.29 & 34.21 & 0.85 & 34.40 & 1.41 & 34.67 & 2.20 \\
\hline
\end{tabular}

Table 4.3. Measured and simulated heat flow (q) for specimens with $200 \times 200 \mathrm{~mm}, 12.5$ mm thickness.

\begin{tabular}{cc|cccccccc}
\hline & Measured & \multicolumn{7}{c}{ Simulated - HEAT3 } \\
\cline { 2 - 10 } & Masked & \multicolumn{2}{|c}{ No Gap } & \multicolumn{2}{c}{$0.5 \mathrm{~mm}$ Gap } & \multicolumn{2}{c}{$0.7 \mathrm{~mm}$ Gap } & \multicolumn{2}{c}{$1 \mathrm{~mm}$ Gap } \\
\hline \hline & $\mathrm{q}\left(\mathrm{W} / \mathrm{m}^{2}\right)$ & $\begin{array}{c}\mathrm{q} \\
\left(\mathrm{W} / \mathrm{m}^{2}\right)\end{array}$ & $\begin{array}{c}\text { Variance } \\
(\%)\end{array}$ & $\begin{array}{c}\mathrm{q} \\
\left(\mathrm{W} / \mathrm{m}^{2}\right)\end{array}$ & $\begin{array}{c}\text { Variance } \\
(\%)\end{array}$ & $\begin{array}{c}\mathrm{q} \\
\left(\mathrm{W} / \mathrm{m}^{2}\right)\end{array}$ & $\begin{array}{c}\text { Variance } \\
(\%)\end{array}$ & $\begin{array}{c}\mathrm{q} \\
\left(\mathrm{W} / \mathrm{m}^{2}\right)\end{array}$ & $\begin{array}{c}\text { Variance } \\
(\%)\end{array}$ \\
\hline \hline EPS & 57.82 & 58.15 & 0.57 & 58.13 & 0.53 & 58.18 & 0.62 & 58.25 & 0.74 \\
XPS & 51.81 & 51.73 & -0.15 & 51.58 & -0.44 & 51.45 & -0.68 & 51.49 & -0.61 \\
PUR & 44.25 & 44.57 & 0.74 & 44.47 & 0.52 & 44.32 & 0.17 & 44.40 & 0.36 \\
ISO & 45.25 & 45.45 & 0.44 & 45.34 & 0.22 & 45.20 & -0.11 & 45.27 & 0.06 \\
HDGF & 59.00 & 59.10 & 0.18 & 58.91 & -0.16 & 58.82 & -0.32 & 58.81 & -0.33 \\
LDGF & 67.3 & 66.86 & -0.65 & 66.61 & -1.01 & 66.56 & -1.09 & 66.51 & -1.19 \\
\hline
\end{tabular}




\subsubsection{0 x $150 \mathrm{~mm}$ Specimens}

In comparisons of measured and simulated heat flow for masked $150 \times 150 \mathrm{~mm}$ specimens with $25 \mathrm{~mm}$ thickness, LDGF had the highest variances of the six materials, greater than $1 \%$ for all gap scenarios (Table 4.4). Results for XPS and PUR also showed variances greater than $1 \%$ in the scenario with a $1 \mathrm{~mm}$ gap, and HDGF had variances greater than $1 \%$ for simulations with $0.7 \mathrm{~mm}$ and $1 \mathrm{~mm}$ gaps. Variances for EPS and ISO were less than $1 \%$ for all gap scenarios.

Comparison of measured and simulated heat flows for $150 \times 150 \mathrm{~mm}$ specimens with $12.5 \mathrm{~mm}$ thickness resulted in variance less than $0.5 \%$ for all materials and gap scenarios (Table 4.5). Heat flow measurements predicted by the model were quite consistent among the four scenarios indicating a minimal effect of gap size.

Table 4.4. Measured and simulated heat flow (q) for specimens with $150 \times 150 \mathrm{~mm}, 25$ mm thickness.

\begin{tabular}{cc|cccccccc}
\hline & Measured & \multicolumn{7}{c}{ Simulated - HEAT3 } \\
\cline { 2 - 11 } & Masked & \multicolumn{2}{|c}{ No Gap } & \multicolumn{2}{c}{$0.5 \mathrm{~mm}$ Gap } & \multicolumn{2}{c}{$0.7 \mathrm{~mm}$ Gap } & \multicolumn{1}{c}{$\mathrm{mm}$ Gap } \\
\cline { 2 - 11 } & $\mathrm{q}\left(\mathrm{W} / \mathrm{m}^{2}\right)$ & $\begin{array}{c}\mathrm{q} \\
\left(\mathrm{W} / \mathrm{m}^{2}\right)\end{array}$ & $\begin{array}{c}\text { Variance } \\
(\%)\end{array}$ & $\begin{array}{c}\mathrm{q} \\
\left(\mathrm{W} / \mathrm{m}^{2}\right)\end{array}$ & $\begin{array}{c}\text { Variance } \\
(\%)\end{array}$ & $\begin{array}{c}\mathrm{q} \\
\left(\mathrm{W} / \mathrm{m}^{2}\right)\end{array}$ & $\begin{array}{c}\text { Variance } \\
(\%)\end{array}$ & $\begin{array}{c}\mathrm{q} \\
\left(\mathrm{W} / \mathrm{m}^{2}\right)\end{array}$ & $\begin{array}{c}\text { Variance } \\
(\%)\end{array}$ \\
\hline \hline EPS & 29.87 & 30.04 & 0.56 & 30.08 & 0.73 & 30.09 & 0.74 & 30.13 & 0.87 \\
XPS & 25.96 & 25.81 & -0.60 & 25.78 & -0.70 & 25.76 & -0.79 & 25.60 & -1.40 \\
PUR & 22.88 & 22.67 & -0.91 & 22.63 & -1.09 & 22.54 & -1.49 & 22.52 & -1.57 \\
ISO & 22.84 & 22.82 & -0.09 & 22.80 & -0.20 & 22.84 & -0.04 & 22.67 & -0.75 \\
HDGF & 29.08 & 28.87 & -0.72 & 28.84 & -0.83 & 28.72 & -1.24 & 28.67 & -1.41 \\
LDGF & 32.09 & 31.61 & -1.50 & 31.58 & -1.60 & 31.40 & -2.17 & 33.12 & 3.19 \\
\hline
\end{tabular}


Table 4.5. Measured and simulated heat flow (q) for specimens with $150 \times 150 \mathrm{~mm}, 12.5$ mm thickness.

\begin{tabular}{cc|cccccccc}
\hline & Measured & \multicolumn{7}{c}{ Simulated - HEAT3 } \\
\cline { 2 - 11 } & Masked & \multicolumn{2}{|c}{ No Gap } & \multicolumn{2}{c}{$0.5 \mathrm{~mm}$ Gap } & \multicolumn{2}{c}{$0.7 \mathrm{~mm}$ Gap } & \multicolumn{1}{c}{ mm Gap } \\
\cline { 2 - 11 } & $\mathrm{q}\left(\mathrm{W} / \mathrm{m}^{2}\right)$ & $\begin{array}{c}\mathrm{q} \\
\left(\mathrm{W} / \mathrm{m}^{2}\right)\end{array}$ & $\begin{array}{c}\text { Variance } \\
(\%)\end{array}$ & $\begin{array}{c}\mathrm{q} \\
\left(\mathrm{W} / \mathrm{m}^{2}\right)\end{array}$ & $\begin{array}{c}\text { Variance } \\
(\%)\end{array}$ & $\begin{array}{c}\mathrm{q} \\
\left(\mathrm{W} / \mathrm{m}^{2}\right)\end{array}$ & $\begin{array}{c}\text { Variance } \\
(\%)\end{array}$ & $\begin{array}{c}\mathrm{q} \\
\left(\mathrm{W} / \mathrm{m}^{2}\right)\end{array}$ & $\begin{array}{c}\text { Variance } \\
(\%)\end{array}$ \\
\hline \hline EPS & 57.93 & 58.02 & 0.15 & 58.03 & 0.18 & 58.06 & 0.22 & 58.11 & 0.27 \\
XPS & 45.79 & 45.75 & -0.07 & 45.91 & 0.25 & 45.78 & -0.01 & 45.73 & -0.12 \\
PUR & 50.81 & 50.95 & 0.28 & 50.95 & 0.29 & 50.86 & 0.12 & 50.79 & -0.03 \\
ISO & 48.06 & 48.09 & 0.08 & 48.12 & 0.14 & 48.01 & -0.09 & 47.94 & -0.25 \\
HDGF & 59.22 & 59.19 & -0.05 & 59.11 & -0.19 & 59.07 & -0.24 & 59.01 & -0.35 \\
LDGF & 64.08 & 64.18 & 0.16 & 64.07 & 0.01 & 64.08 & 0.01 & 64.01 & -0.10 \\
\hline
\end{tabular}

\subsection{3 $100 \times 100 \mathrm{~mm}$ Specimens}

Comparison of measured and simulated heat flow for $100 \times 100 \mathrm{~mm}$ specimens with $25 \mathrm{~mm}$ thickness showed variances less than $1 \%$ for EPS, XPS, PUR, ISO and LDGF for all scenarios calculated and a variance of $-2.43 \%$ for HDGF for scenario with $1 \mathrm{~mm}$ gap.(Table 4.6). It also observed that greater gap size resulted in greater variance.

Results for specimens with $12.5 \mathrm{~mm}$ thickness had variances below $1 \%$ for EPS, XPS, ISO, HDGF and LDGF in all four scenarios (Table 4.7). PUR had variances greater than $1 \%$ for all simulations with a gap. 
Table 4.6. Measured and simulated heat flow (q) for specimens with $100 \times 100 \mathrm{~mm}, 25$ mm thickness.

\begin{tabular}{cc|cccccccc}
\hline & Measured & \multicolumn{7}{c}{ Simulated - HEAT3 } \\
\cline { 2 - 11 } & Masked & \multicolumn{2}{|c}{ No Gap } & \multicolumn{2}{c}{$0.5 \mathrm{~mm}$ Gap } & \multicolumn{2}{c}{$0.7 \mathrm{~mm}$ Gap } & \multicolumn{1}{c}{ mm Gap } \\
\cline { 2 - 11 } & $\mathrm{q}\left(\mathrm{W} / \mathrm{m}^{2}\right)$ & $\begin{array}{c}\mathrm{q} \\
\left(\mathrm{W} / \mathrm{m}^{2}\right)\end{array}$ & $\begin{array}{c}\text { Variance } \\
(\%)\end{array}$ & $\begin{array}{c}\mathrm{q} \\
\left(\mathrm{W} / \mathrm{m}^{2}\right)\end{array}$ & $\begin{array}{c}\text { Variance } \\
(\%)\end{array}$ & $\begin{array}{c}\mathrm{q} \\
\left(\mathrm{W} / \mathrm{m}^{2}\right)\end{array}$ & $\begin{array}{c}\text { Variance } \\
(\%)\end{array}$ & $\begin{array}{c}\mathrm{q} \\
\left(\mathrm{W} / \mathrm{m}^{2}\right)\end{array}$ & $\begin{array}{c}\text { Variance } \\
(\%)\end{array}$ \\
\hline \hline EPS & 31.41 & 31.46 & 0.20 & 31.55 & 0.40 & 31.64 & 0.70 & 31.69 & 0.90 \\
XPS & 27.6 & 27.61 & 0.05 & 27.59 & -0.02 & 27.57 & -0.08 & 27.46 & -0.48 \\
PUR & 25.89 & 25.91 & 0.08 & 25.67 & -0.85 & 25.65 & -0.93 & 25.64 & -0.97 \\
ISO & 25.90 & 25.89 & -0.04 & 25.89 & -0.04 & 25.84 & -0.23 & 25.81 & -0.35 \\
HDGF & 29.34 & 29.30 & -0.16 & 29.27 & -0.25 & 29.26 & -0.29 & 28.63 & -2.43 \\
LDGF & 31.02 & 30.98 & -0.14 & 31.13 & 0.35 & 31.16 & 0.43 & 31.18 & 0.49 \\
\hline
\end{tabular}

Table 4.7. Measured and simulated heat flow (q) for specimens with $100 \times 100 \mathrm{~mm}, 12.5$ mm thickness.

\begin{tabular}{cc|ccccccccc}
\hline & Measured & \multicolumn{7}{c}{ Simulated - HEAT3 } \\
\cline { 2 - 10 } & Masked & \multicolumn{2}{|c}{ No Gap } & \multicolumn{2}{c}{$0.5 \mathrm{~mm}$ Gap } & \multicolumn{2}{c}{$0.7 \mathrm{~mm}$ Gap } & \multicolumn{1}{c}{ mm Gap } \\
\cline { 2 - 10 } & $\mathrm{q}\left(\mathrm{W} / \mathrm{m}^{2}\right)$ & $\begin{array}{c}\mathrm{q} \\
\left(\mathrm{W} / \mathrm{m}^{2}\right)\end{array}$ & $\begin{array}{c}\text { Variance } \\
(\%)\end{array}$ & $\begin{array}{c}\mathrm{q} \\
\left(\mathrm{W} / \mathrm{m}^{2}\right)\end{array}$ & $\begin{array}{c}\text { Variance } \\
(\%)\end{array}$ & $\begin{array}{c}\mathrm{q} \\
\left(\mathrm{W} / \mathrm{m}^{2}\right)\end{array}$ & $\begin{array}{c}\text { Variance } \\
(\%)\end{array}$ & $\begin{array}{c}\mathrm{q} \\
\left(\mathrm{W} / \mathrm{m}^{2}\right)\end{array}$ & $\begin{array}{c}\text { Variance } \\
(\%)\end{array}$ \\
\hline \hline EPS & 58.84 & 58.95 & 0.18 & 58.95 & 0.19 & 58.97 & 0.23 & 58.99 & 0.25 \\
XPS & 54.45 & 54.72 & 0.51 & 54.59 & 0.26 & 54.61 & 0.30 & 54.62 & 0.33 \\
PUR & 51.96 & 52.06 & 0.20 & 51.31 & -1.24 & 51.33 & -1.21 & 51.37 & -1.13 \\
ISO & 51.88 & 51.98 & 0.19 & 51.84 & -0.07 & 51.86 & -0.04 & 51.89 & 0.03 \\
HDGF & 59.84 & 59.83 & 0.01 & 59.69 & -0.24 & 59.73 & -0.18 & 59.71 & -0.22 \\
LDGF & 60.86 & 60.53 & -0.54 & 61.06 & 0.34 & 61.09 & 0.39 & 61.06 & 0.34 \\
\hline
\end{tabular}

\subsubsection{0 x $50 \mathrm{~mm}$ specimens}

Comparison of measured and simulated heat flow for masked $50 \times 50 \mathrm{~mm}$ specimens with $25 \mathrm{~mm}$ thickness showed the highest variance for HDGF $(-2.44 \%)$ with a $1 \mathrm{~mm}$ gap 
(Table 4.8). XPS with a $1 \mathrm{~mm}$ gap also had a variance greater than $1 \%$, while EPS, PUR, ISO, and LDGF had variances less than $1 \%$ for all gap scenarios.

Comparison for specimens with $12.5 \mathrm{~mm}$ thickness, variances were less than $1 \%$ for all gap scenarios (Table 4.9).

Table 4.8. Measured and simulated heat flow (q) for specimens with 50 x $50 \mathrm{~mm}, 25 \mathrm{~mm}$ thickness.

\begin{tabular}{cc|cccccccc}
\hline & Measured & \multicolumn{7}{|c}{ Simulated - HEAT3 } \\
\cline { 2 - 10 } & Masked & \multicolumn{2}{|c}{ No Gap } & \multicolumn{2}{c}{$0.5 \mathrm{~mm}$ Gap } & \multicolumn{2}{c}{$\mathbf{0 . 7} \mathrm{mm}$ Gap } & \multicolumn{1}{l}{$\mathrm{mm}$ Gap } \\
\cline { 2 - 10 } & $\mathrm{q}\left(\mathrm{W} / \mathrm{m}^{2}\right)$ & $\begin{array}{c}\mathrm{q} \\
\left(\mathrm{W} / \mathrm{m}^{2}\right)\end{array}$ & $\begin{array}{c}\text { Variance } \\
(\%)\end{array}$ & $\begin{array}{c}\mathrm{q} \\
\left(\mathrm{W} / \mathrm{m}^{2}\right)\end{array}$ & $\begin{array}{c}\text { Variance } \\
(\%)\end{array}$ & $\begin{array}{c}\mathrm{q} \\
\left(\mathrm{W} / \mathrm{m}^{2}\right)\end{array}$ & $\begin{array}{c}\text { Variance } \\
(\%)\end{array}$ & $\begin{array}{c}\mathrm{q} \\
\left(\mathrm{W} / \mathrm{m}^{2}\right)\end{array}$ & $\begin{array}{c}\text { Variance } \\
(\%)\end{array}$ \\
\hline \hline EPS & 33.23 & 33.45 & 0.66 & 33.48 & 0.75 & 33.52 & 0.87 & 33.54 & 0.93 \\
XPS & 29.26 & 29.44 & 0.62 & 29.36 & 0.33 & 29.42 & 0.52 & 28.91 & -1.21 \\
PUR & 29.26 & 29.35 & 0.31 & 29.09 & -0.58 & 29.10 & -0.55 & 29.07 & -0.65 \\
ISO & 28.82 & 28.81 & -0.03 & 28.78 & -0.14 & 29.02 & 0.69 & 28.77 & -0.17 \\
HDGF & 29.75 & 29.57 & -0.62 & 29.54 & -0.72 & 29.48 & -0.91 & 29.03 & -2.44 \\
LDGF & 30.13 & 30.06 & -0.23 & 30.03 & -0.32 & 29.97 & -0.52 & 30.31 & 0.61 \\
\hline
\end{tabular}

Table 4.9. Measured and simulated heat flow (q) for specimens with 50 x $50 \mathrm{~mm}, 12.5$ mm thickness.

\begin{tabular}{cc|cccccccc}
\hline & Measured & \multicolumn{7}{c}{ Simulated - HEAT3 } \\
\cline { 2 - 11 } & Masked & \multicolumn{2}{|c}{ No Gap } & \multicolumn{2}{c}{$0.5 \mathrm{~mm}$ Gap } & \multicolumn{2}{c}{$0.7 \mathrm{~mm}$ Gap } & \multicolumn{1}{l}{ mm Gap } \\
\cline { 2 - 11 } & $\mathrm{q}\left(\mathrm{W} / \mathrm{m}^{2}\right)$ & $\begin{array}{c}\mathrm{q} \\
\left(\mathrm{W} / \mathrm{m}^{2}\right)\end{array}$ & $\begin{array}{c}\text { Variance } \\
(\%)\end{array}$ & $\begin{array}{c}\mathrm{q} \\
\left(\mathrm{W} / \mathrm{m}^{2}\right)\end{array}$ & $\begin{array}{c}\text { Variance } \\
(\%)\end{array}$ & $\begin{array}{c}\mathrm{q} \\
\left(\mathrm{W} / \mathrm{m}^{2}\right)\end{array}$ & $\begin{array}{c}\text { Variance } \\
(\%)\end{array}$ & $\begin{array}{c}\mathrm{q} \\
\left(\mathrm{W} / \mathrm{m}^{2}\right)\end{array}$ & $\begin{array}{c}\text { Variance } \\
(\%)\end{array}$ \\
\hline \hline EPS & 57.95 & 58.07 & 0.22 & 58.08 & 0.23 & 58.11 & 0.27 & 58.14 & 0.32 \\
XPS & 56.87 & 56.83 & -0.06 & 56.7 & -0.30 & 56.82 & -0.08 & 56.78 & -0.14 \\
PUR & 55.59 & 55.36 & -0.41 & 55.22 & -0.66 & 55.35 & -0.43 & 55.32 & -0.48 \\
ISO & 56.7 & 56.68 & -0.03 & 56.54 & -0.27 & 56.67 & -0.04 & 56.64 & -0.11 \\
HDGF & 57.63 & 57.81 & 0.32 & 57.68 & 0.09 & 57.8 & 0.30 & 57.76 & 0.24 \\
LDGF & 60.87 & 61.02 & 0.25 & 60.88 & 0.03 & 61.01 & 0.24 & 60.95 & 0.14 \\
\hline
\end{tabular}




\subsubsection{Summary}

Results of heat flow simulations using the four gap scenarios were similar to each other and to the experimental results. The results were also fairly consistent for the two thicknesses. A gap up to $1 \mathrm{~mm}$ did not significantly affect simulated heat flows, indicating that small gaps between sample and masking materials should not affect thermal conductivity measurements using smaller specimens of insulation when considering only heat conduction.

It has been observed that simulated results of the heat flow for the EPS specimens also had variations, between $0.15 \%$ to $0.75 \%$ (less than $1 \%$ ), when compared to EPS masked from the experimental results; these variations are well within experimental tolerance of the ASTM C518 test results.

Close agreement between experimental data and model predictions indicate that the masked smaller specimens provide accurate measures of heat flow through all of the insulation materials tested. 


\section{Chapter 5: Conclusions and Recommendations}

\subsection{Conclusions}

The primary goal of the research described in this thesis was to establish a new methodology for measuring thermal conductivity of small insulation specimens $(200 \times 200$ $\mathrm{mm} ; 150 \times 150 \mathrm{~mm} ; 100 \times 100 \mathrm{~mm} ; 50 \times 50 \mathrm{~mm}$ ), using a heat flow meter apparatus (300 $\times 300 \mathrm{~mm}$ ) with metering area of $150 \times 150 \mathrm{~mm}$ and smaller specimens. The new method used smaller specimens inserted in a mask made of insulation with known thermal conductivity. The new method was tested on six insulation materials of two thicknesses (12.5 $\mathrm{mm}$ and $25 \mathrm{~mm}$ ). The empirical data were used to generate equations relating thermal conductivity (k) measured according to the standard method (ASTM C518) with standard size samples $(300 \mathrm{~mm} \times 300 \mathrm{~mm})$ to thermal conductivity $\left(\mathrm{k}_{0}\right)$ measured with the smaller masked samples.

Based on the research reported in this thesis, the following conclusions can be drawn on the assessment of thermal conductivity using smaller specimens:

1. The new method can be used to accurately measure thermal conductivity for a variety of insulation materials with different thicknesses, using samples down to $100 \mathrm{~mm} \times 100 \mathrm{~mm}$. 
2. It has been observed that samples with $50 \mathrm{~mm} \times 50 \mathrm{~mm}$ are too small for accurate assessment of thermal conductivity using a heat flow meter $(300 \times 300$ $\mathrm{mm}$ ) with a metering area $150 \times 150 \mathrm{~mm}$ and did not provide reliable thermal conductivity values.

3. From the simulation results with no gap and with gap $(1 \mathrm{~mm}, 0.7 \mathrm{~mm}$ and $0.5 \mathrm{~mm}$ ), it can be noticed that a gap between the mask and the smaller specimen does not significantly influence the variance between the experimental tests and the modelling simulation.

4. Experimental data and model predictions indicate that the masked smaller specimens provide accurate measures of heat flow through all of the insulation materials tested.

The suggested methodology allows measurement of thermal conductivity for insulation materials when large samples are not available, e.g., smaller specimens of new materials are being produced experimentally in a laboratory. Furthermore, the same test can be carried out to assess the thermal conductivity of smaller insulation specimens, collected from existing building envelopes, to study the long-term insulation performance.

Application of this method will accelerate the assessment of thermal conductivity of the new insulation materials and will expedite the introduction of the next generation of insulation material. 


\subsection{Recommendations for Future Work}

Following verification of the new methodology using smaller specimens of insulation should be carried out.

- Different mask material for smaller specimens should be applied to study the effect of the mask on the thermal conductivity for smaller specimens.

- The proposed new methodology must go through further verification/ investigation in different laboratories and critical peer review before adopting it as a standard test method in the future 


\section{References}

1. Stazi, F., Di Perna, C., and Munafo, P., 2009, Durability of 20-year-old insulation and assessment of various types of retrofitting to meet new energy regulations, Energy Building 41, pp. $721-731$.

2. Bolaturk, A., 2006, Determination of Optimum Insulation Thickness for Building Walls With Respect to Various Fuels and Climate Zones in Turkey, Appl. Therm. Eng., 26, pp. 1301-1309.

3. Mohammad, S. A., 2005, Performance Characteristics and Practical Application of Common Building Thermal Insulation Materials, Building and Environment 40, pp. 353-366.

4. Cengel, Heat Transfer, 2nd edition, McGraw-Hill, New York City, NY, 2003.

5. Jijji, L. M., 2009, Heat Conduction, Springer, pp. 1-23.

6. Kern, D., 1950, Process Heat Transfer, McGraw-Hill, New York City, pp. 2-104.

7. Kreith, F., Manglik, R. M., and Bohn, M., 2011. Principles of heat transfer. Stamford, Cengage Learning, pp. 10-25.

8. Houston, R. L. and Korpela, S. A., Heat Transfer through Fiberglass Insulations, in Procedding of the 7 International Heat Transfer Conference - Munich, Washington: Hemisphere Publ. Co., Vol.2, pp. 322-334.

9. Insulation Malta, http://www.insulationsmalta.com/Why_to_insulate.htm, accessed: September 2012.

10. Hasan, A., 1999, Optimizing Insulation Thickness for Buildings Using Life Cycle Cost, Applied Energy 63, pp. 115-124.

11. Frawley, E., Thermal testing of innovative building insulations, 2009, MASc. Thesis Dublin Institute of Technology.

12. Powell, Frank J., Matthews, Stanley L. III. Committee C-16 on Thermal Insulation, Dallas, TX, 2-6 Dec. 1984.

13. Kumaran, M. K., Lackey, J. C., Normandin, N., Tariku, F., Van Reenen, D., 2004, A Thermal and Moisture Transport Property Database for Common Insulating Materials 
Used in Canada, Institute for Research in Construction, National Research Council Canda, Ottawa, Canada.

14. Tye, R., 1969, Thermal Conductivity, Vol. 1, Academic Press, New York.

15. De Ponte, F., and Klarsfeld, S., 1990, What Property Do We Measure - Considerations on a Decade of ISO/TC 163, Journal of Thermal Insulation, Vol. 13, pp. 160190.

16. Pratt, A. W., 1968, Heat Transmission in Low Conductivity Materials, in Thermal Conductivity, R. P. Tye, ed., Academic Press, New York, pp. 301-300.

17. Shirtliffe, C. J., 2005, Thermal Resistance of Building Insulation, Canadian Building Digests, NRC-IRC publications.

18. Strother E. and Turner W., 1990, "Thermal Insulation Building guide," pp 8-12.

19. Shirtliffe, C. J., 1980, Effect of Thickness on the Thermal Properties of Thick Specimens of Low-Density Thermal Insulation, ASTM STP 718, Philadelphia: ASTM, pp. 36-50.

20. Mukhopadhyaya, P., Kumaran, M. K., 2008, Long-Term Thermal of Closed-cell Foam Insulation: Research Update from Canada, 3rd Global Insulation Conference and Exhibition, Barcelona, Spain, pp.1-12.

21. Guyer, E. C., and Brownwell D. L., 1999, Handbook of Applied Thermal Design, Taylor \& Francis, Philadelphia, Part 3, Chapter 1, pp. 2 and 3.

22. Abdou, A. A., Budaiwi, I. M., 2005, Comparison of Thermal Conductivity Meaurements of Building Insulation Materials under Various Operating Temperatures, Journal of Building Physics, Vol. 29, No. 2, Sage Publications, pp. 171-184

23. Zarr, R.R., A History of Testing Heat Insulators at the National Institute of Standards and Technology. ASHRAE Transactions, 2001. 107 Pt. 2(2): p. 111.

24. Zarr, R.R., Kumaran, M.K., and Lagergren, E.S., 2002, NIST/NRC-Canada Interlaboratory comparison of Guarded Hot Plate Measurements, U.S Government printing office, Washington, DC.

25. Powell, F. J., and Matthews, S. L., Thermal insulation: materials and systems / a conference sponsored by ASTM Committee C-16 on Thermal Insulation, Dallas, TX, 26 Dec. 1984.

26. Roder, H. M, Perkins R. A, and De Castro, C. A. N, and Laesecke, A., 2000, Absolute Steady-State Thermal Conductivity Measurements by Use of a Transient HotWire System. Journal of Research of the National Institute of Standards and Technology, , Vol. 105, No. 2, p. 221.

27. ASTM Cl77, 2004, Standard Method for Steady-State Heat Flux Measurements and Thermal Transmission Properties by Means of the Guarded Hot Plate Apparatus. 
28. ISO 8302:1991, 1991, Thermal Insulation-Determination of Steady-State Thermal Resistance and Related Properties- Guarded Hot Plate Apparatus.

29. DINEN 12939, 1996, European Standard for Measurements of Insulating Materials Using the Guarded Hot Plate Technique.

30. JIS A 1412-1, 1999, Test Method for Thermal Resistance and Related Properties of Thermal Insulations, Part 1: Guarded Hot Plate Apparatus, Japanese Standards Association, Tokyo.

31. Zarr, R. R., and Filliben J. J., 2002, International Comparison of Guarded Hot Plate Apparatus Using National and Regional Reference Materials, NIST TN 1444.

32. ASTM C 518, 2004, Standard Test Method for Steady-State Thermal Transmission Properties by Means of the Heat Flow Meter Apparatus.

33. ISO 8301:1991, 1991, Thermal Insulation-Determination of Steady-State Thermal Resistance and Related Properties-Heat Flow Meter Apparatus.

34. DINEN 12667, 2001, European Standard for Measurements of Insulating Materials Using the Heat Flow Meter Method.

35. Bomberg, M., and Solvason, R., 1985, Discussion of Heat Flow Meter Apparatus and Transfer Standards Used for Error Analysis, in Guarded Hot Plate and Heat Flow Meter Methodology, STM STP 879,

36. C. J. Shirtliffe and R. P. Tye, eds., American Society for Testing and Materials, Philadelphia, pp. 140-153.

37. Hahn, M. H., Robinson, H. E., and Flynn, D. R., 1974, Robinson Line-Heat-Source Guarded Hot Plate Apparatus, Heat Transmission Measurements in Thermal Insulations, ASTM SIP 544, R. P. Tye, ed., American Society for Testing and Materials, pp. 167-192.

38. Marcus, M, and Reading, M., Method and Apparatus for Thermal Conductivity Measurements, US Patent 5,334,994, August 8, 1994.

39. Flynn, D. R., and Gorthala, R., 1997, Thermal Design of A Miniature Guarded Hot Plate Apparatus, in Insulation Materials: Testing and Applications, ASTM STP 1320, R.R.Z. R.S. Graves, ed., American Society for Testing and Materials, West Conshohocken, PA.

40. Flynn, D. R., and Gorthala, R., 1996, Design of a Subminiature Guarded Hot Plate Apparatus, in Thermal Conductivity, R.B.D. Kenneth Earl Wilkes, Ronald S. Graves, Editor.

41. Miller, R., and Kuczmarski, M., 2009, Method for Measuring Thermal Conductivity of Small samples Having Very Low Thermal Conductivity, NASA Center for AeroSpace Information (CASI) 7115 Standard Drive Hanover, MD 21076-1320. 
42. Miller, R., and Kuczmarski, M., Method and Apparatus for Measuring Thermal Conductivity of Small, Highly Insulating Specimens, US Patent 8,220,989 B1, July 17, 2012.

43. Fujino, J., and Honda, T., 2007, Study on Guarded Hot Plate Apparatus for Measurement of Thermal Conductivity of Small Polymer Specimens, Thermal Engineering Heat Transfer Summer Conference collocated with the ASME 2007 InterPACK, Volume 3, July 8-12,Vancouver, British Columbia, Canada.

44. Mukhopadhyaya, P., Ngo, T., Ton-That, M., Masson, J. F., and Sherrer, G., 2011, Hygrothermal Properties of Biobased Polyurethane Foam Insulation for Building Envelope Construction, 9th Nordic Symposium on Building Physics, Finland, pp. 1-8.

45. Masson, J.F., Bundalo-Perc, S. Mukhopadhyaya, P., 2012, On the accuracy of ASTM E 1952 for the thermal conductivity of foams used as building insulation, National Research Canada, Ottawa.

46. ASTM E1952, 2011, Standard Test Method for Thermal Conductivity and Thermal Diffusivity by Modulated Temperature Differential Scanning Calorimetry.

47. Martinez. I. H., Heat Conduction Modelling, http://webserver.dmt.upm.es/ isidoro/, accessed: January, 2012.

48. Irons, B. M., and Ahmad, S., 1980, Techniques of Finite Elements, John Wiley, New York.

49. Asad, A. S., and Rama, S., 2004, Finite Element Heat Transfer and Structural Analysis, Proceedings of the WSEAS/LASME Int. Conference on Heat and Mass Transfer, Corfu, Greece, pp. 112-120.

50. Lewis, R. W., Morgan, K., Thomas, H. R., and Seetharamu, K. N., 1996, The Finite Element Analysis for Heat Transfer Analysis, John Wiley New York, pp. 1-80.

51. Wang, B. L., and Tian, Z. H., 2005, Application of Finite Element - Finite Difference Method to the Determination of Transient Temperature Field in Functionally Graded Materials, Finite Element Analyses. Design, 41, pp. 335-349.

52. Blomberg, T., 1996, Heat conduction in two and three dimensions. Computer modelling of Building Physics Applications, Department of Building Physics, Lund University, Sweden. ISBN 91-88722-05-8.

53. Paris, F., and Cañas, J., 1997, Boundary Element Method: Fundamentals and Applications, Oxford University Press, Oxford.

54. Keithley, 1991, Model 706 Scanner Instruction Manual, http://www.artisantg.com/info/Keithley_706_Manual.pdf access: September, 2012.

55. Agilient Technologies, http://www.home.agilent.com, access: September 2012. 
56. Blomberg, T., 1994a, HEAT3 - A three-dimensional heat transfer computer program. Manual for HEAT3, Department of Building Physics, Lund University, Lund, Sweden. CODEN:LUTVDG/(TVBH-7169) 


\section{Appendix A. Thermal Conductivity of Small Specimen with 25 and $12.5 \mathrm{~mm}$ thickness.}

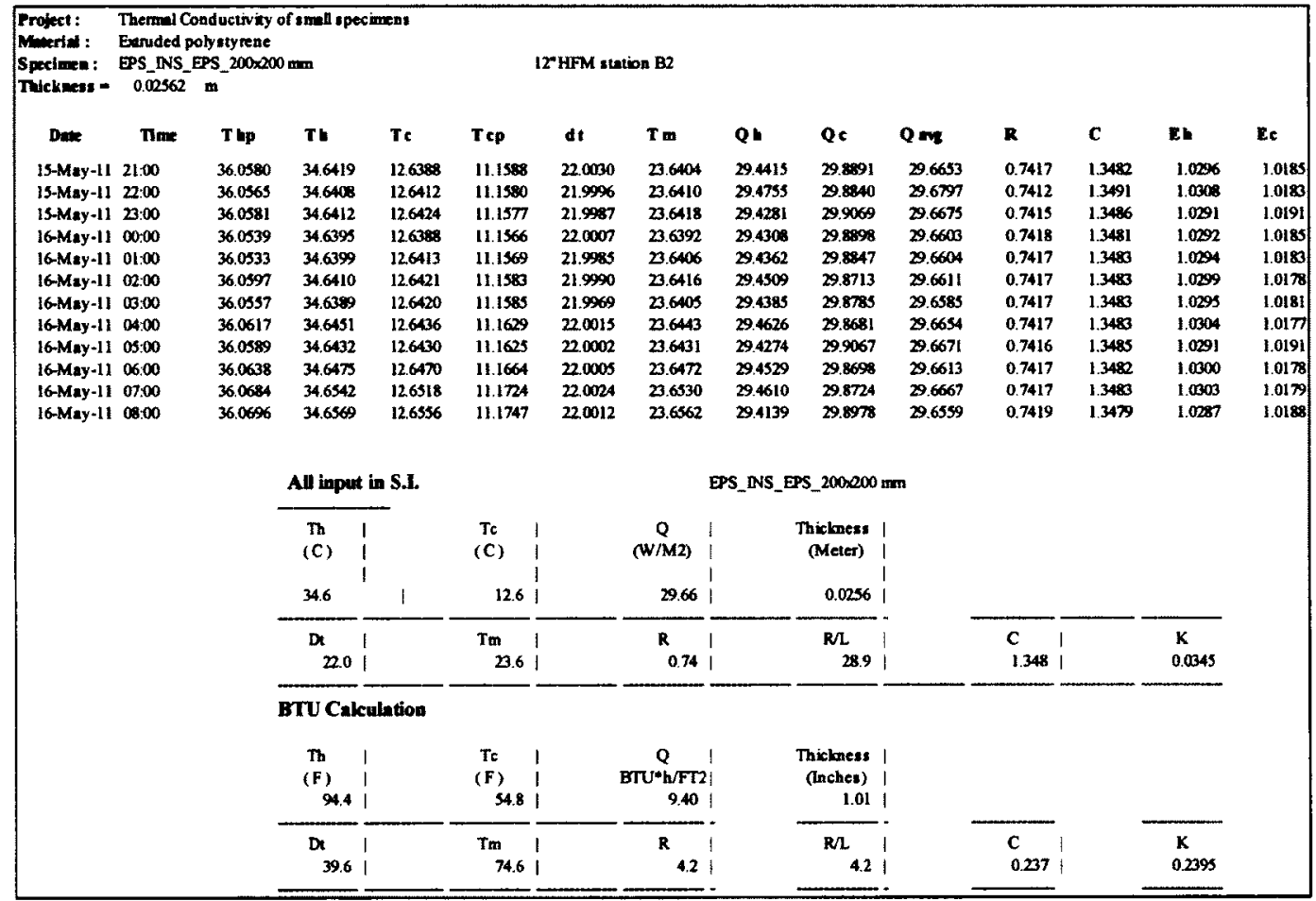




\begin{tabular}{|c|c|c|c|c|c|c|c|c|c|c|c|c|c|c|}
\hline $\begin{array}{l}\text { Projoct: } \\
\text { Mawital : } \\
\text { Spocimon : } \\
\text { Thicknom : }\end{array}$ & $\begin{array}{l}\text { emol Cond } \\
\text { truded polys } \\
\text { 'S_WNS_EPS } \\
0.02580\end{array}$ & $\begin{array}{l}\text { ctivity of o } \\
\text { tyreac } \\
150 \times 150 \mathrm{mon} \\
\end{array}$ & all specime & & & 12 hF $\mathrm{M}$ st & tation 82 & & & & & & & \\
\hline Dav & Time & Thp & Th & Te & T cp & $d t$ & $T m$ & $a_{h}$ & ac & a avo & $\mathbf{R}$ & c & En & E c \\
\hline $16-M a y-11$ & $21: 00$ & 36.0697 & 34.6433 & 12.6588 & 11.1681 & 21.9004 & 23.6501 & 20.5852 & 29.9253 & 29.7752 & 0.7384 & 1.3542 & 1.0338 & 1.0217 \\
\hline $18-M a y-11$ & $22: 00$ & 36.0641 & 34.841 & 12.6553 & 11.1699 & 21,9688 & 23.6407 & 29.5387 & 29.0001 & 29.784 & 0.7368 & 1.3536 & 1.0330 & 1.0219 \\
\hline 16-1may-11 & $23: 00$ & 36.0710 & 34.6475 & 12.6551 & 11.1670 & 21.9924 & 23.6513 & 29.5653 & 30.0234 & 29.7944 & 0.7362 & 1.3647 & 1.0339 & 1.0230 \\
\hline $17+$ May-11 & $\infty 0: \infty$ & 36.0688 & 34.8476 & 12.6594 & $\$ 1.1703$ & 21.9881 & 23.6535 & 29.5225 & 28.2863 & 29.7504 & 0.7380 & 1.3634 & 1.0324 & 1.0221 \\
\hline $17-M \times y-11$ & $01: 00$ & 36.0669 & 34.6445 & 12.6562 & 11.1672 & 21.9683 & 23.6504 & 29.5363 & 30.0025 & 20.7004 & 0.7386 & 1.3630 & 1.0329 & 1.0223 \\
\hline $17-$ May-11 & $02: 00$ & 36.0097 & 34.6478 & 126553 & $\$ 1.1884$ & 21.9925 & 23.6515 & 29.5507 & 30,0027 & 20.7787 & 0.7360 & 1.3639 & 1.0334 & 1.0223 \\
\hline $17+M=y-11$ & $03: 00$ & 36.0637 & 346432 & 12.6544 & 11.1885 & 21.9888 & 23.6688 & 29.5203 & 29.8069 & 29.7536 & 0.7380 & 1.3531 & 1.0324 & 1.0218 \\
\hline $17-M=y-11$ & $04: \infty$ & 36.0687 & 34.6460 & 12.6540 & 11.1661 & 21.9929 & 23.6505 & 29.52265 & 30.0063 & 20.7684 & 0.7388 & 1.3635 & 1.0326 & 1.0225 \\
\hline $17+$ May-11 & $05: 00$ & 36.0679 & 34.6446 & 12.6527 & 11.1833 & 21.9918 & 23.6483 & 29.5884 & 30.0248 & 29.6058 & 0.7378 & 1.3663 & 1.0347 & 1.0231 \\
\hline 17 May-11 & $08: 00$ & 36.0649 & 34.6413 & 12.6574 & 11.1670 & 21.9640 & 23.6493 & 20.5375 & 20.9819 & 20.7507 & 0.7387 & 1.3537 & 1.0330 & 1.0216 \\
\hline 17-May-11 & $07: 00$ & 36.0760 & 34.6503 & 12.6646 & 11.1780 & 21.8857 & 23.6575 & 29.5712 & 28.0067 & 29.7840 & 0.7382 & 1.3547 & 1.0341 & 1.0221 \\
\hline $17+M=y-11$ & $\infty 8: \infty$ & 36.0754 & 34.6538 & 12.6644 & 11.1782 & 21.9694 & 23.6501 & 20.5411 & 30.0063 & 29.7737 & 0.7386 & 1.3540 & 1.0331 & 1.0225 \\
\hline & & & All inpu & in S.I. & & & & EPS_NS_E & EPS_150×15 & $50 \mathrm{~mm}$ & & & & \\
\hline & & & $\begin{array}{c}m \\
(c)\end{array}$ & & $\begin{array}{c}\text { TC } \\
(C)\end{array}$ & i & $\begin{array}{c}Q \\
\text { WMZ) }\end{array}$ & & $\begin{array}{c}\text { Thickness I } \\
\text { (Meter) }\end{array}$ & & & & & \\
\hline & & & 34.6 & 1 & 12.7 & t & 29.77 & & 0.0258 & & & & & \\
\hline & & & 20 & & ${ }_{23.7}$ & I & \begin{tabular}{c|c}
$R$ & \\
0.74 &
\end{tabular} & & \begin{tabular}{c|}
$R / 28.8$ \\
\end{tabular} & & \begin{tabular}{l|}
$c$ \\
1.354
\end{tabular} & & $\begin{array}{c}K \\
0.03467\end{array}$ & \\
\hline & & & BTU Cal & ulation & & & & & & & & & & \\
\hline & & & $\begin{array}{l}\text { Th } \\
\text { (F) }\end{array}$ & & $\begin{array}{l}T C \\
(F) \\
54.8\end{array}$ & $\begin{array}{l}1 \\
\vdots \\
1\end{array}$ & $\begin{array}{c}Q \\
\text { BTurh/FT2 } \\
0.44\end{array}$ & & $\begin{array}{r}\text { Thickness } \\
\text { (mches) } \\
1.09\end{array}$ & & & & & \\
\hline & & & ${ }_{39.6}$ & & $\operatorname{Tm}_{74.6}$ & 1 & \begin{tabular}{l|l}
$R_{4}$ &
\end{tabular} & & \begin{tabular}{l|l} 
Rl & \\
4.2 &
\end{tabular} & & \begin{tabular}{l|}
$c$ \\
0.230
\end{tabular} & & $\begin{array}{c}K \\
0.2404\end{array}$ & \\
\hline
\end{tabular}

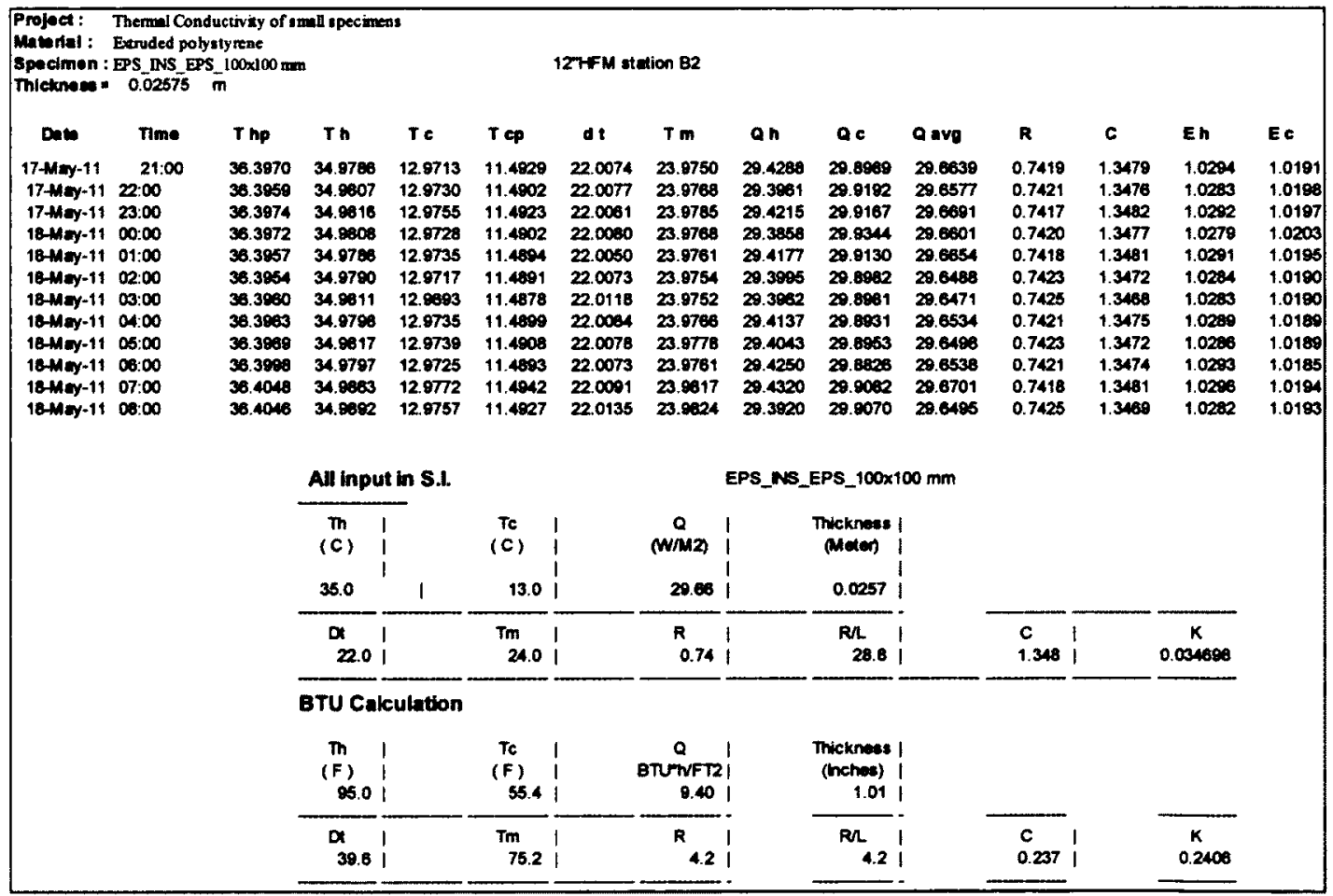




\begin{tabular}{|c|c|c|c|c|c|c|c|c|c|c|c|c|c|c|}
\hline \multicolumn{15}{|c|}{ 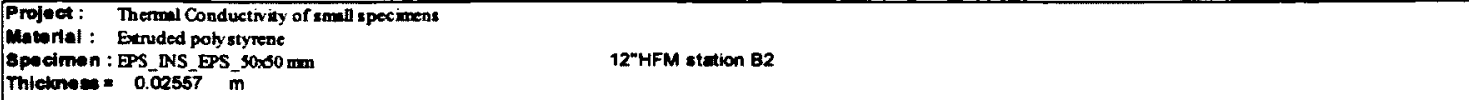 } \\
\hline Date & Time & Thp & rn & Te & 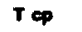 & dt & $\mathrm{Tm}$ & $a_{n}$ & Qc & a ave & $\mathbf{R}$ & c & En & Ee \\
\hline 18-May-11 & $21: 00$ & 36.4100 & 34.9706 & 13.0095 & 11.5038 & 21.8812 & 23.9901 & 29.8560 & $\mathbf{3 0 . 3 3 7 8}$ & 30.0504 & 0.7297 & 1.3705 & 1.0444 & 1.0340 \\
\hline 18-May-11 & $22: 00$ & 36.4079 & 34.9877 & 13.0138 & 11.5087 & 21.0540 & 23.0008 & 29.8542 & 30.3058 & 30.0000 & 0.7299 & 1.3701 & 1.0443 & 1.0328 \\
\hline $18-M=y-11$ & $23: 02$ & 36.4107 & 34.9707 & 13.0130 & 11.6080 & 21.9677 & 23.9910 & 29.8040 & 30.3126 & 30.1063 & 0.7283 & 1.3712 & 1.0460 & 1.0331 \\
\hline $19-M=y-11$ & $\infty: \infty 2$ & 36.4073 & 34.9888 & 13.0115 & 11.5075 & 21.9571 & 23.9901 & 29.8711 & 30.3249 & 30.0900 & 0.7295 & 1.3707 & 1.0449 & 1.0336 \\
\hline $19 \mathrm{Ma} y-11$ & $04: 02$ & 38.3983 & 34.8024 & 13.0029 & 11.4985 & 21.9595 & 23.9026 & 29.6472 & 30.3126 & 30.0799 & 0.7300 & 1.3698 & 1.0440 & 1.0331 \\
\hline $19 \mathrm{M}=\mathrm{y}-11$ & $02: 02$ & 38.3008 & 34.9800 & 13.0011 & 11.4925 & 21.9609 & 23.9008 & 29.8484 & 30.3029 & 30.0756 & 0.7301 & 1.3686 & 1.0441 & 1.0328 \\
\hline $19-$ May-11 & $03: 02$ & 36.3974 & 34.9688 & 12.9001 & 11.4916 & 21.9587 & 23.9774 & 29.8021 & 30.3273 & 30.0947 & 0.7297 & 1.3705 & 1.0445 & 1.0338 \\
\hline 19 May-11 & 04:02 & 36.3904 & 34.9557 & 12.8089 & 11.4941 & 21.9588 & 23.9763 & 29.8107 & 30.3080 & 30.0584 & 0.7306 & 1.3688 & 1.0427 & 1.0328 \\
\hline $12 \mathrm{May}-11$ & $05: 02$ & 36.3902 & 34.9554 & 12.9976 & 11.4918 & 21.9577 & 23.9785 & 29.8769 & 30.2907 & 30.0838 & 0.7299 & 1.3701 & 1.0450 & 1.0324 \\
\hline 19-May-11 & 06:02 & 36.3931 & 34.9666 & 12.9008 & 11.4819 & 21.8600 & 23.9778 & 29.8044 & 30.3072 & 30.0558 & 0.7300 & 1.3888 & 1.0425 & 1.0329 \\
\hline $10-M \times y-11$ & $07: 02$ & 36.3943 & 34.9572 & 12.9095 & 11.4943 & 21.9607 & 23.9788 & 29.8461 & 30.2809 & 30.0635 & 0.7305 & 9.3690 & 1.0440 & 1.0321 \\
\hline $19 \mathrm{M}=11$ & $06: 02$ & 36.3984 & 34.9588 & 120974 & 11.4894 & 21.9814 & 23.9781 & 29.8591 & 30.3448 & 30.1020 & 0.7296 & 1.3707 & 1.044 & 1.0342 \\
\hline \multicolumn{8}{|c|}{ All input in S.l. } & \multicolumn{7}{|c|}{ EPS_INS_EPS_50X50 mm } \\
\hline & & & $\begin{array}{l}\mathrm{m} \\
\text { (c) }\end{array}$ & & $\begin{array}{l}\text { Tc } \\
\text { (C) }\end{array}$ & I & $\underset{(W / M 2)}{a}$ & & $\begin{array}{c}\text { Thickness } \\
\text { (Meten) }\end{array}$ & & & & & \\
\hline & & & & 1 & & I & 30.081 & & & & & & & \\
\hline & & & $\begin{array}{ll}D t & 1 \\
22.0 & 1\end{array}$ & & $\operatorname{Tm}_{24.0}$ & 1 & \begin{tabular}{l|l}
$R$ & 1 \\
0.73 &
\end{tabular} & & \begin{tabular}{c|c}
$R / L$ & 1 \\
28.6 &
\end{tabular} & & $\begin{array}{l}\mathrm{C} \\
1.370\end{array}$ & & $\begin{array}{c}K \\
0.03502\end{array}$ & \\
\hline & & & \multicolumn{12}{|c|}{ BTU Calcuintion } \\
\hline & & & $\stackrel{\text { Th }}{(\mathrm{F})}$ & & $\begin{array}{l}\text { Tc } \\
\text { (F) } \\
55.4\end{array}$ & $\begin{array}{l}1 \\
1 \\
1\end{array}$ & \begin{tabular}{c|c|c|}
$Q$ \\
BTUTHFT2
\end{tabular} & & $\begin{array}{r}\text { Thicknos: } \\
\text { (Inches) } \\
1.01\end{array}$ & & & & & \\
\hline & & & ot & & $\operatorname{Tm}_{75.2}$ & 1 & ${ }^{R} 4$ & & \begin{tabular}{ll|}
$R / L$ & \\
4.1
\end{tabular} & & $\begin{array}{l}c \\
0.241\end{array}$ & & $\begin{array}{c}K \\
0.2428\end{array}$ & \\
\hline
\end{tabular}

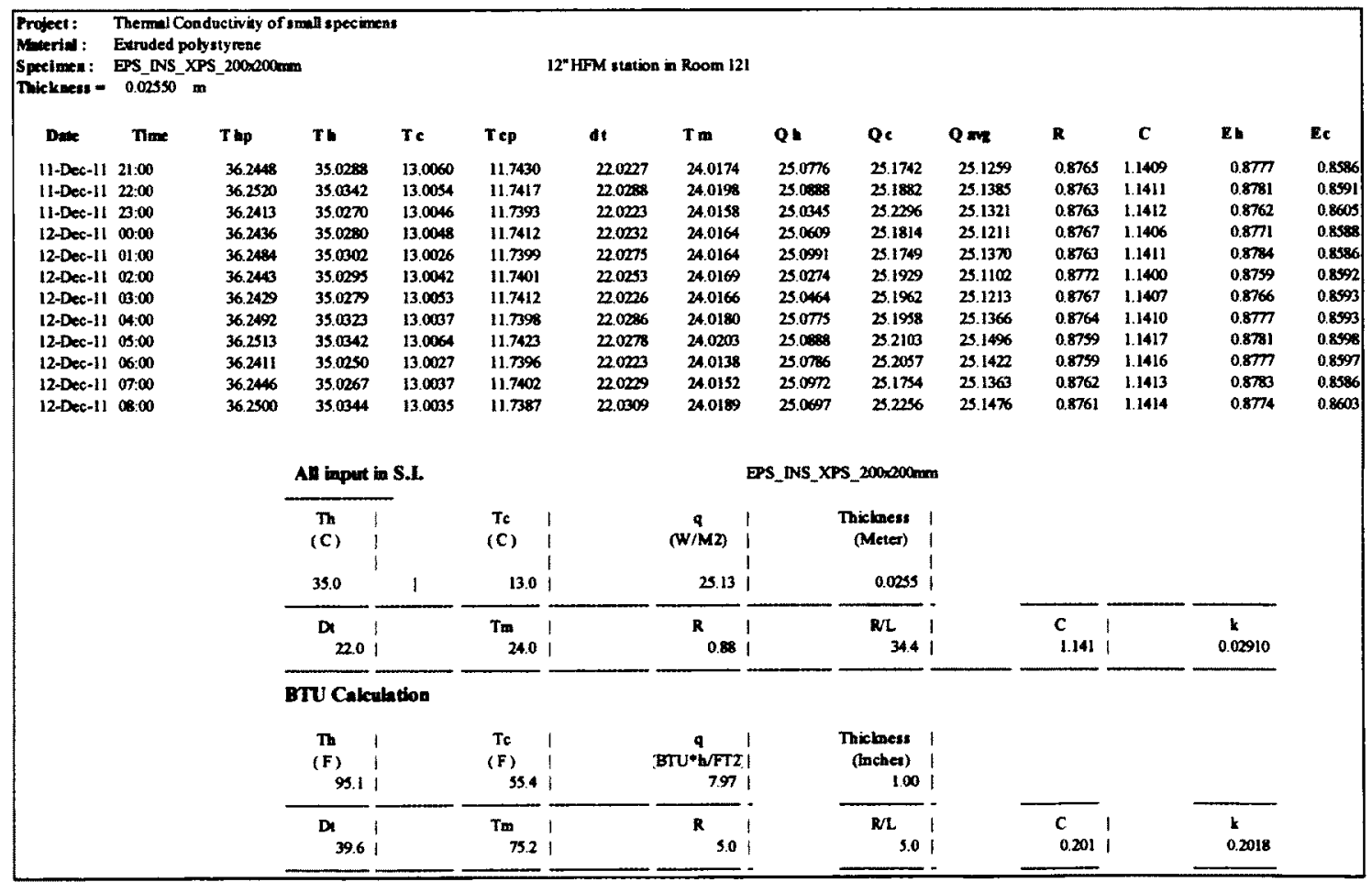




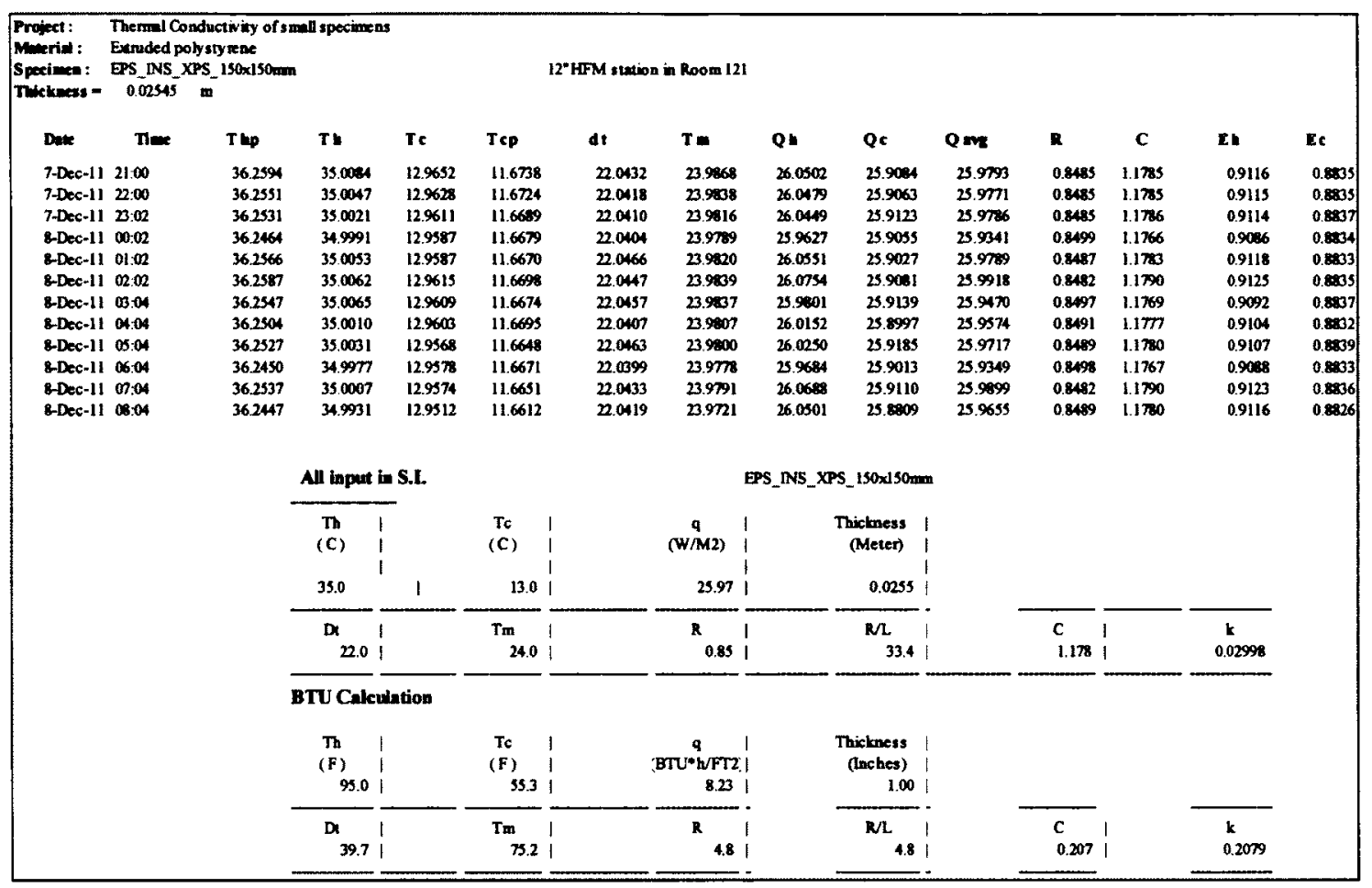

Project: Thermal Conductivity of smell i pecimens Moverin: Extrudod polystyrenc Specimea : EPS_INS_XPS_100x100mm

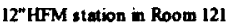
nickeess $=0.02562 \mathrm{~m}$

\begin{tabular}{|c|c|c|c|c|c|c|c|c|c|c|c|c|c|c|}
\hline Dente & Time & $T \mathrm{pp}$ & T: & $\mathbf{T c}$ & $T \mathbf{c p}$ & $d t$ & $T \mathbf{m}$ & Q & Qc & $Q=$ & $\mathbf{R}$ & c & El & Ee \\
\hline 12-Doc-11 & $21: 00$ & 36.3190 & 34.9906 & 130225 & 11.6435 & 21.9680 & 24.0065 & 27.5535 & 27.6694 & 27.6114 & 0.7956 & 1.2569 & 0.9640 & 0.9434 \\
\hline 12-Dec-11 & $22: 00$ & 36.3188 & 34.9921 & 13.0180 & 11.6397 & 21.9742 & 24.0050 & 27.5312 & 27.6612 & 27.5962 & 0.7963 & 1.2558 & 0.9633 & 0.9431 \\
\hline 12-Dec-11 & 23.00 & 36.3160 & 34.9879 & 13.0165 & 11.6372 & 21.9714 & 24.0022 & 27.5409 & 27.6586 & 27.5997 & 0.7961 & 1.2561 & 0.9636 & 0.9430 \\
\hline |3-Dec-11] & $00: 00$ & 36.3135 & 34.9854 & 13.0157 & 11.6386 & 21.9698 & 24.0005 & 27.5481 & 27.6341 & 27.5911 & 0.7963 & 1.2558 & 0.9638 & 0.9422 \\
\hline 13-Dec+11 & 0100 & 36.3151 & 34.9879 & 13.0161 & 11.6383 & 21.9718 & 24.0020 & 27.5363 & 27.6301 & 27.5832 & 0.7966 & 1.2553 & 0.9634 & 09420 \\
\hline |3-Dec-1] & 02.00 & 36.3100 & 34.9838 & 13.0135 & 11.6343 & 21.9703 & 23.9986 & 27.4892 & 27.6640 & 27.5766 & 0.7967 & 1.2551 & 0.9618 & 0.9432 \\
\hline |3-Dec-11 & 03.00 & 36.3162 & 34.9851 & 13.0145 & 11.6338 & 21.9705 & 20.9998 & 27.5980 & 27.6929 & 27.6455 & 0.7948 & 1.2583 & 0.9656 & 0.942 \\
\hline |3-Dec-i| & $04: 00$ & 36.3135 & 34.9841 & 13.0146 & 11.6341 & 21.905 & 23.9994 & 27.5596 & 27.6607 & 27.6102 & 0.7957 & 1.2567 & 0.9642 & 0.9431 \\
\hline 13-Doc-11 & 05:00 & 36.3100 & 34.9808 & 13.0122 & 11.6343 & 21.9685 & 23.9965 & 27.5818 & 27.6509 & 27.6164 & 0.7955 & 1.2571 & 0.950 & 0.9428 \\
\hline 13-Dec-11 & $06: 00$ & 36.3067 & 34.9418 & 130088 & 11.6298 & 21.9729 & 23.9953 & 27.5056 & 27.6391 & 27.5724 & 0.7969 & 1.2548 & 0.9624 & 0.9423 \\
\hline [3-Doc-11 & 07:00 & 36.3093 & 34.9800 & 13.0100 & 11.6291 & 21.9700 & 23.9950 & 27.5679 & 27.6642 & 27.6161 & 0.7956 & 1.2569 & 0.9645 & 0.9432 \\
\hline 13-Dec-11 & $08: 00$ & 36.3075 & 34.9311 & 13.0110 & 11.6326 & 21.9702 & 23.9961 & 27.5180 & 27.6470 & 27.5825 & 0.7966 & 1.2554 & 0.9628 & 0.9426 \\
\hline
\end{tabular}

All input in S.I.

EPS_INS_XPS_100x1000um

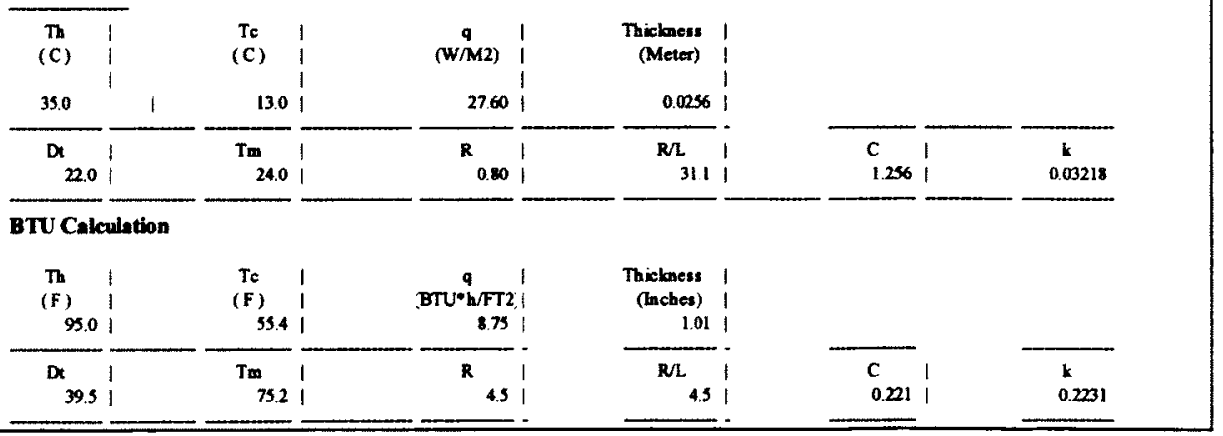




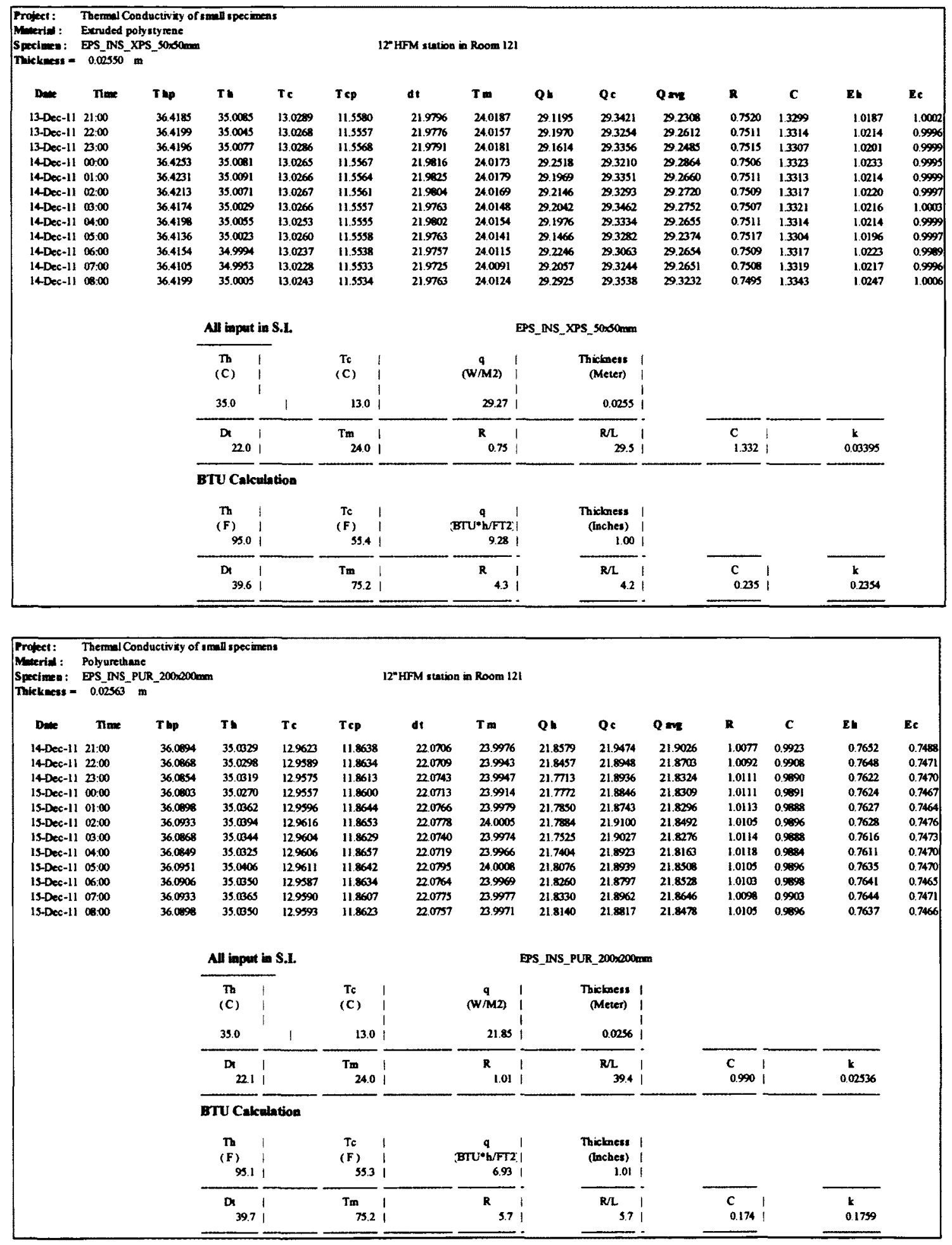




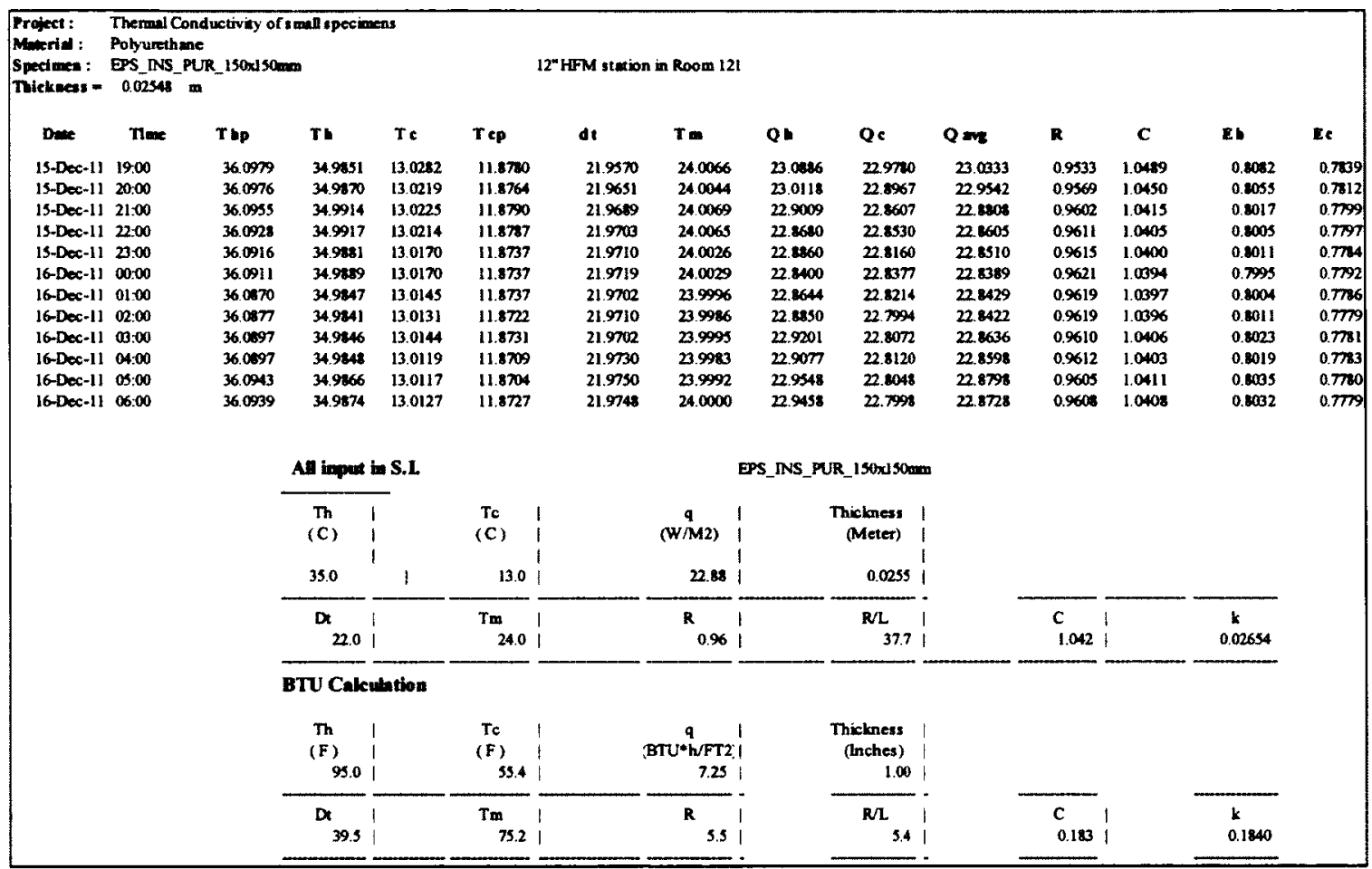

Project: Thermal Conductivity of small speciuens Maverial: Polyurethane Specimen: EPS_DNS_PUR_1000100mm niekness: $0.02540 \mathrm{~m}$ S-5en-12 21:58 5-3m-12 22:58 3-14n-12 23.58 6-1am-12 00.58 6-Jan-12 01.58 6-5en-12 02.58 6-5un-12 0358 6-jen-12 04.58 6-jen-12 0s:58 6-Jan-1206:58 6-Jen-12 07.58

$$
\begin{aligned}
& \text { The } \\
& 36.1305 \\
& 36.1343 \\
& 36.1347 \\
& 36.1352 \\
& 36.1424 \\
& 36.1385 \\
& 36.1464 \\
& 36.1348 \\
& 36.1381 \\
& 36.1329 \\
& 36.1474 \\
& 36.1428
\end{aligned}
$$$$
\text { T. }
$$

12" HFM strion in Room 121

34.8960
34.8973
34.9001
34.8967
34.9044
34.9025
34.9094
34.9008
34.9038
34.8753
34.9000
34.9068

$\begin{array}{lll}\text { Tc } & \text { Tcp } & \text { dt } \\ 13.1174 & 11.8326 & 21.7786 \\ 13.1170 & 11.8321 & 21.7803 \\ 13.1199 & 11.8351 & 21.7002 \\ 13.1187 & 11.8335 & 21.7780 \\ 13.1238 & 11.8364 & 21.7006 \\ 13.1236 & 11.8375 & 21.7789 \\ 13.1250 & 11.8392 & 21.7844 \\ 13.1213 & 11.8379 & 21.779 \\ 13.1235 & 11.8372 & 21.793 \\ 13.1233 & 11.8392 & 21.742 \\ 13.1269 & 11.8421 & 21.7811 \\ 13.128 & 11.842 & 21.776\end{array}$

$T=$
24.0067
24.0072
24.0100
24.0077
24.0141
24.0130
24.0172
24.0110
24.0136
24.0104
24.0175
24.0175

Q⿻

Qc
25.9754
25.9278
25.9575
25.9607
25.9775
25.9576
25.9780
25.9485
25.9812
25.9247
25.9587
25.9744

$\begin{array}{lll}Q m & R & C \\ 25.8913 & 0.8412 & 1.1898 \\ 25.8922 & 0.8412 & 1.1887 \\ 25.8795 & 0.8416 & 1.1832 \\ 25.9203 & 0.8402 & 1.1901 \\ 25.9079 & 0.8407 & 1.1894 \\ 25.9015 & 0.8409 & 1.1893 \\ 25.9066 & 0.8409 & 1.1892 \\ 25.8753 & 0.8418 & 1.1879 \\ 25.8852 & 0.8414 & 1.1844 \\ 25.8700 & 0.8417 & 1.1881 \\ 25.9202 & 0.8404 & 1.1900 \\ 259001 & 0.8407 & 1.1896\end{array}$

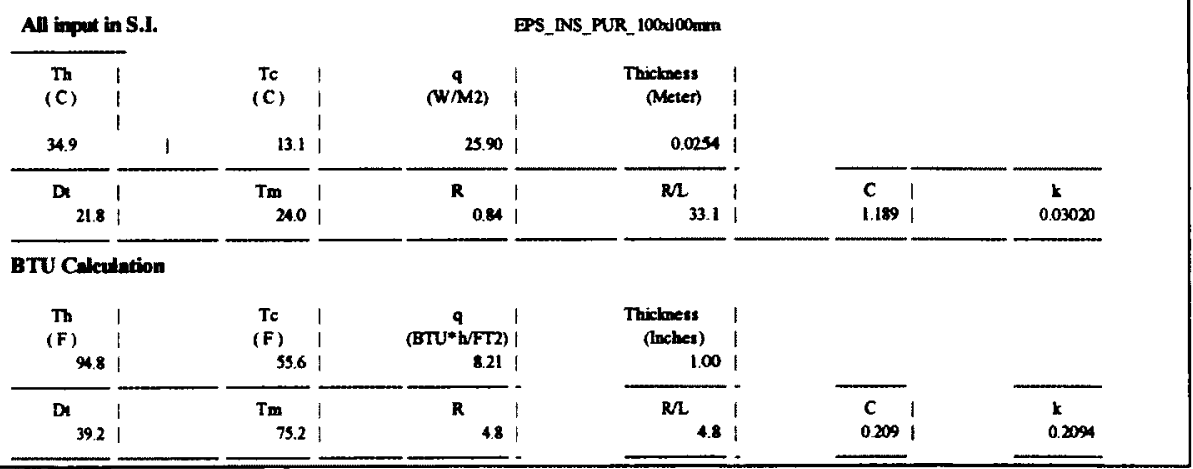




\begin{tabular}{|c|c|c|c|c|c|c|c|c|c|c|c|c|c|c|}
\hline $\begin{array}{l}\text { Project: } \\
\text { Minerid : } \\
\text { Specines: } \\
\text { Thickeses m }\end{array}$ & $\begin{array}{l}\text { Thermuld } \\
\text { Polyureth } \\
\text { EPS_INS } \\
-\quad 0.025\end{array}$ & $50000 \mathrm{~mm}$ & anll speximens & & & HFM statio & ion in Room 12 & & & & & & & \\
\hline Dave & $n=m$ & rop & T & Te & $T$ ep & $d t$ & $T=$ & $Q$ & Qe & $Q=$ & R & c & et & er \\
\hline 12-han-12 & 20058 & 36.3670 & 34.9005 & 13.0448 & 11.5995 & 21.9358 & 240127 & 28.6796 & 28.8570 & 28.7603 & 0.7625 & 1.3114 & 1,0003 & 0.9837 \\
\hline $12-\operatorname{sun}-12$ & 221.58 & 36.3736 & 34.9608 & 13.0448 & 115984 & 21.9361 & 24.0128 & 28.2035 & 28.8582 & 28.8308 & 0.7609 & 1.3143 & 1.0076 & 0.9838 \\
\hline 12-Jan-12 & 2238 & 36.3610 & 34.9735 & 13.0426 & 11.5992 & 21.9308 & 24.001 & 28.6711 & 28.8607 & 28.7659 & 0.7624 & 1.3116 & 1.0030 & 0.9839 \\
\hline 12-Jan-12 & 23.58 & 36.3711 & 34.9783 & 130045 & 116014 & 21.9337 & 24.0114 & 28728 & 28.2055 & 28.797 & 0.7617 & 1.3129 & 1.0071 & 0.9220 \\
\hline 13-Jun-12 & $200: 58$ & 36.3766 & 34.9000 & 13.0438 & 115909 & 21.9363 & 24.0119 & 2804 & 28.837 & 28.8631 & 0.7600 & 1.3157 & 1.0106 & 0.9601 \\
\hline 13-Jan-12 & 20158 & $36.36 \%$ & 34.9785 & 13.0448 & 11.6005 & 21.9337 & 24.0116 & 28.7641 & 28.8426 & 28.8034 & 0.7616 & 1.3131 & 10063 & 0.9832 \\
\hline $13-\sqrt{a n}+12$ & 20258 & 36.3637 & 34.9747 & 13.0440 & 11.6002 & 21.9307 & 24.0094 & 28.7053 & 28.8466 & 28.7760 & 0.7621 & 1.3121 & 1.0042 & 0.9634 \\
\hline $13-\operatorname{Ian}-12$ & 203.58 & 36.3702 & 34.979 & 13.043 & 11.5974 & 21.9354 & 240120 & 28.7259 & 28.8903 & 28.8096 & 0.7614 & 1.3133 & 1.0050 & 0.9248 \\
\hline $13-\ln n+12$ & 204.58 & 36.3692 & 34.9762 & 13.0449 & $1159 \%$ & 21.9313 & 24.0106 & 28.7679 & 28.8141 & 28.7910 & 0.7618 & 1.3127 & 1.0064 & 0.9823 \\
\hline 13-Jan-12 & $2005: 58$ & 36.369 & 34.9749 & 13.0445 & 11.5983 & 21.9304 & 24.0097 & 23.8092 & 28.8501 & 28.8297 & 0.7607 & 1.3146 & 1.0078 & 0.9835 \\
\hline $13-\operatorname{Sun}-12$ & 206.58 & 36.3687 & $34.97 \%$ & 13.0462 & 11.6030 & 21.9334 & 24.0129 & 28.7150 & 28.8009 & 28.7579 & 0.7627 & 1.3111 & 1.0045 & 0.9818 \\
\hline 13-5an-12 & 207.58 & 36.3776 & 34960 & 13.0500 & 11.6074 & 21.9359 & 240180 & 28.7574 & 28.8475 & 28.8024 & 0.7616 & 1.3130 & 1.0060 & 0.9834 \\
\hline & & & All inpet in & & & & & S_INS_PUI & $R_{-} 50 \times 60 \mathrm{~mm}$ & & & & & \\
\hline & & & $\begin{array}{c:}\text { Th } \\
\text { (C) }\end{array}$ & & $\begin{array}{l}\text { Te } \\
\text { (C) }\end{array}$ & & (W/M2) & & $\begin{array}{c}\text { Thichness } \\
\text { (Meter) }\end{array}$ & & & & & \\
\hline & & & 35.0 & 1 & 13.0 & & 28.80 & & 0.0255 & & & & & \\
\hline & & & ${ }^{D t}$ & & $\mathrm{Tm}_{24,0}$ & & ${ }^{R} 0.76$ & & $\mathrm{R}_{29.9}$ & & $\mathrm{C}_{1.313}$ & & $\underset{0.03346}{k}$ & \\
\hline & & & BTU Calcu & tion & & & & & & & & & & \\
\hline & & & \begin{tabular}{l|l} 
Th & 1 \\
(F) &
\end{tabular} & & $\begin{array}{l}\text { Tc } \\
\text { (F) } \\
\text { 55.5 }\end{array}$ & & $\begin{array}{c}\mathrm{q} \\
(\mathrm{BrT} * \mathrm{~h} / \mathrm{FT} 2) \\
9.13\end{array}$ & & $\begin{array}{r}\text { Thickness } \\
\text { (Inches) } \\
1.00\end{array}$ & & & & & \\
\hline & & & $D_{39.5}$ & & $T_{75.2}$ & & $R_{4.3}$ & & $\mathbf{R A}_{4}$ & & $\mathrm{C}_{0.231}$ & & $\begin{array}{l}k \\
0.2320\end{array}$ & \\
\hline
\end{tabular}




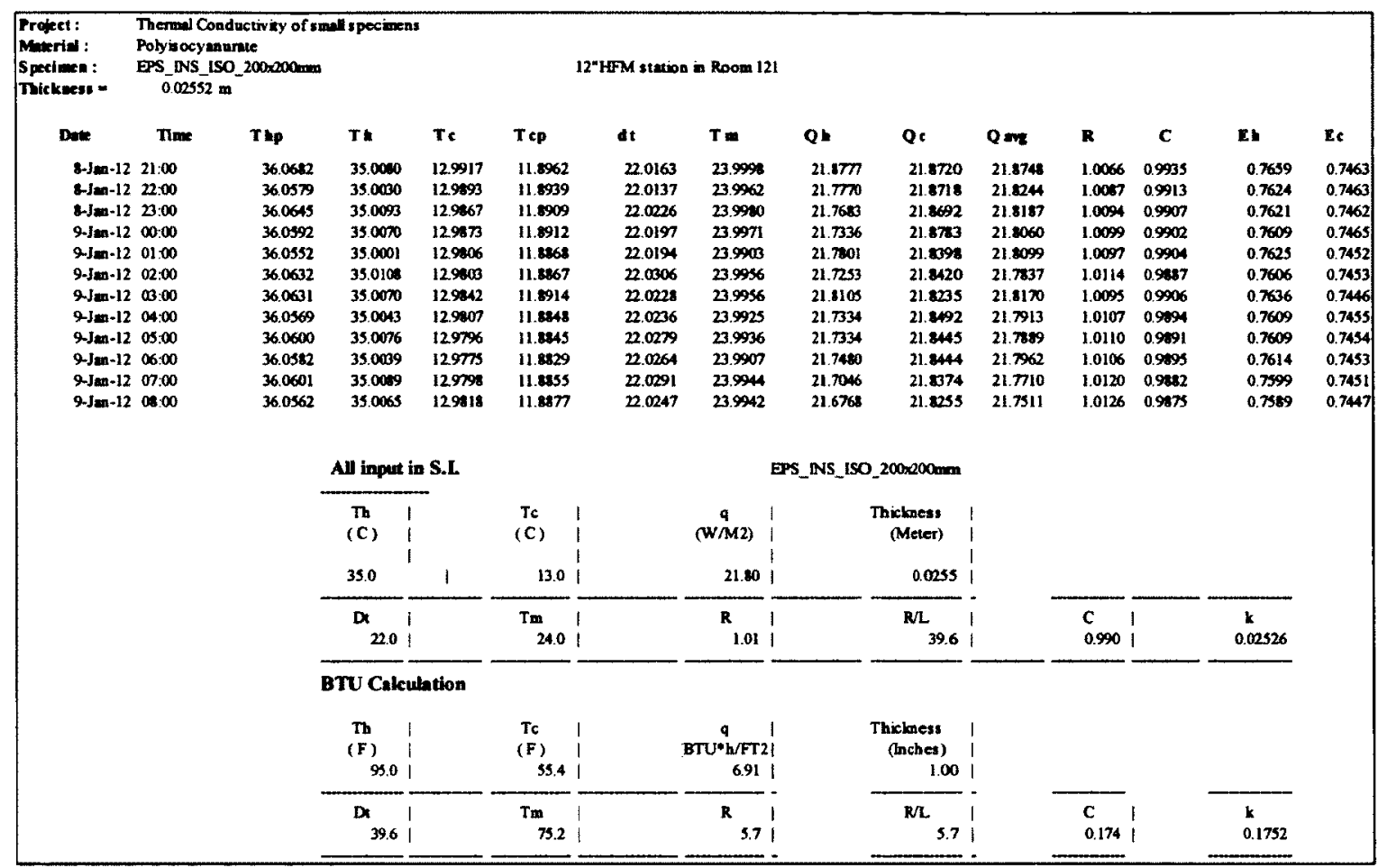

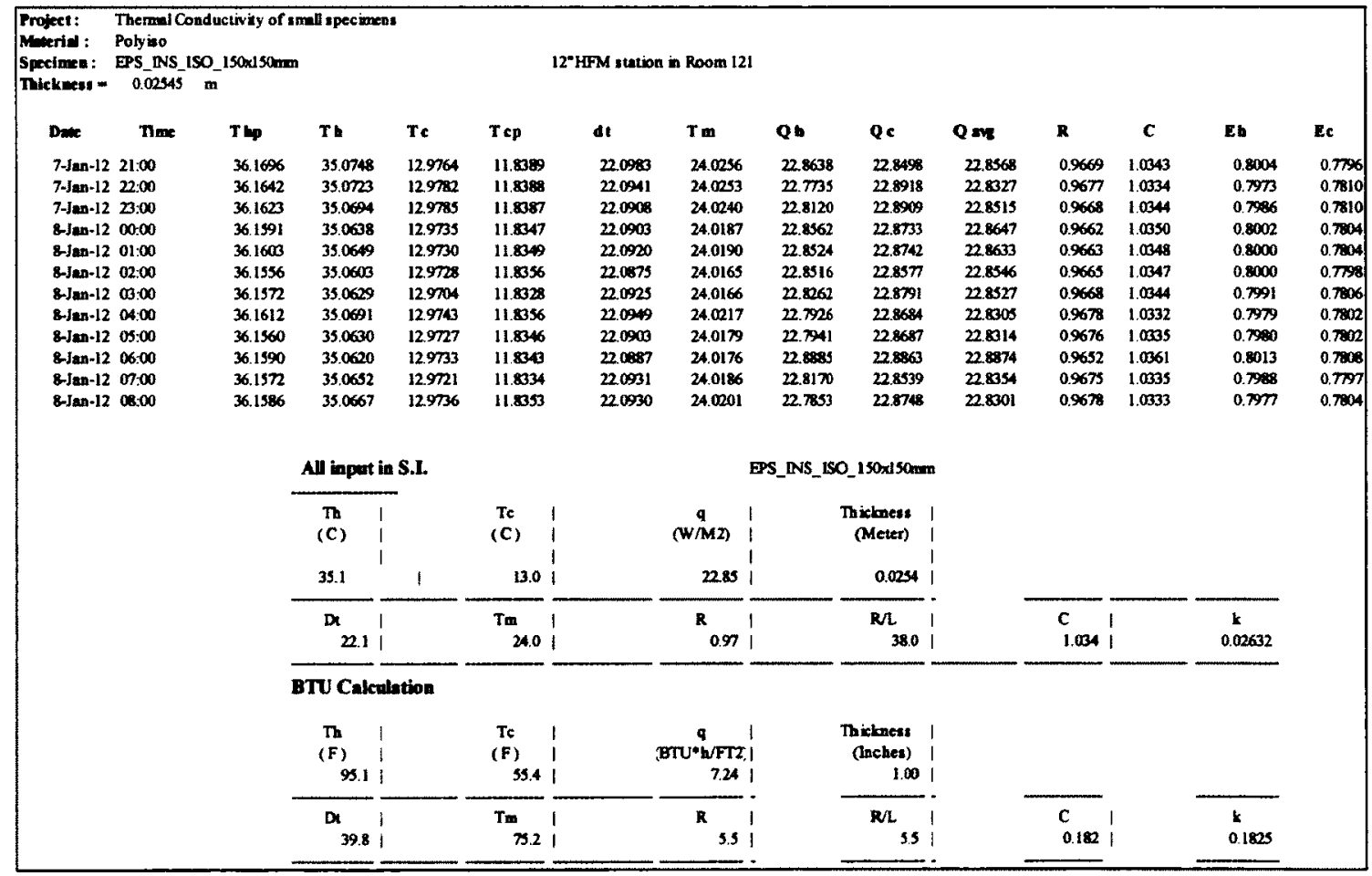




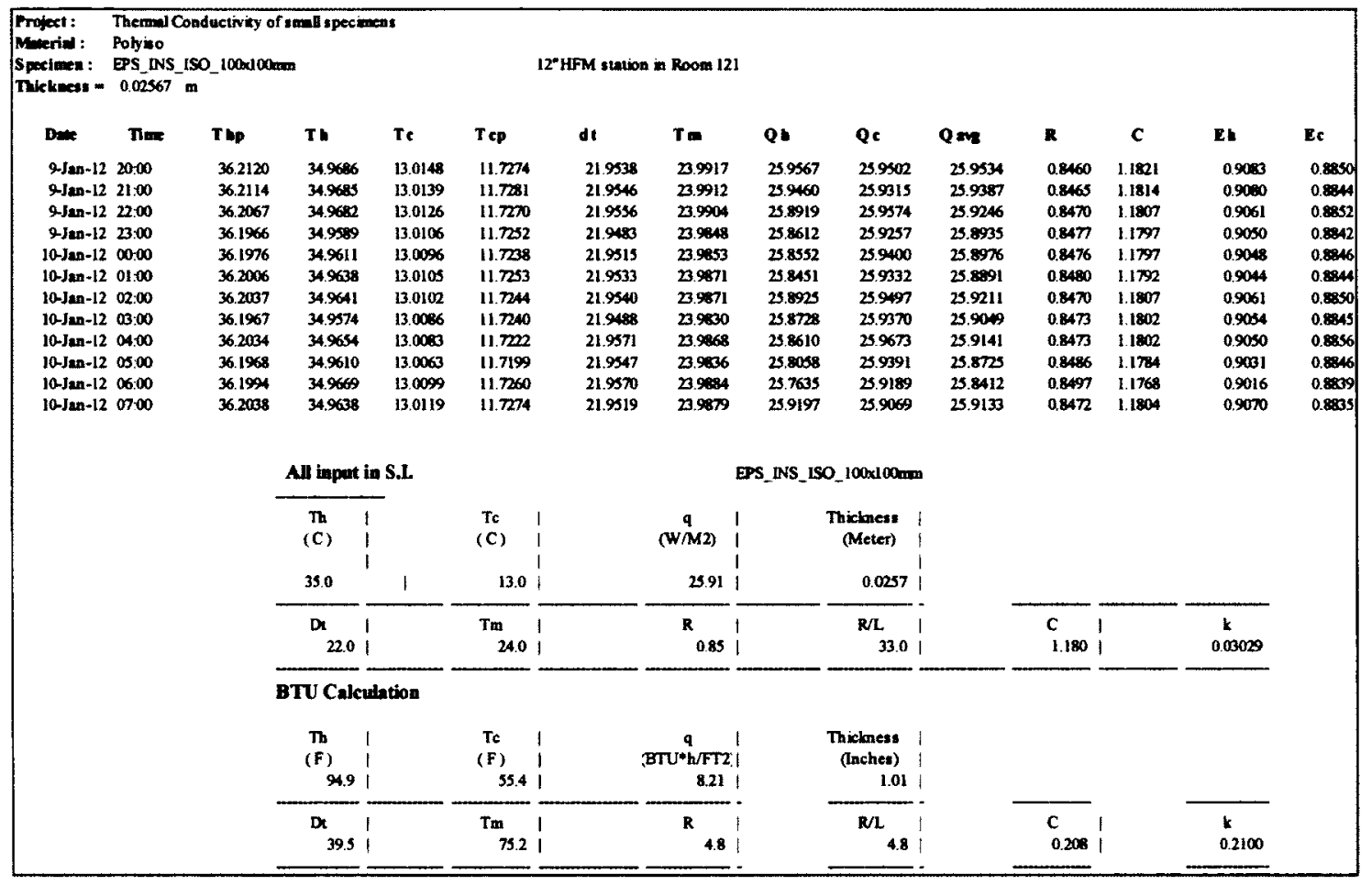

Profect: Thermal Conductivity of small apecimens

Muterial : Polyiso

Specimem: EPS_INS_1SO_50060mm

Thickness - $0.02548 \mathrm{~m}$

\begin{tabular}{|c|c|c|c|c|c|c|c|c|c|c|c|c|c|c|}
\hline Dane & Mine & Thp & $T$ & Tc & T cp & dt & $T \mathrm{~m}$ & Qh & Qc & $Q m$ & $\mathbf{R}$ & c & El & Ec \\
\hline $10-\operatorname{Jan}-12$ & 21:01 & 36.3545 & 34.9665 & 13.0405 & 11.5961 & 21.9260 & 24.0035 & 28.6704 & 28.8473 & 28.7589 & 0.7623 & 1.3116 & 1.0030 & 0.9634 \\
\hline $10-\tan -12$ & 23:0I & 36.3640 & 34.9700 & 13.0344 & 11.5911 & 21.9357 & 24.0022 & 28.8017 & 28.8443 & 28.8230 & 0.7611 & 1.3139 & 1.0076 & 0.9833 \\
\hline $11-\sqrt{a} m-12$ & $\infty: 01$ & 36.3564 & 34.9638 & 13.0340 & 01.5878 & 21.9298 & 23.9989 & $28.77 \%$ & 28.8991 & 28.8393 & 0.7604 & 1.3150 & 1.0068 & 0.9851 \\
\hline $11-$ Jan-12 & $02: 01$ & 36.3624 & 34.9644 & 13.0913 & 11.5834 & 21.9331 & 23.9978 & 28.9016 & 28,9010 & 28.9013 & 0.7989 & 1.3177 & 1.0110 & 0.9852 \\
\hline $11 \cdot \operatorname{lan}-12$ & $\omega 0: 01$ & 36.3527 & 34.912 & 13.0291 & 11.5822 & 21.9321 & 23.9951 & 28.7988 & 28.9057 & 28.8408 & 0.7605 & 1.3149 & 1.0066 & 0.9834 \\
\hline $11-\sqrt{a n}-12$ & $04: 01$ & 36.3553 & 34.9602 & 13.0294 & 11.5820 & 21.9308 & 23.9948 & 28.8204 & 28.8874 & 28.8539 & 0.7601 & 1.3136 & 1.0082 & 0.9947 \\
\hline 13-Jan-12 & 18:05 & 36.3606 & 34.9658 & 13.0312 & 11.5853 & 21.9346 & 23.9985 & 28.8102 & 28.8950 & 28.8526 & 0.7603 & 1.3153 & 1.0078 & 0.985 \\
\hline
\end{tabular}

All inpout in S.L

EPS_INS_1SO_50600m

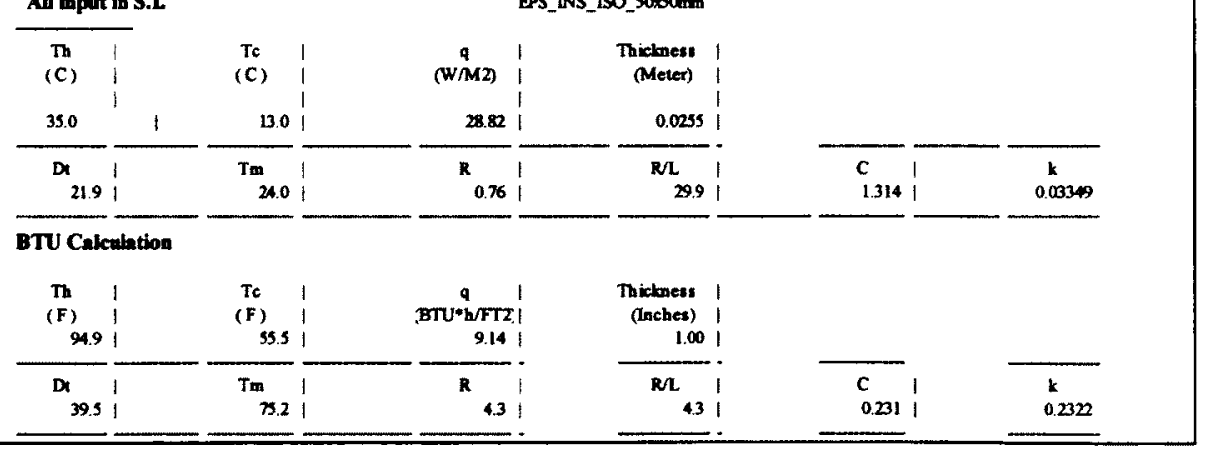




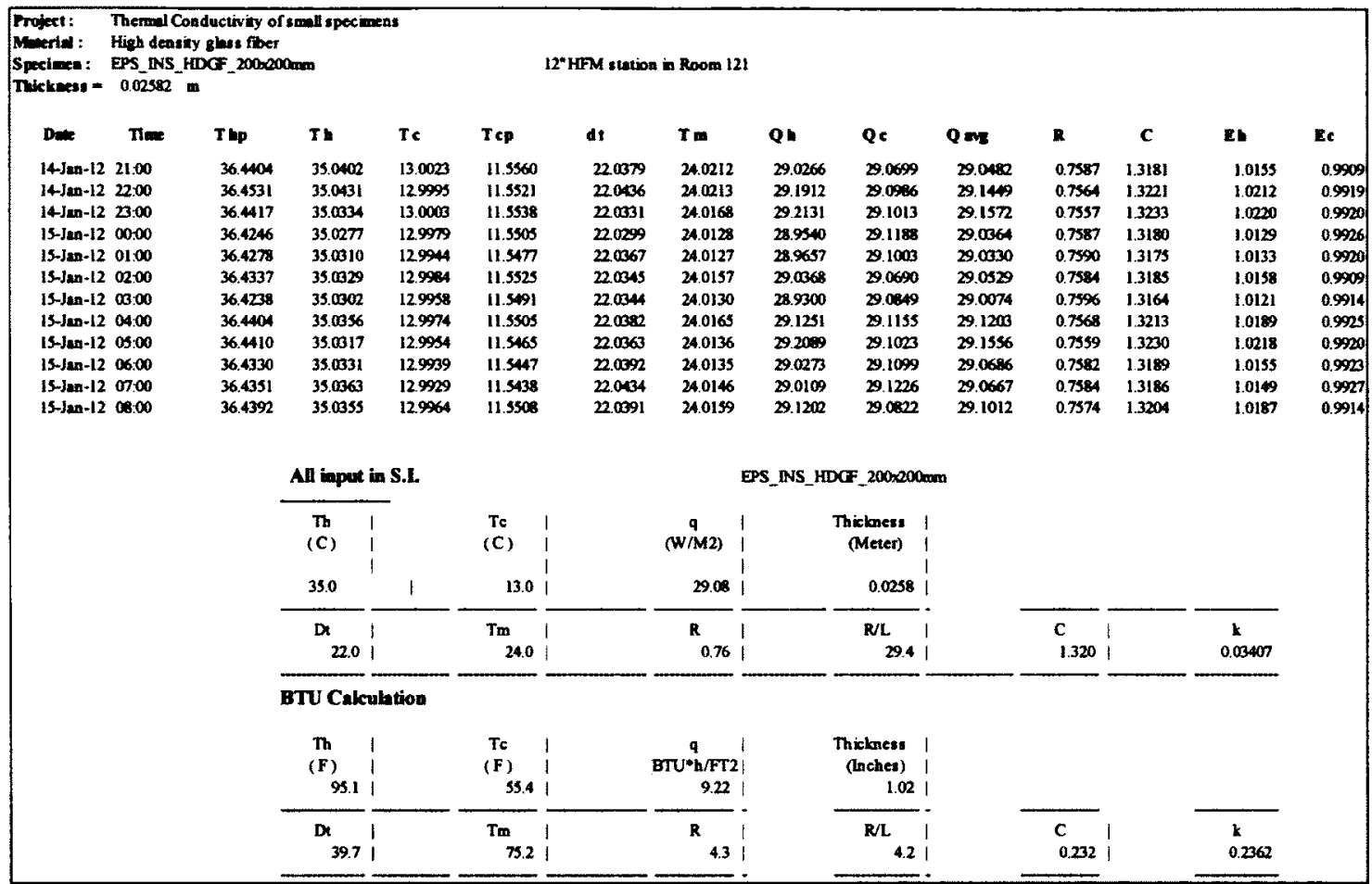

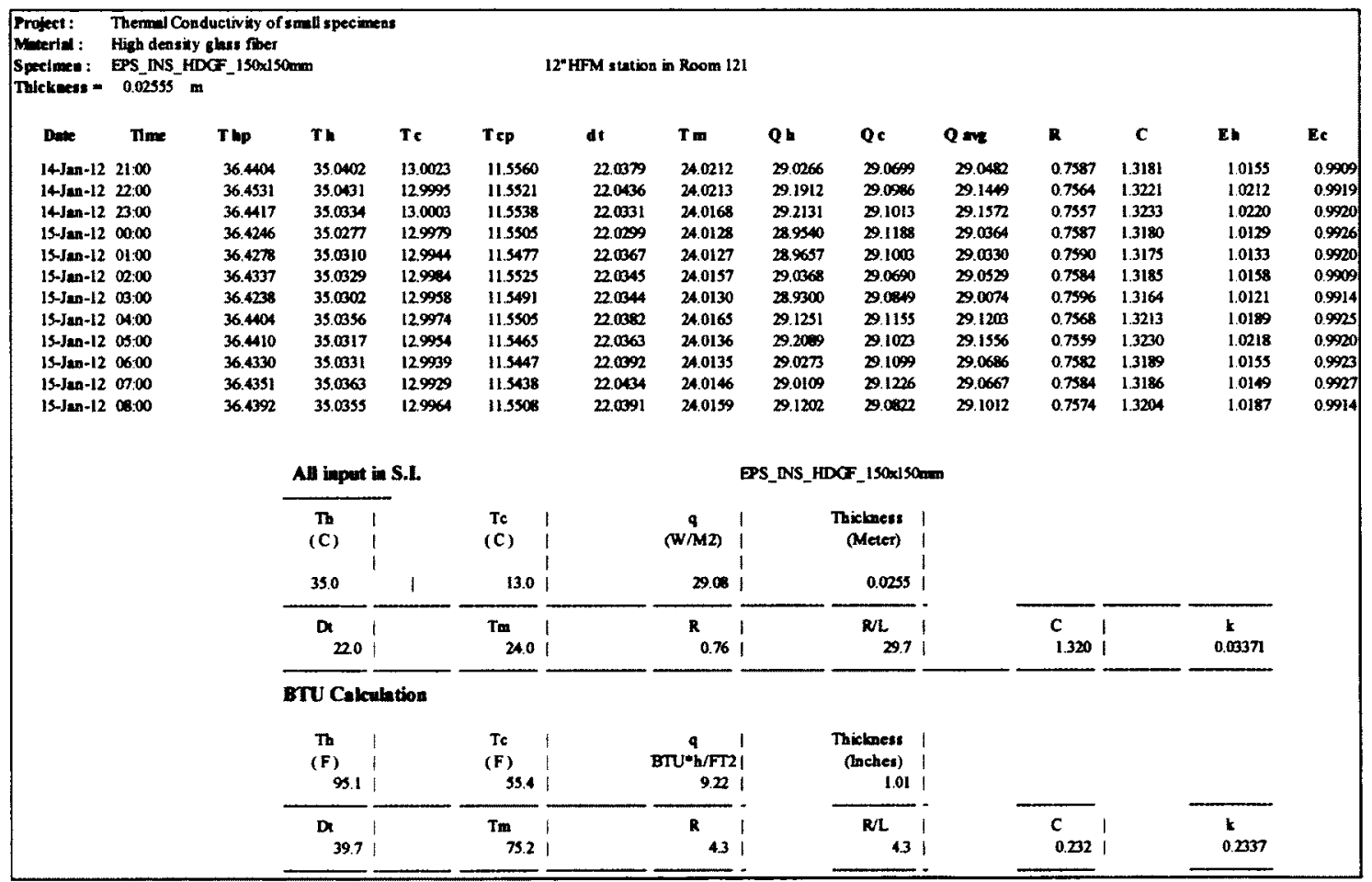




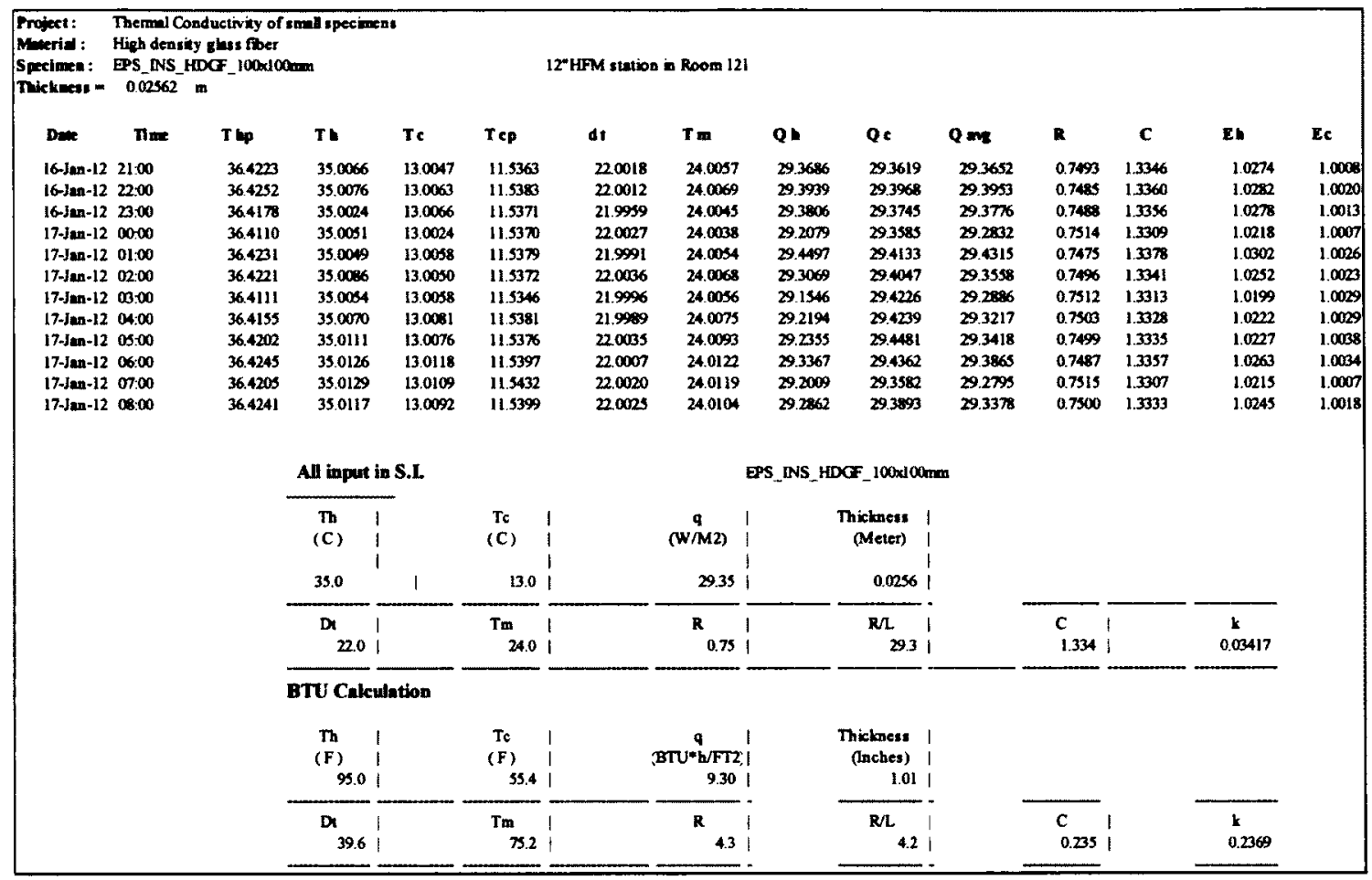

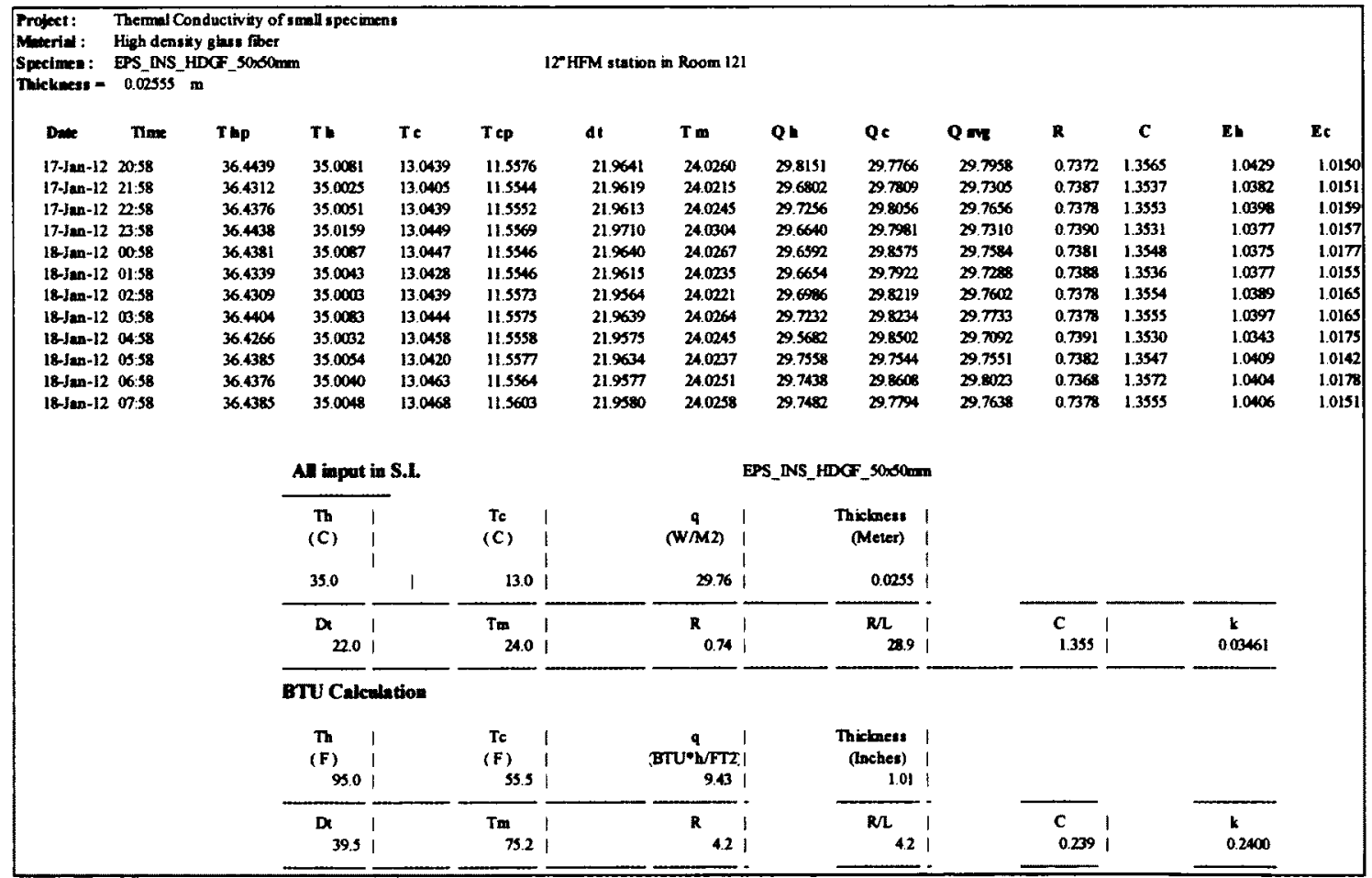




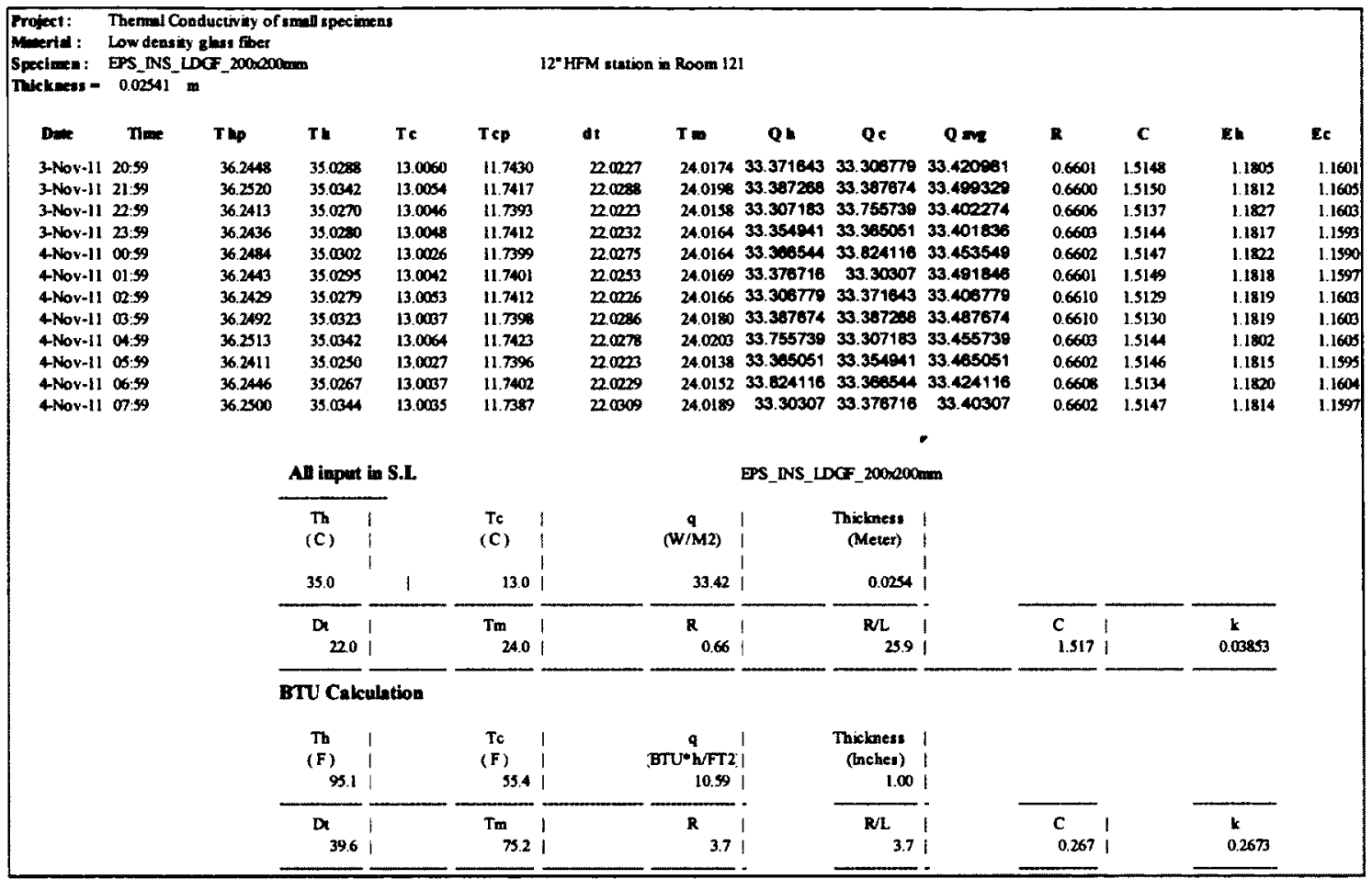

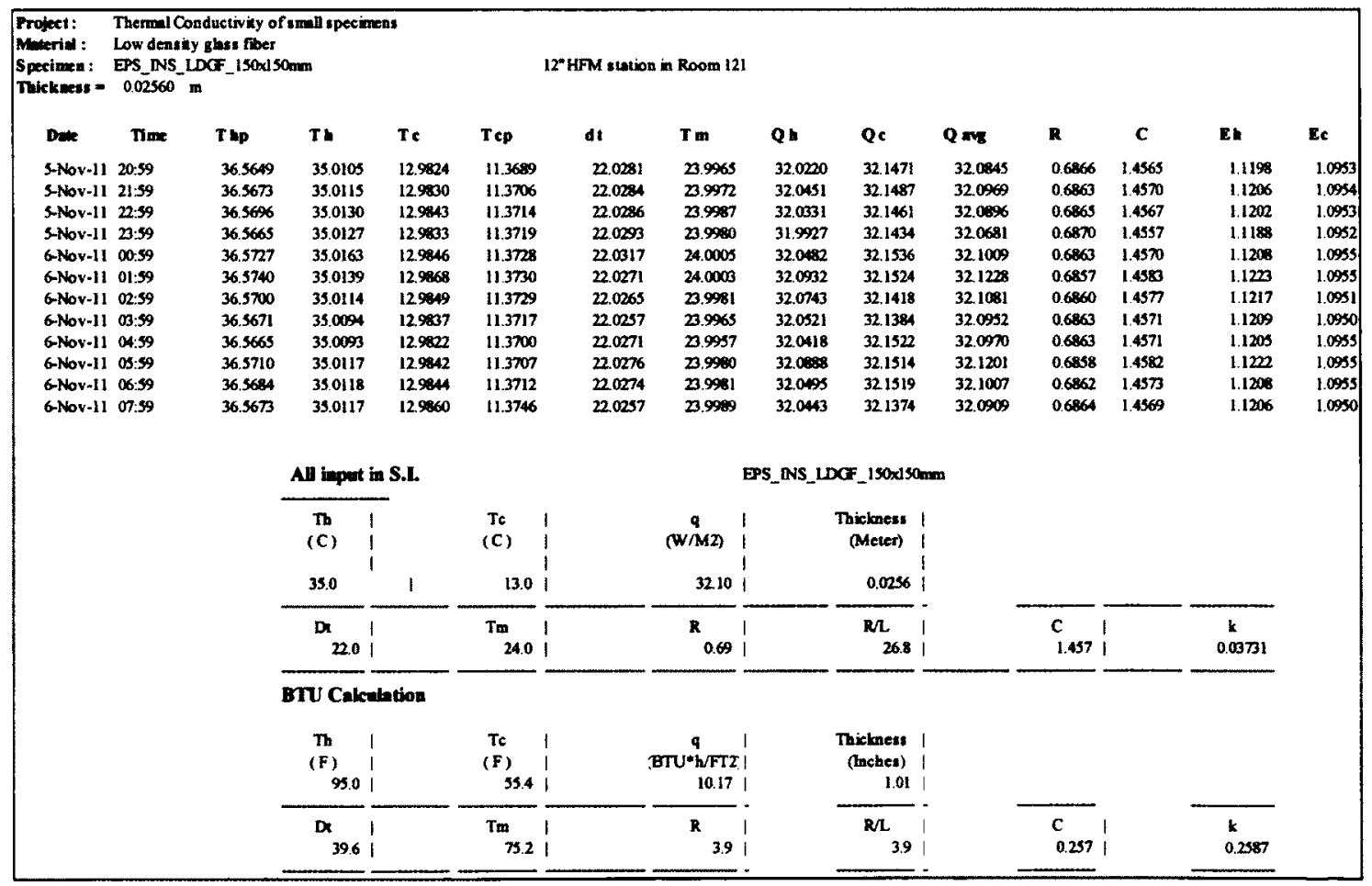


Project: Thermal Conductivity of small specimeas

Mmerist: Low density glass foer

Specimen: EPS DNS LDCF_100x100mm

Tikekess: $=0.02575$

12-HFM atution in Room 12

\begin{tabular}{|c|c|c|c|c|c|}
\hline $\mathbf{D} m$ & Time & Thp & Tr & $\mathrm{Tc}_{\mathrm{c}}$ & T cp \\
\hline 7-Nov-1 & 21.01 & 36.5254 & 35.0168 & 129741 & 11.4087 \\
\hline $7-\mathrm{Nov}-1$ & 22.01 & 36.5284 & 35,0198 & 12.9768 & 11.4117 \\
\hline 7-Nov-1 & 23001 & 36.5295 & 35.0244 & 129730 & 11.4115 \\
\hline B-Nov $=1$ & $\infty 001$ & 36.5331 & 35.0253 & 12.9002 & 11.4157 \\
\hline 8.Nov-1 & 0101 & 36.5299 & 35.0037 & 12,9791 & 11.4136 \\
\hline Rov-1 & $02: 01$ & 36.5366 & 35.0258 & 12.9819 & 11.4164 \\
\hline $8-\mathrm{Nov}-1$ & 03.01 & 36.5330 & 35.0246 & $12 \% 14$ & 11.4156 \\
\hline 8-Nov-1 & $04: 01$ & 36.5299 & 35.0234 & 12.9818 & 11.4154 \\
\hline $8 \times \mathrm{Nov}-1$ & 05.01 & 36.5347 & 35.0275 & 129815 & 11.4158 \\
\hline $8 \mathrm{Nov}-1$ & 0601 & 36.5300 & 35.0226 & 12.9796 & 11.4134 \\
\hline $8 \times N o v-1$ & 07.01 & 36.5300 & 35.0237 & 129798 & 11.4143 \\
\hline Nov=1 & 0801 & 365367 & 350037 & 129006 & 11416 \\
\hline
\end{tabular}

\begin{tabular}{|c|c|c|c|c|}
\hline$d t$ & $T \mathbf{m}$ & Q & Qc & $Q=$ \\
\hline 22.0427 & 23.9955 & 30.9180 & 31.1572 & 31.0376 \\
\hline 22,0430 & 20.9960 & 30.9325 & 31.1387 & 31.0356 \\
\hline 220463 & 24.0012 & 30.8602 & 31.1569 & 31.0085 \\
\hline 220451 & 24.0027 & 30.9340 & 31.1350 & 31.0345 \\
\hline 22.0446 & 24.0014 & 30.8981 & 31.1335 & 31.0158 \\
\hline 220439 & 24.0039 & 309658 & $31.12 \%$ & 31.0477 \\
\hline 22.0432 & 24.0030 & 30.9274 & 31.1403 & 31.0339 \\
\hline 22.0436 & 24.0036 & 30.8811 & 31.1414 & 31.0113 \\
\hline 22.0460 & 240045 & 30.846 & 31.1354 & 31.0150 \\
\hline 220440 & 24.0006 & 30.9009 & 31.1347 & 31.0178 \\
\hline 22.0439 & 24.0018 & 30.8738 & 31.1351 & 31.0053 \\
\hline & & 309865 & & \\
\hline
\end{tabular}

$\begin{array}{ll}\mathbf{R} & \mathbf{C} \\ 0.7102 & 1.4000 \\ 0.7103 & 1.4079 \\ 0.7110 & 1.4065 \\ 0.7104 & 1.4077 \\ 0.7108 & 1.4069 \\ 0.7100 & 1.4094 \\ 0.7103 & 1.4078 \\ 0.7108 & 1.4068 \\ 0.7108 & 1.4068 \\ 0.7107 & 1.4071 \\ 0.7110 & 1.4065 \\ 0.7006 & 1.409\end{array}$

All inpot in S.I.

EPS_INS_IDCF_100x100mm

\begin{tabular}{|c|c|c|c|c|c|c|c|}
\hline $\begin{array}{l}\text { Th } \\
\text { (C) }\end{array}$ & $\begin{array}{l}1 \\
1 \\
1\end{array}$ & & $\begin{array}{l}\text { Tc } \\
\text { (C) }\end{array}$ & $\begin{array}{l}1 \\
1 \\
1\end{array}$ & $\begin{array}{c}q \\
(W / M 2)\end{array}$ & 1 & $\begin{array}{c}\text { Thickness } \\
\text { (Meter) }\end{array}$ \\
\hline 35.0 & & 1 & 13.0 & i & 31.03 & 31 & 0.0257 \\
\hline${ }_{2}{ }_{2}$ & I & & $\operatorname{Tm}_{24.0}$ & 1 & ${ }^{\mathbf{R}}{ }_{0.71}$ & 1 & ${ }_{27.6}$ \\
\hline
\end{tabular}

BTU Calculation

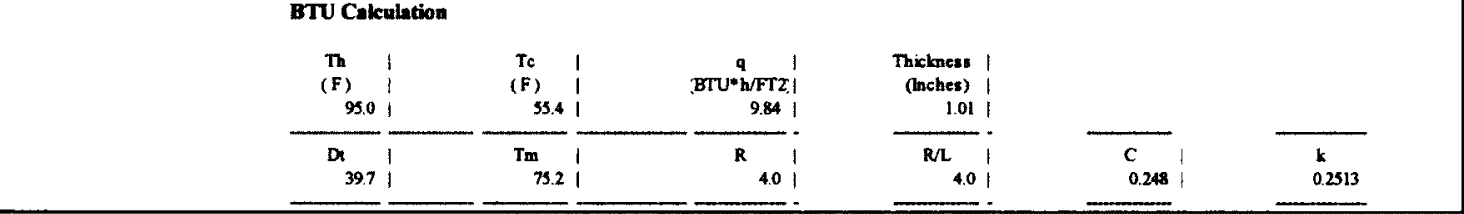
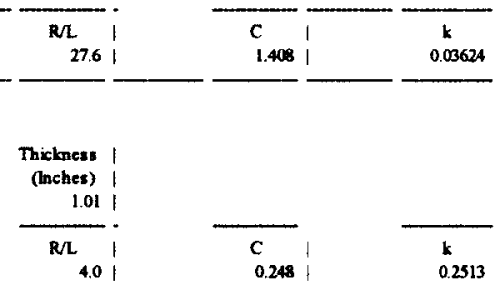

0.03624

Project: Thermal Conductivity of umal specimens

Moterial: Low density glass fiber

Specinen: EPS_NS_LDG_50no6mm

Thkkmess = $0.02557 \mathrm{~m}$

\begin{tabular}{|c|c|c|c|c|c|c|c|c|c|c|c|c|c|c|}
\hline Dase & $\mathrm{n}=$ & Thp & TV & Te & $T_{\text {cp }}$ & $d t$ & $T=$ & Q & Qc & $Q m$ & $\mathbf{R}$ & C & $\mathbf{E h}$ & Ec \\
\hline 8-Nov-11 & $20: 59$ & 36.4464 & 34.9942 & 12.9330 & 11.4197 & 22.0612 & 23.9636 & 30.0316 & 30.2378 & 30.1347 & 0.7321 & 1.3659 & 1.0505 & 1.03 \\
\hline 8-Nov-11 & 2159 & 36.4437 & 349922 & 12.9336 & 11.4212 & 220586 & 23.629 & 300108 & 30.2135 & 30.1121 & 0.7326 & 13651 & 1.0497 & 102 \\
\hline $8-\mathrm{Nov}-11$ & 22.59 & 36.4432 & 34.9907 & 12.9310 & 11.4197 & 22.0597 & 239608 & 30.0743 & 30.1986 & 30.1369 & 0.7320 & 1.3661 & 1.0520 & 1.02 \\
\hline 8-Nov.11 & 23:59 & 36.442 & 34.9930 & 12.9333 & 11.4206 & 22.0597 & 239632 & 30.0134 & 30.2098 & 30.1116 & 0.7326 & 1.3650 & $1.04 \%$ & 1.0 \\
\hline 9-Nov-11 & $00: 59$ & 36.4426 & 349903 & 12.9296 & 11.4190 & 220607 & 23.9599 & 30.0379 & 30.2125 & 30.1252 & 0.7323 & 1.3659 & 1050 & 102 \\
\hline exrov-11 & $01: 59$ & 36.4422 & 34.9867 & 12.9271 & 11.4136 & $22.05 \%$ & 239369 & 30.0860 & 30.2244 & 30.1352 & 0.7315 & 1.3670 & 1.0524 & 1.0 \\
\hline 9-Nov-11 & 02:59 & 36.4009 & 34.9878 & 12.9268 & 11.4146 & 22.0610 & 23.9573 & 30.0427 & 30.2265 & 30.1346 & 0.7321 & 1.3659 & 1.0508 & 1.0 \\
\hline 9-Nov-11 & 0359 & 36.437 & 34.9843 & 12.9281 & 11.4165 & 2200562 & 23.9562 & 30.0578 & 30.1972 & 30.1275 & 0.7321 & 1.3659 & 1.0514 & 1.0 \\
\hline $9-\mathrm{Nov}-11$ & at:59 & 36.4114 & 34.9857 & 12.9254 & 11.4127 & 22.0593 & 23.9560 & 30.0936 & 30.2230 & 30.1583 & 0.7315 & 1.3671 & 1.0526 & \\
\hline 9-Nov. II & $05: 59$ & 36.4370 & 34.9856 & 12.9248 & 11.4117 & 22.0608 & 23.9552 & 30.0307 & 30.2231 & 30.1269 & 0.7323 & 1.3656 & 1.0504 & \\
\hline 9-Nov-11 & $06: 59$ & 36.4366 & 34.9850 & 12.9250 & 11.4114 & 22.0600 & 23.9550 & 30.0251 & 30.2271 & 30.1261 & 0.7323 & 1.3656 & 1.0502 & \\
\hline $9-\mathrm{Nov} \cdot 11$ & $07: 59$ & 36.4410 & 34.9871 & 12.9284 & 11.4146 & 22.0587 & 23.957 & 30.0682 & 30.2109 & $30.13 \%$ & 0.7319 & 1.3663 & 1.0517 & \\
\hline
\end{tabular}

9-Nov.11 on:59

All inpen in S.L.

EPS INS LDG $50,50 \mathrm{~mm}$

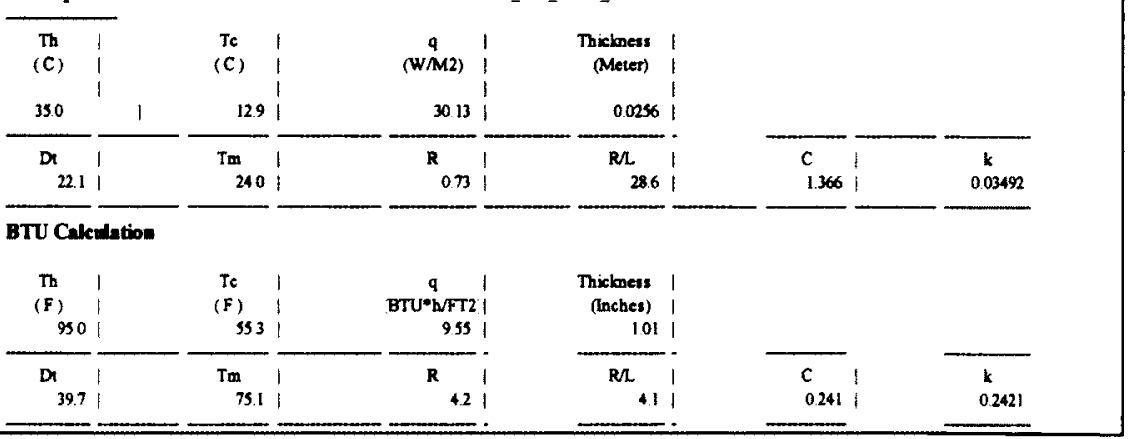




\begin{tabular}{|c|c|c|c|c|c|c|c|c|c|c|c|c|c|c|}
\hline $\begin{array}{l}\text { Preject: } \\
\text { Merial : } \\
\text { Specimes : } \\
\text { Thickmess = }\end{array}$ & $\begin{array}{c}\text { Thermal C } \\
\text { Expanded } \\
\text { EPS_INS } \\
0.0127\end{array}$ & $\begin{array}{l}\text { ductivity a } \\
\text { tystyrene } \\
S_{+} 2002000 \\
\end{array}$ & mel specimex & insulatio & & $12^{*} \mathrm{HFM}$ \& tatio & in in Room 121 & & & & & & & \\
\hline 19-Jun-11 & $22: 00$ & 37.7554 & 35.0063 & 13.0262 & 10.1337 & 21.9902 & 24.0163 & 57.3868 & $58.277 \mathrm{~B}$ & 57.8323 & 0.3801 & 2.6311 & 20016 & 1.9787 \\
\hline 19-bun-11 & 23.00 & 37.7561 & 35.0044 & 13.0239 & 10.1373 & 21.9805 & 24.0142 & 57.371 & 58.2379 & 57.8045 & 0.3803 & 2.6298 & 20010 & 1.977 \\
\hline 20-Jun-11 & 10000 & 37.7547 & 34.9995 & 13.0256 & 10.1350 & 21.9739 & 24.0126 & 57.3753 & 58.2635 & 57.8194 & 0.3880 & 2.6313 & 20012 & 1.9782 \\
\hline 20-Jun-11 & 0400 & 37.7520 & 35.0013 & 13.0239 & 10.1355 & $21.9 \mathrm{~m} / 4$ & 24.0126 & 57.3343 & 58.2486 & 57.7914 & 0.3803 & $2.62 \%$ & 1.9997 & 1.977 \\
\hline 20--1ua-11 & $05: 00$ & 37.7528 & 35.0003 & 13.0212 & 10.1321 & 21.9792 & 24.0108 & 57.3820 & 58.2669 & 57.8244 & 0.3801 & 26309 & 20014 & 1.9783 \\
\hline 20-/un-11 & 06.00 & 37.7516 & 34.9988 & 13.0236 & 10.1337 & 21.9731 & 24.0112 & 57.4040 & 58.2720 & 57.8380 & 0.3799 & 2.6320 & 20022 & 1.9785 \\
\hline 20-Jun-11 & 0700 & 37.7523 & 35.0029 & 13.0264 & 10.1354 & 21.9766 & 24.0146 & 57.3250 & 58.2588 & 57.7938 & 0.3803 & 26298 & 1.9996 & 1.9780 \\
\hline 20-Jun-11 & 08.00 & 37.7517 & 35.0000 & 13,0257 & 10.1358 & 21.9742 & 24.0129 & 57.3739 & 58.2593 & 37.8166 & 0.3801 & 26311 & 20011 & 1.9781 \\
\hline 20-Jun-11 & 09,00 & 37.7575 & 35.0024 & 13.0248 & 10.1358 & 21.977 & 24.0136 & 57,4265 & 58.2831 & 57.8573 & 0.3799 & 2.6325 & 20029 & 1.9790 \\
\hline & & & ${ }_{220}^{D}$ & & $\operatorname{Tm}_{24.0}$ & 1 & ${ }^{R}$ & & \begin{tabular}{r|r} 
RL & \\
29.8 &
\end{tabular} & & $\begin{array}{l}\mathrm{C} \\
2.631\end{array}$ & & $\begin{array}{c}K \\
0.03361\end{array}$ & \\
\hline & & & BTU Calc & lation & & & & & & & & & & \\
\hline & & & $\begin{array}{l}\mathrm{Th} \\
\text { (F) } \\
95.0\end{array}$ & & \begin{tabular}{l|} 
Te \\
(F) \\
55.4
\end{tabular} & 1 & $\begin{array}{c}Q \\
\text { BTU*h/FT2 } \\
18.33\end{array}$ & & $\begin{aligned} \text { Thickness } & \mid \\
\text { (Inches) } & \\
0.50 & \text { | }\end{aligned}$ & & & & & \\
\hline & & & $\begin{array}{l}D_{39.6}\end{array}$ & & $\operatorname{Tm}$ & 1 & $R_{2.2}$ & & \begin{tabular}{l|l}
$\mathrm{R} / \mathrm{L}$ \\
4.3
\end{tabular} & & $\begin{array}{l}\mathrm{C} \\
0.463\end{array}$ & & $\begin{array}{l}K \\
0.2330\end{array}$ & \\
\hline
\end{tabular}

Project: Thermal Conductivity umal specimen of insulation Meterial: Epanded Poly ityrene Specimen: EPS_INS_EPS_1 $190 \times 150 \mathrm{~mm}$

12"HFM station in Room 121 Tickness $=0.01275$

\begin{tabular}{|c|c|c|c|c|c|c|c|c|c|c|c|c|c|c|}
\hline Dave & Time & T hp & $T *$ & Te & Tep & $d t$ & $T \mathrm{~m}$ & $Q$ & $Q C$ & $Q m$ & $\mathbf{R}$ & c & Ek & Ec \\
\hline $21-j_{u n}-11$ & $04: 04$ & 37.7526 & 34.9903 & 13.0358 & 10.1332 & 21.9545 & 24,0131 & 57.4992 & 58.3478 & 57.9200 & 0.3791 & 2.6382 & 20052 & 1.9810 \\
\hline 2I-Jun-1I & os:04 & 37.7568 & 34.99013 & 13.0380 & 10.1343 & 21.9523 & 24.0142 & 57.5216 & 58.3728 & 57.9472 & 0.3788 & 2.6397 & 2.0062 & 1.9819 \\
\hline 21-Jun-11 & $06: 04$ & 37.7513 & 34.9874 & 13.0406 & 10.1378 & 21.9468 & 24.0140 & 97.4681 & 58.3882 & 37.9282 & 0.3789 & 2.6395 & 2.0043 & 1.9824 \\
\hline $21-f_{u n}-11$ & $07: 04$ & 37.7549 & 34.9904 & 13.0416 & 10.1386 & 21.9488 & 24.0160 & 57.4809 & 58.3767 & 57.9288 & 0.3789 & 2.6393 & 2.0048 & 1.9620 \\
\hline 21. Jun 111 & $08: 04$ & 37.7560 & 34.9891 & 13.0414 & 10.1400 & 21.9477 & 24.0152 & 57.5101 & 58.3563 & 97.9332 & 0.3788 & 2.6396 & 2.0058 & 1.9813 \\
\hline 21-Jun-11 & 09.04 & 37.7599 & 34.9941 & 13.0392 & 10.1351 & 21.9548 & 24.0167 & 57.5079 & 58.3716 & 57.9398 & 0.3709 & 26390 & 2.0057 & 1.9618 \\
\hline 21-Jun-11 & $10: 04$ & 37.7584 & 34.9943 & 13.0455 & 10.1416 & 21.9488 & 24.0199 & 57.4457 & 58.3517 & 57.8987 & 0.3791 & 2.6379 & 2.0036 & 1.9811 \\
\hline 21-Jun-11 & $11: 04$ & 37.7540 & 34.9908 & 13.0430 & 10.1423 & 21.9478 & 24.0169 & $\$ 7.4801$ & 58.347 & 37.9154 & 0.3790 & 2.6388 & 2.0049 & 1.9810 \\
\hline 21-Jun-11 & $12: 04$ & 37.7605 & 34.9951 & 13.0444 & 10.1421 & 21.9507 & 24.0198 & 97.5008 & 58.3693 & 57.9351 & 0.3789 & 2.6393 & 20055 & 1.9818 \\
\hline 21-JUD-11 & 13:04 & 37.7580 & 34.9918 & 13.0437 & 10.1410 & 21.9481 & 24.0178 & 57.4894 & 58.3692 & 57.9293 & 0.3789 & 26394 & 2.0051 & 1.9817 \\
\hline 21-Jun-11 & $14: 04$ & 37.7594 & 34.9977 & 13.044 & 10.1436 & 21.9531 & 24.0811 & 57.4687 & 58.3735 & 57.9221 & 0.3790 & 2.6384 & 2.0044 & 1.9600 \\
\hline 21-Jun-11 & 15:04 & 377652 & 34.9966 & 13.0442 & 10.1427 & 21.9524 & 24.0204 & 57.5105 & 58.3607 & 57.9356 & 0.3769 & 2.6391 & 2.0058 & 1.9819 \\
\hline
\end{tabular}

All inpat in S.I.

EPS_INS_EPS_150\%150 mm

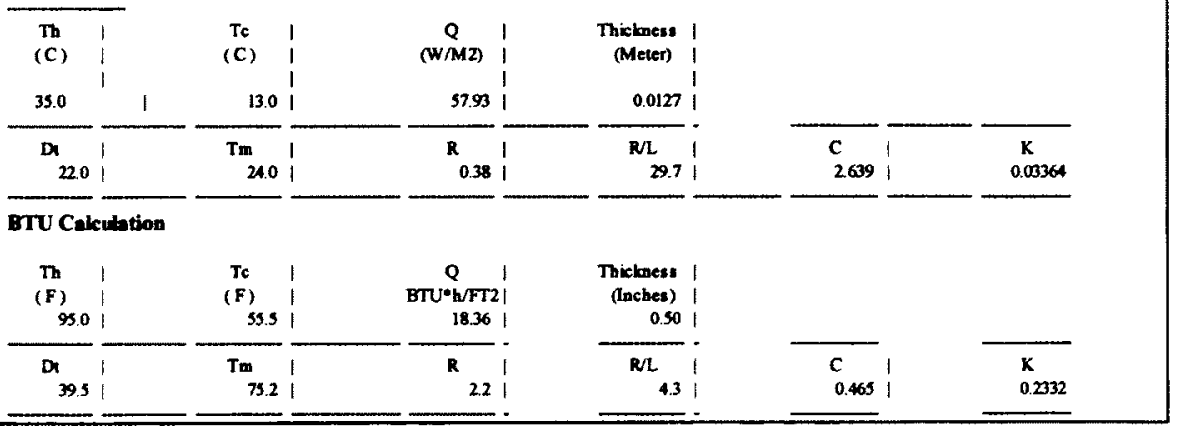




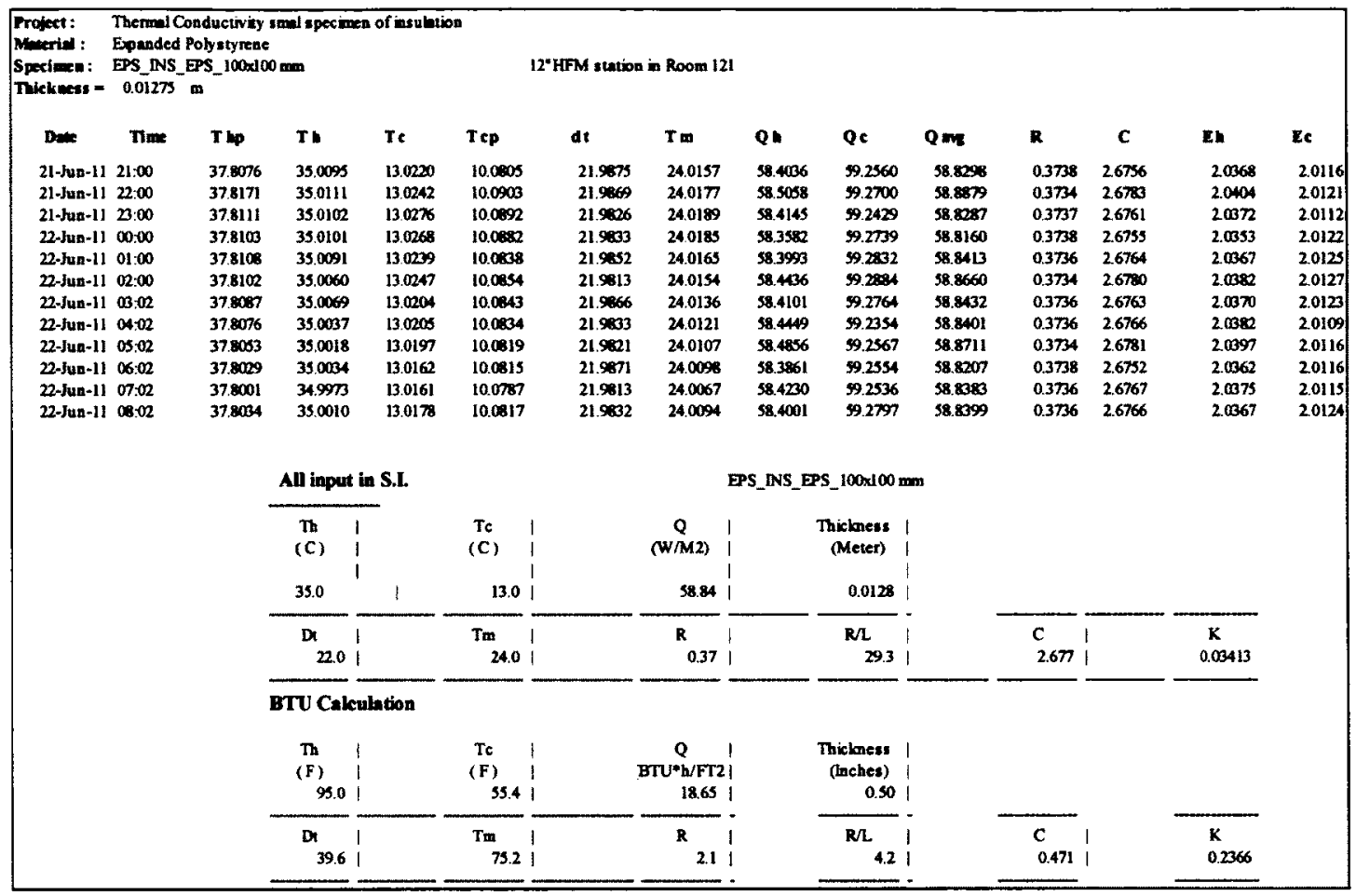




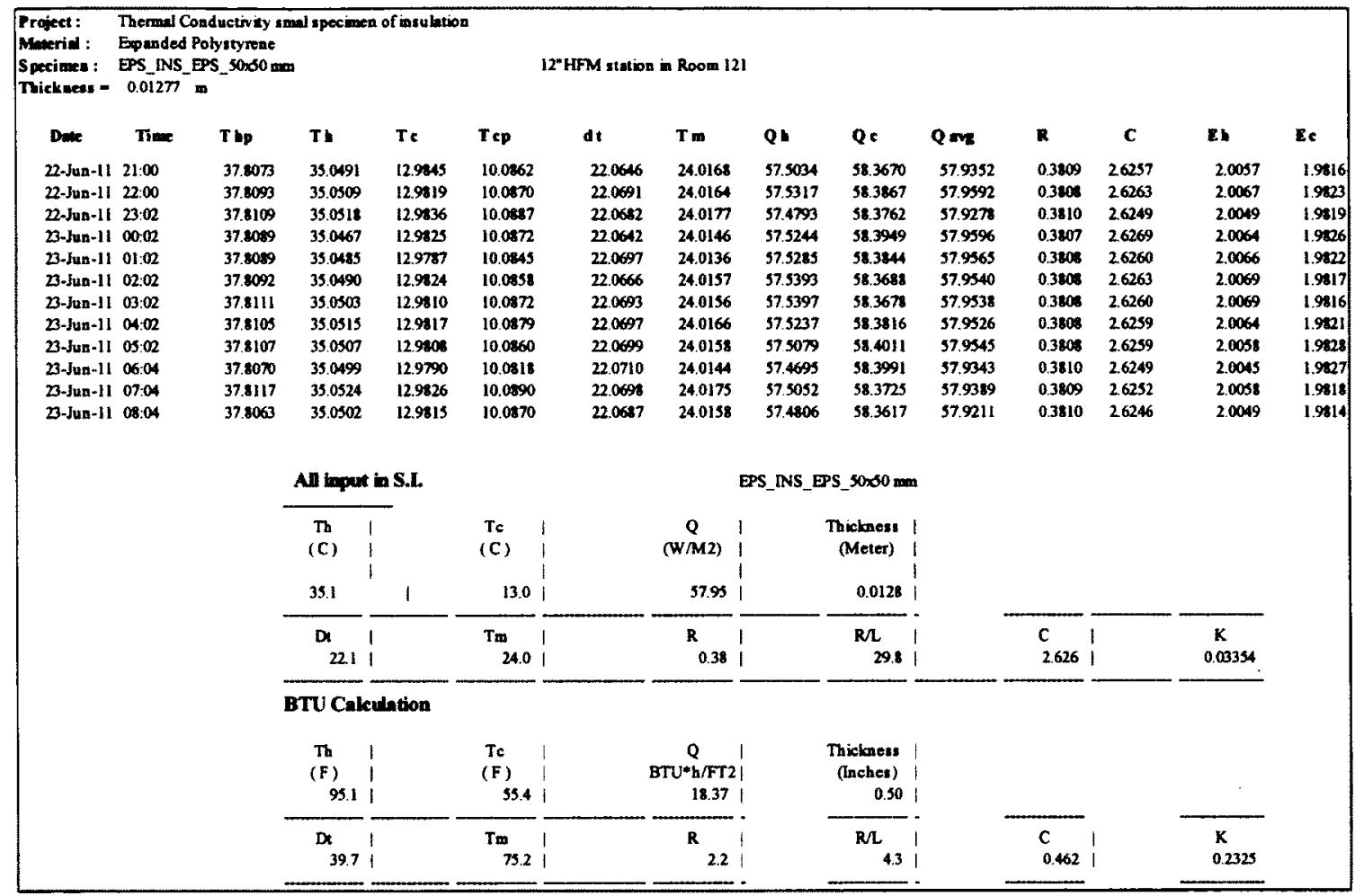

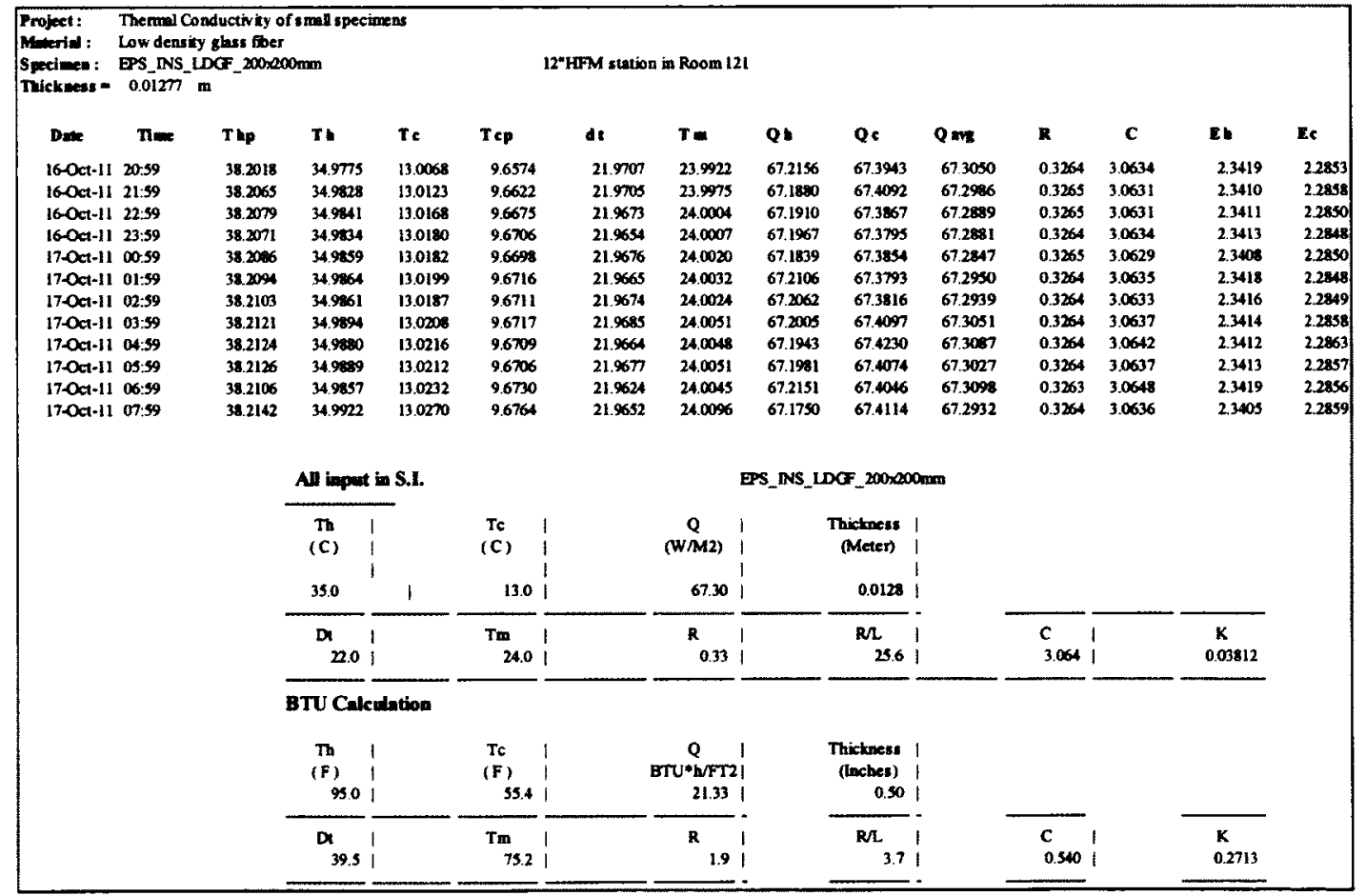




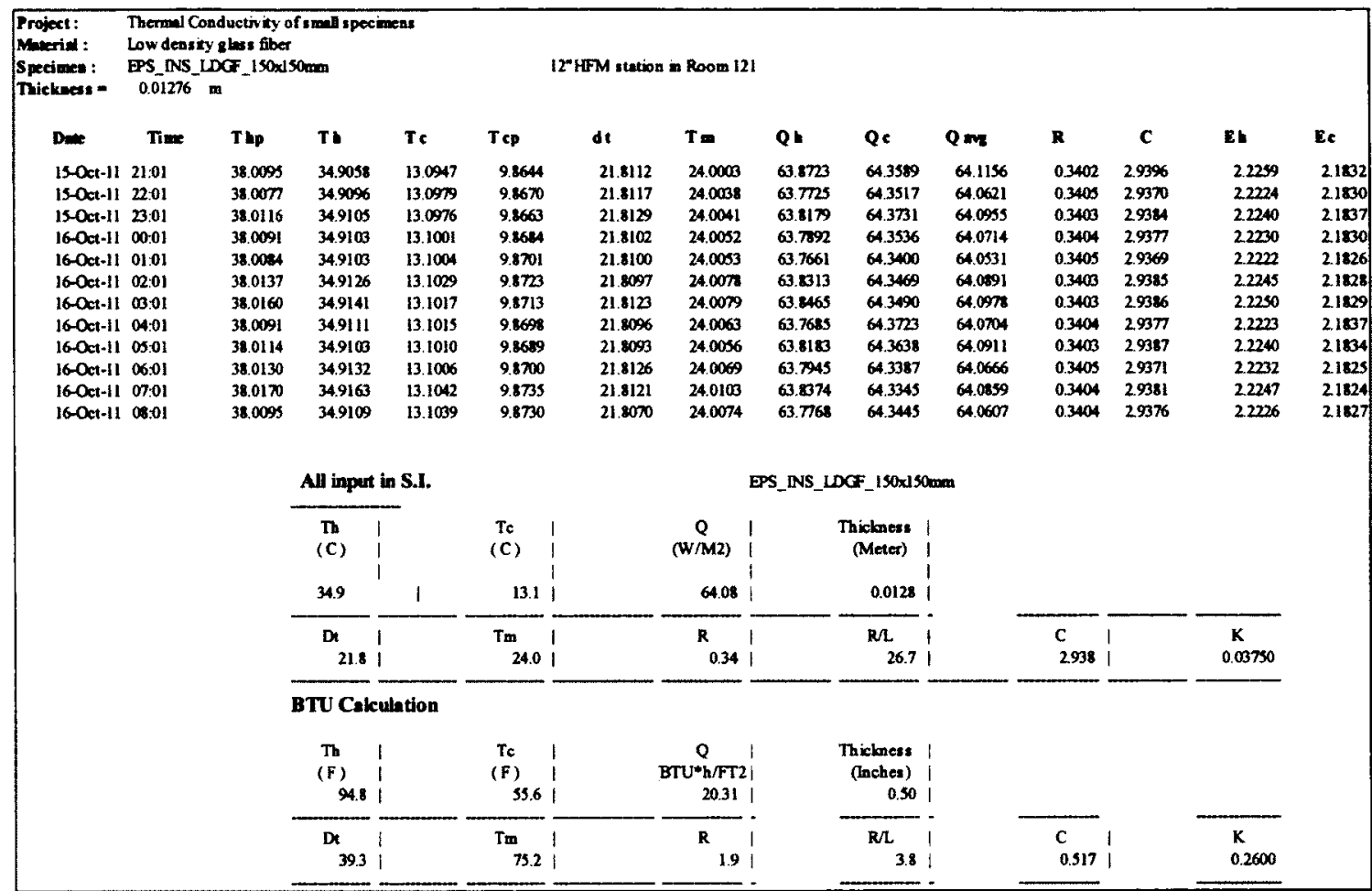




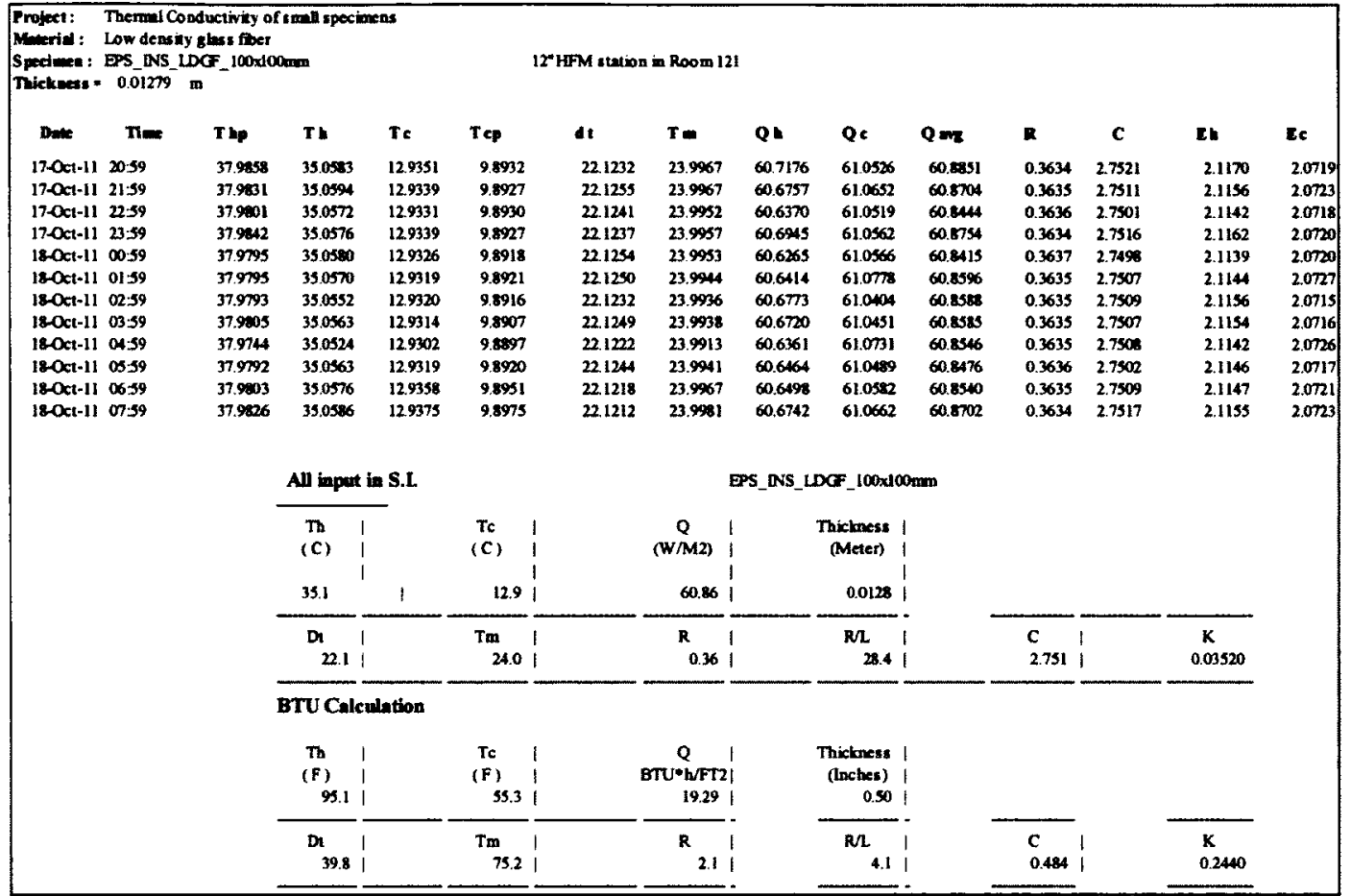

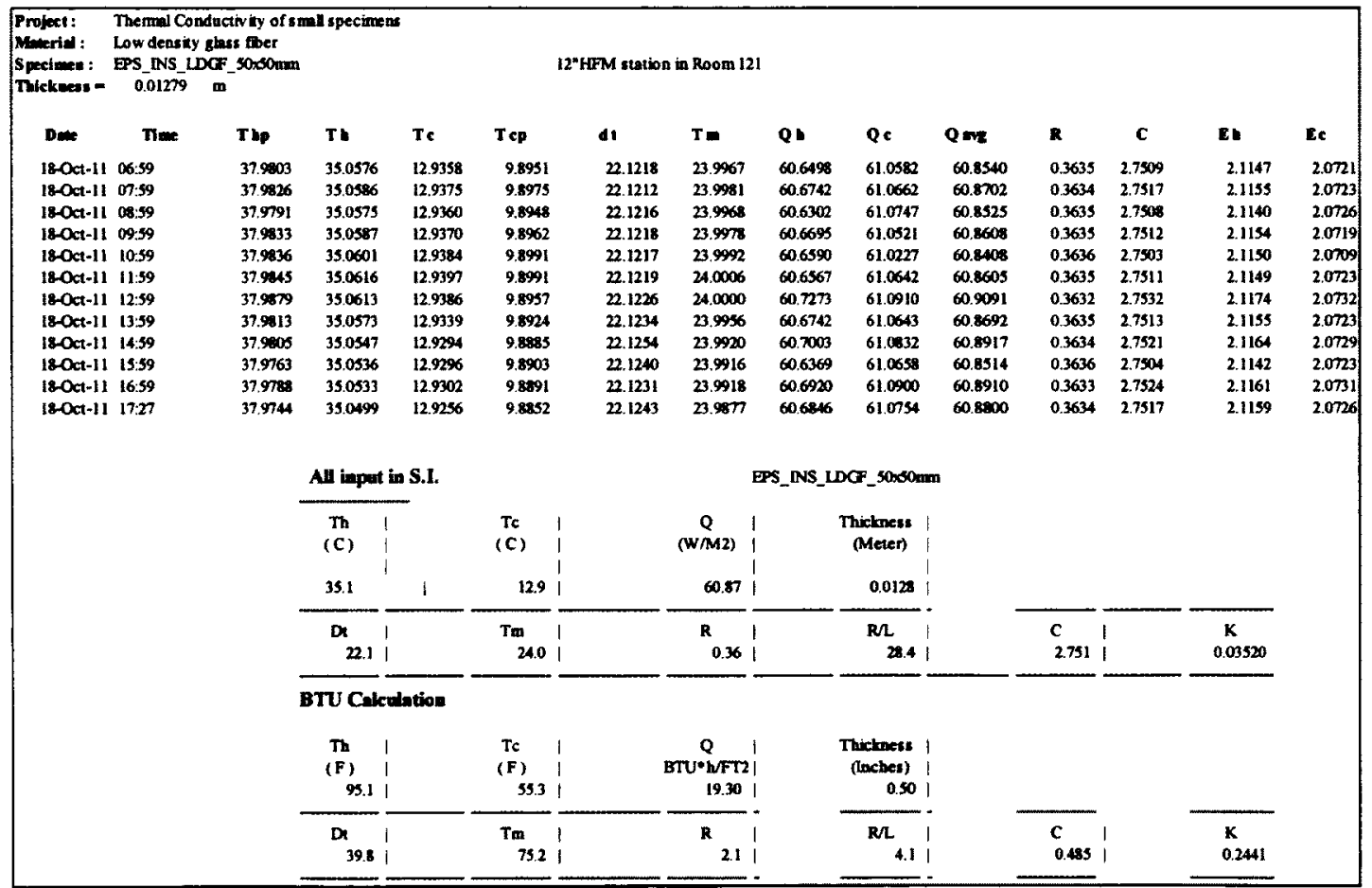




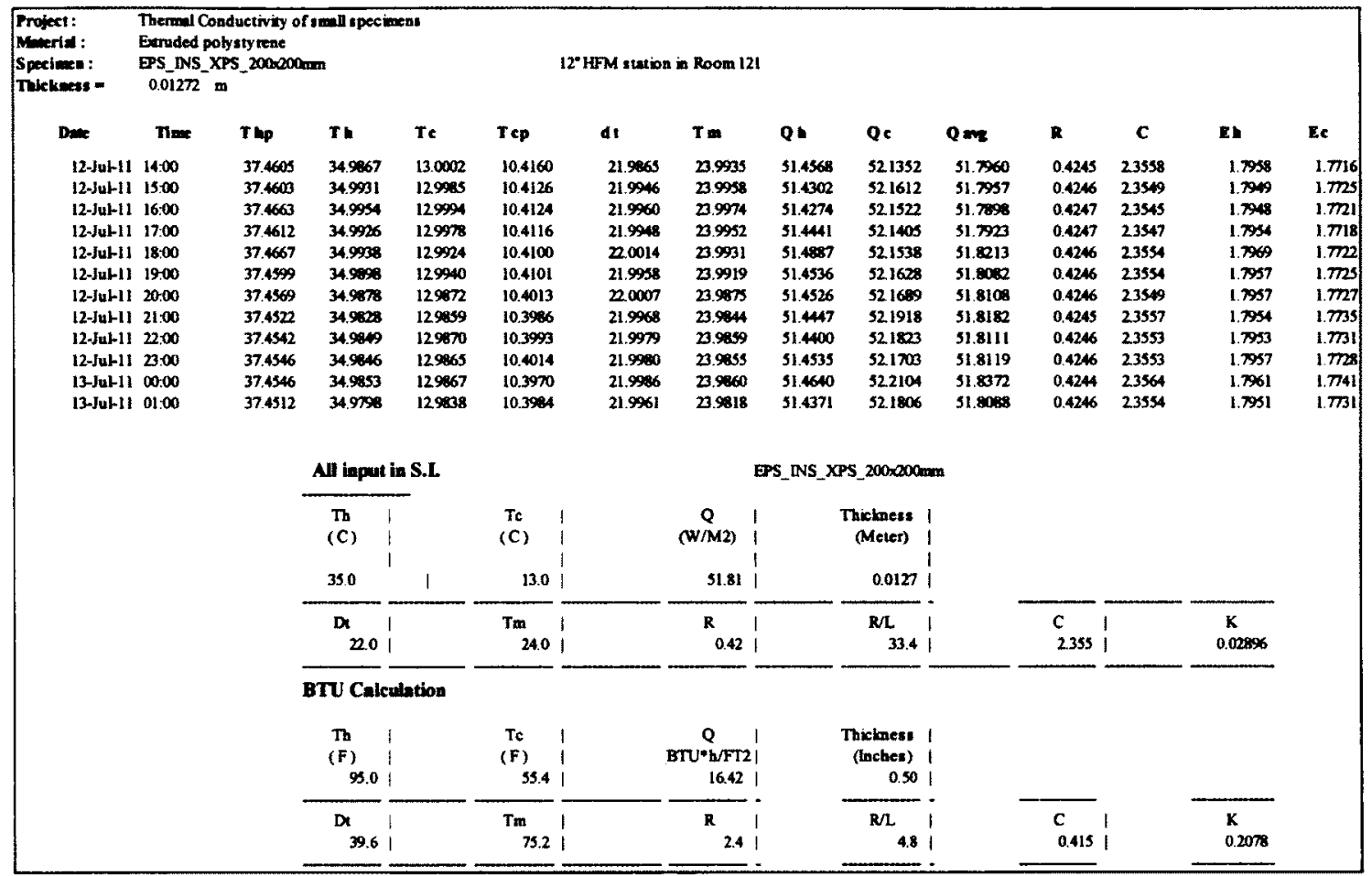

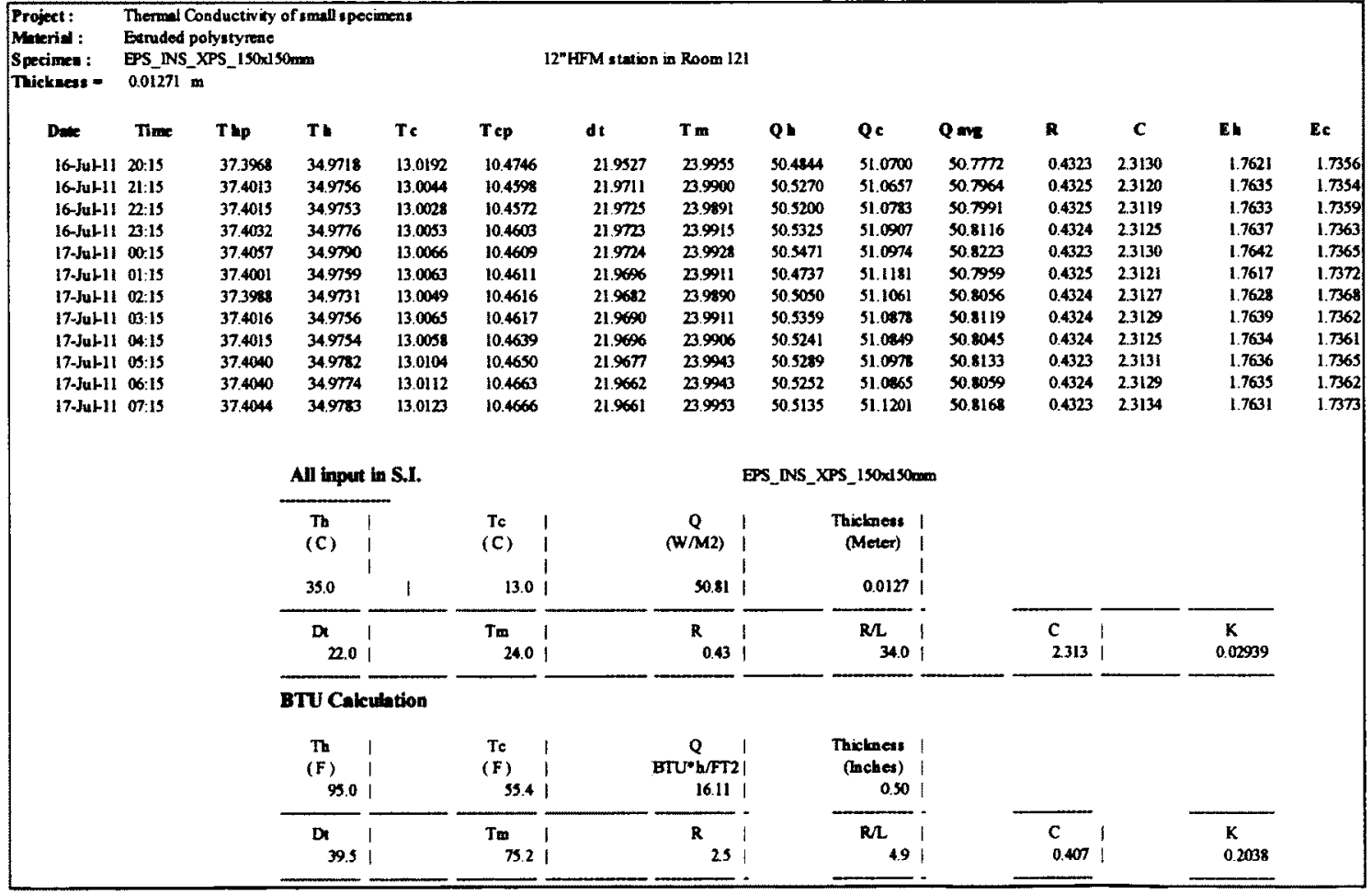




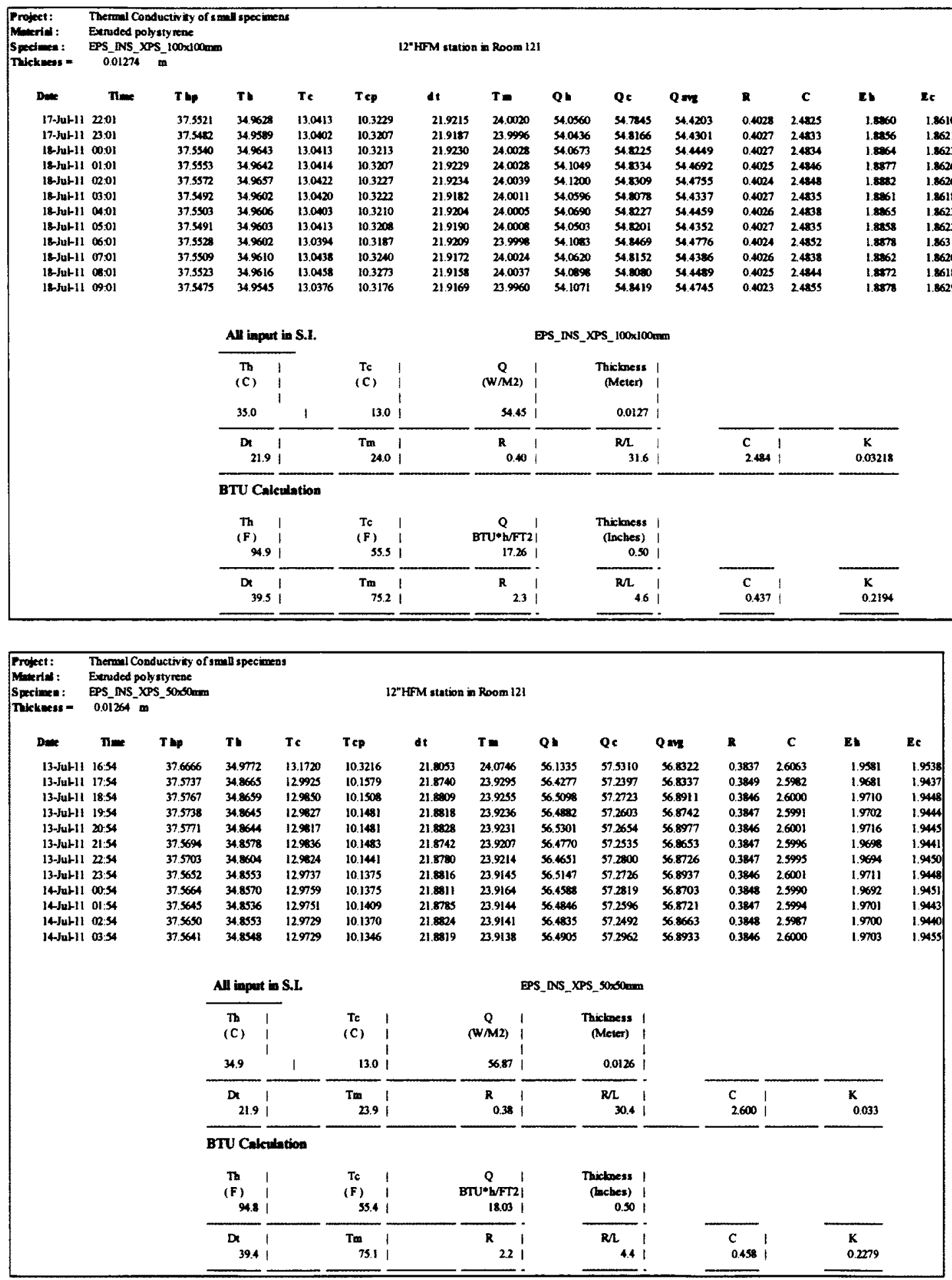




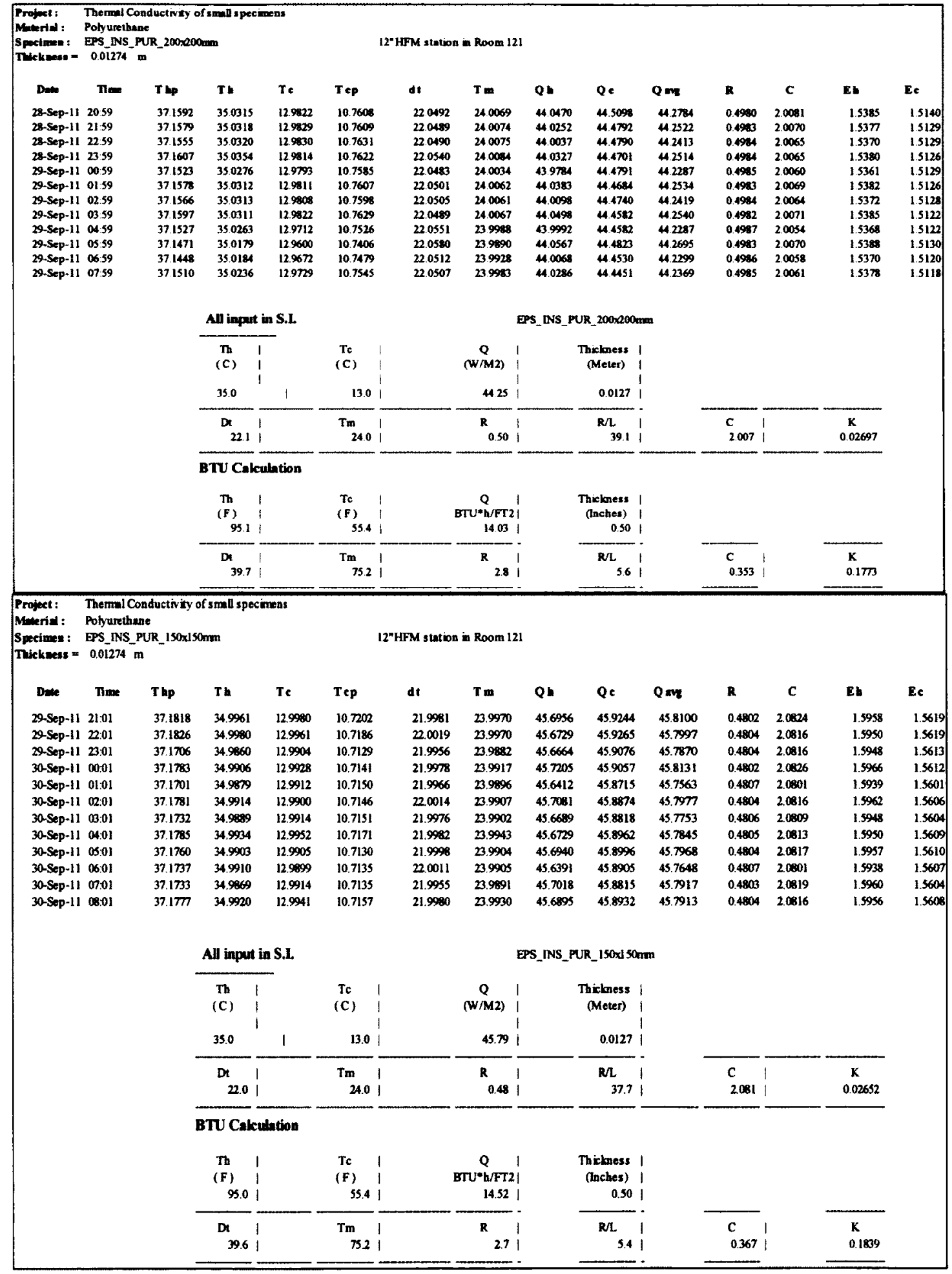




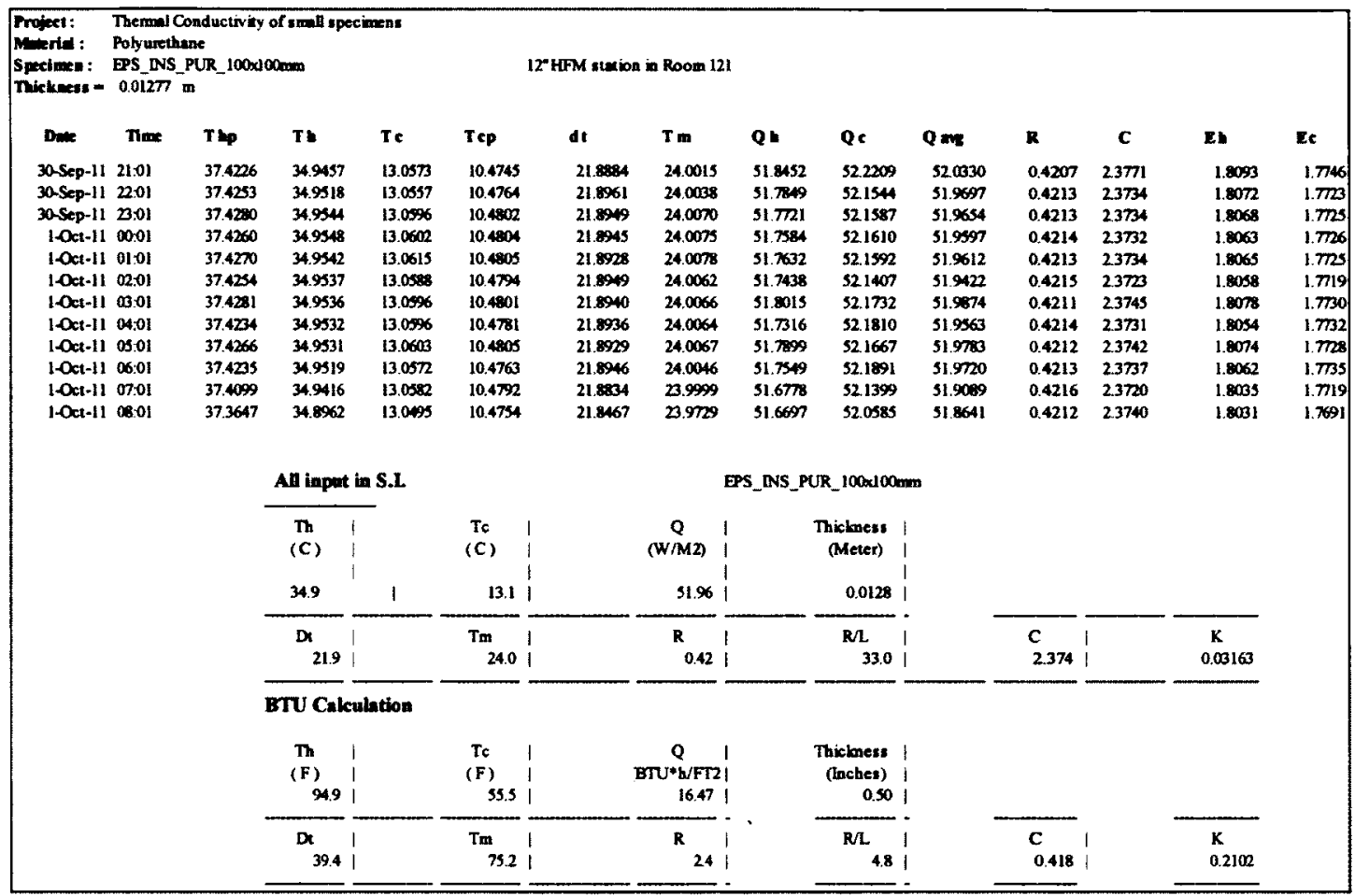

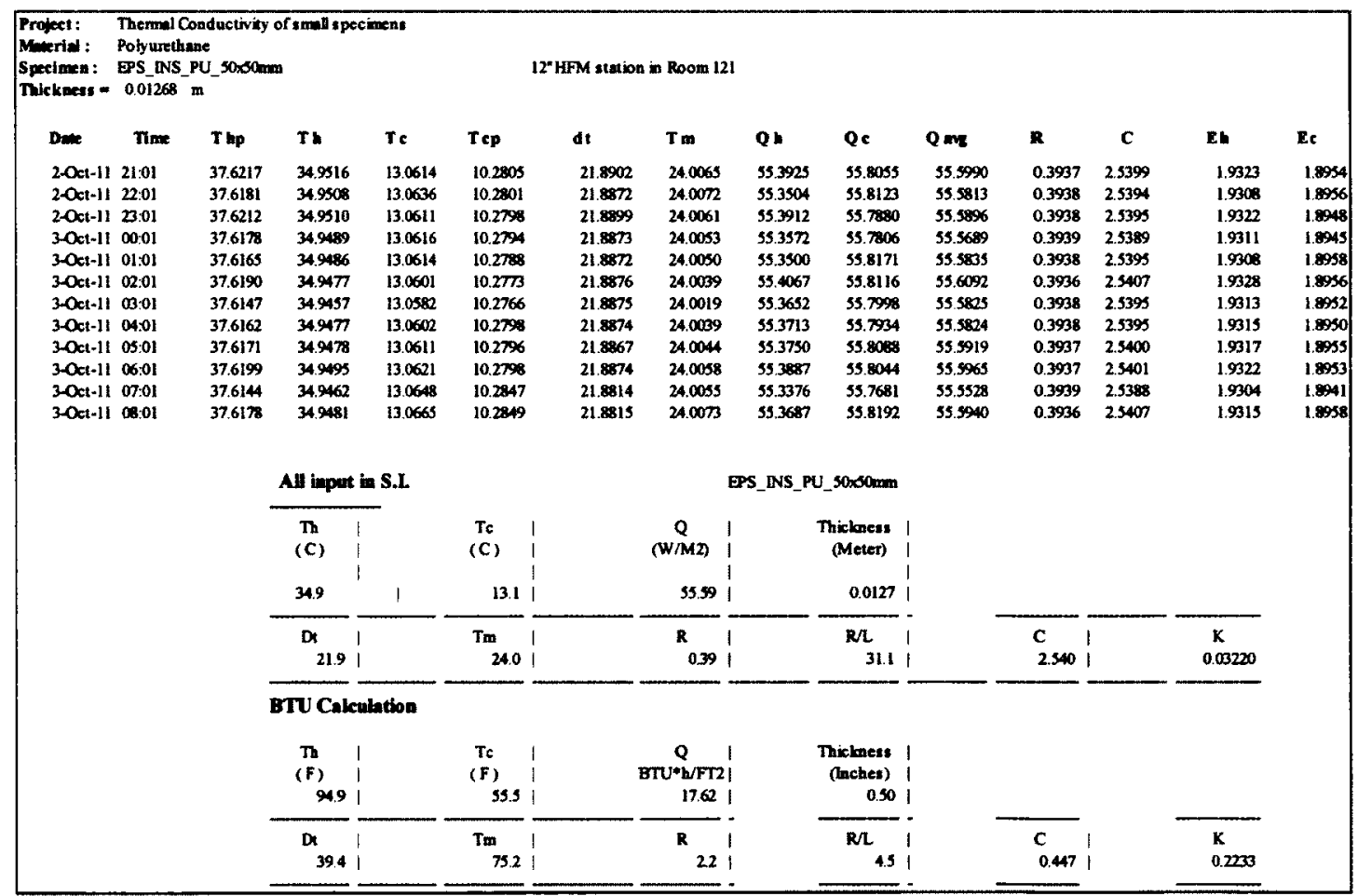




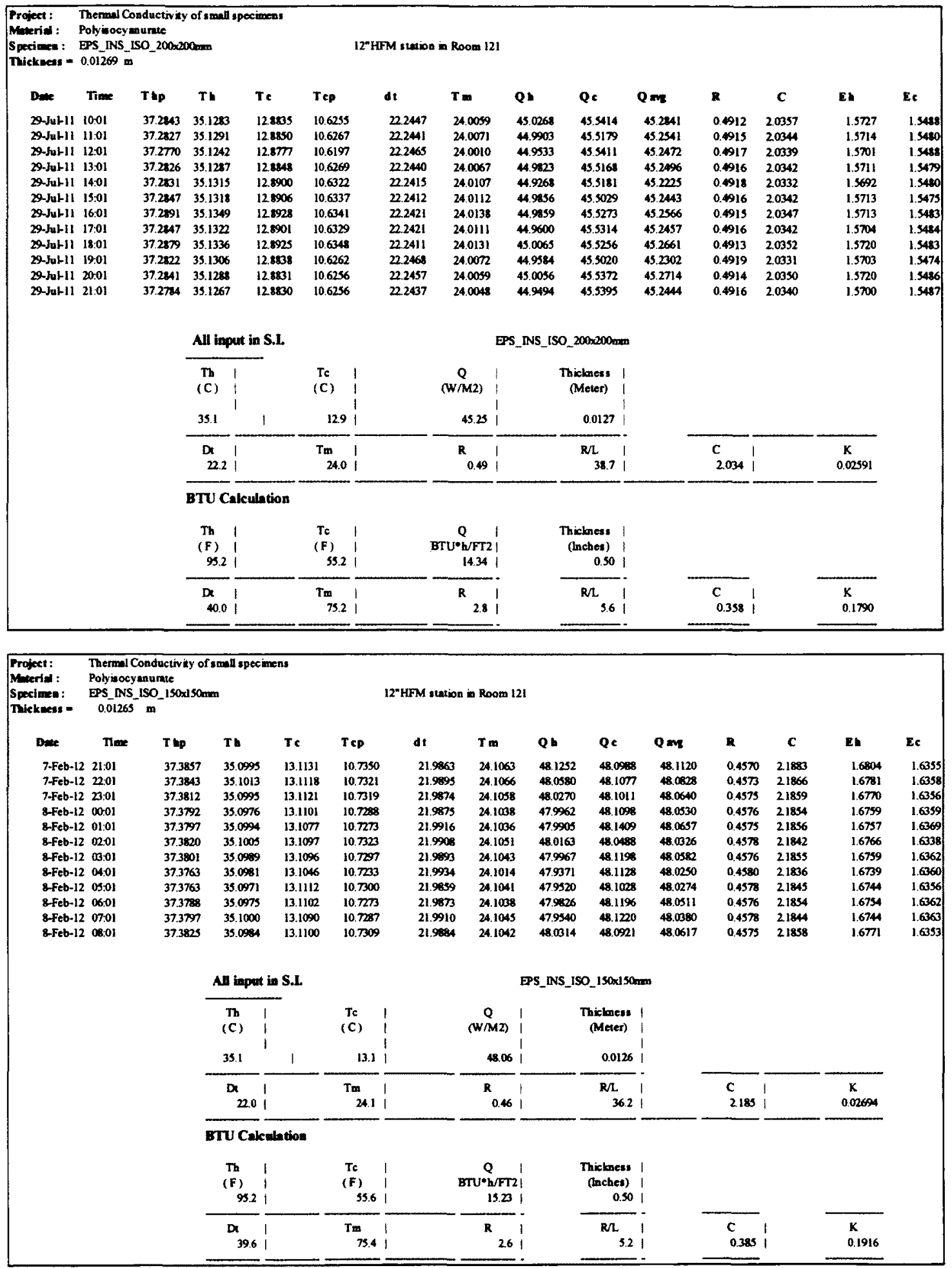




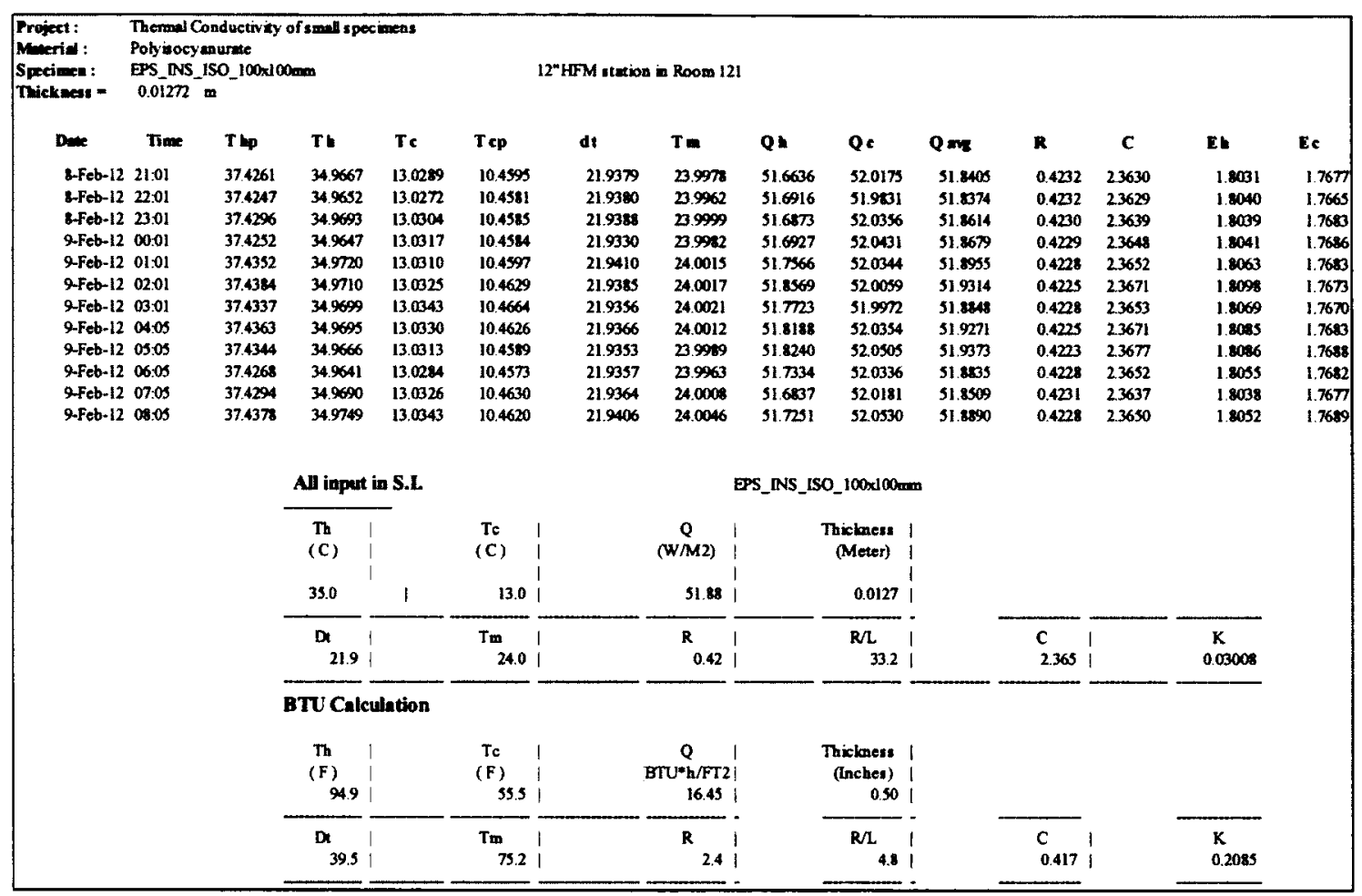

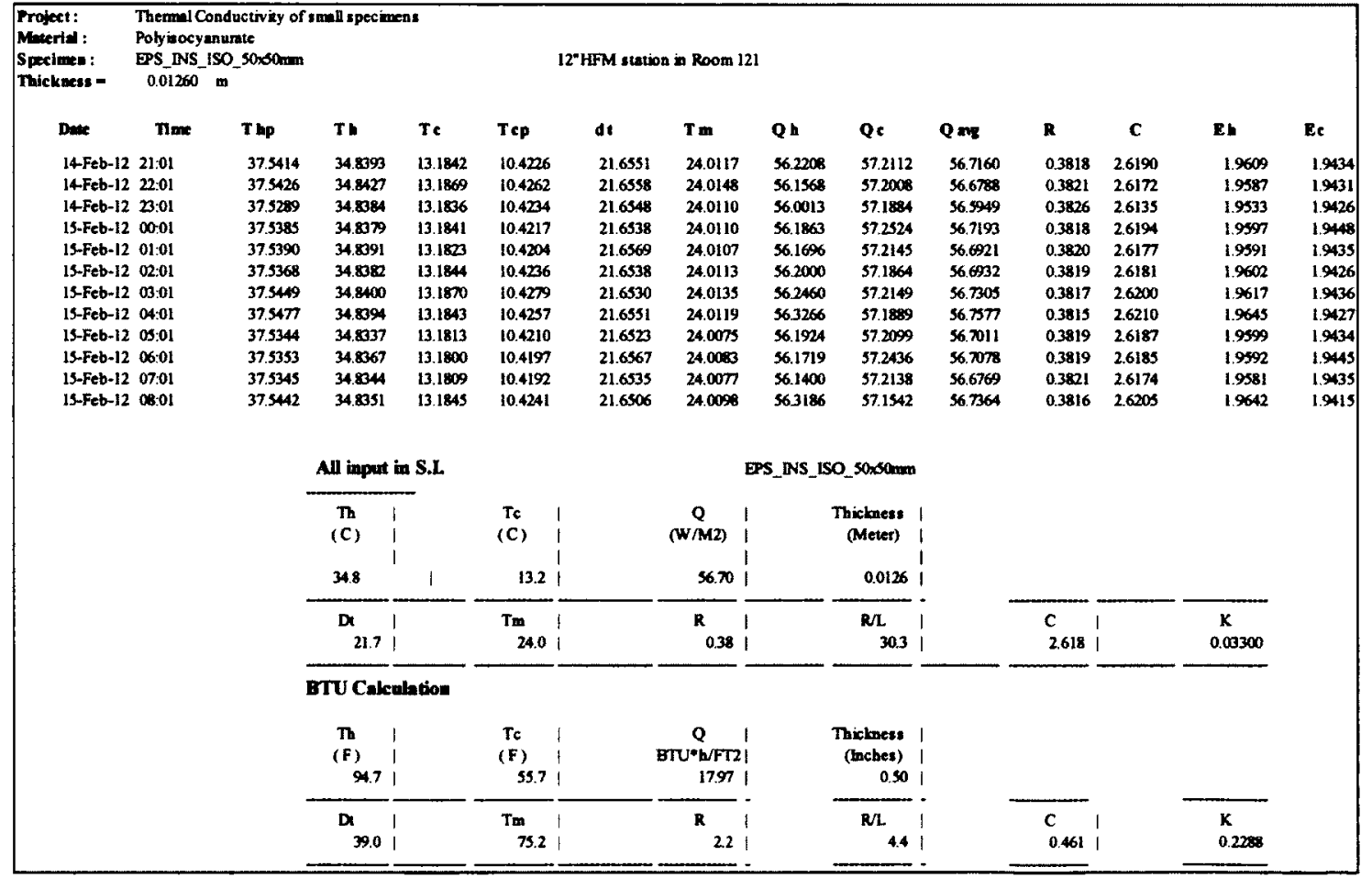




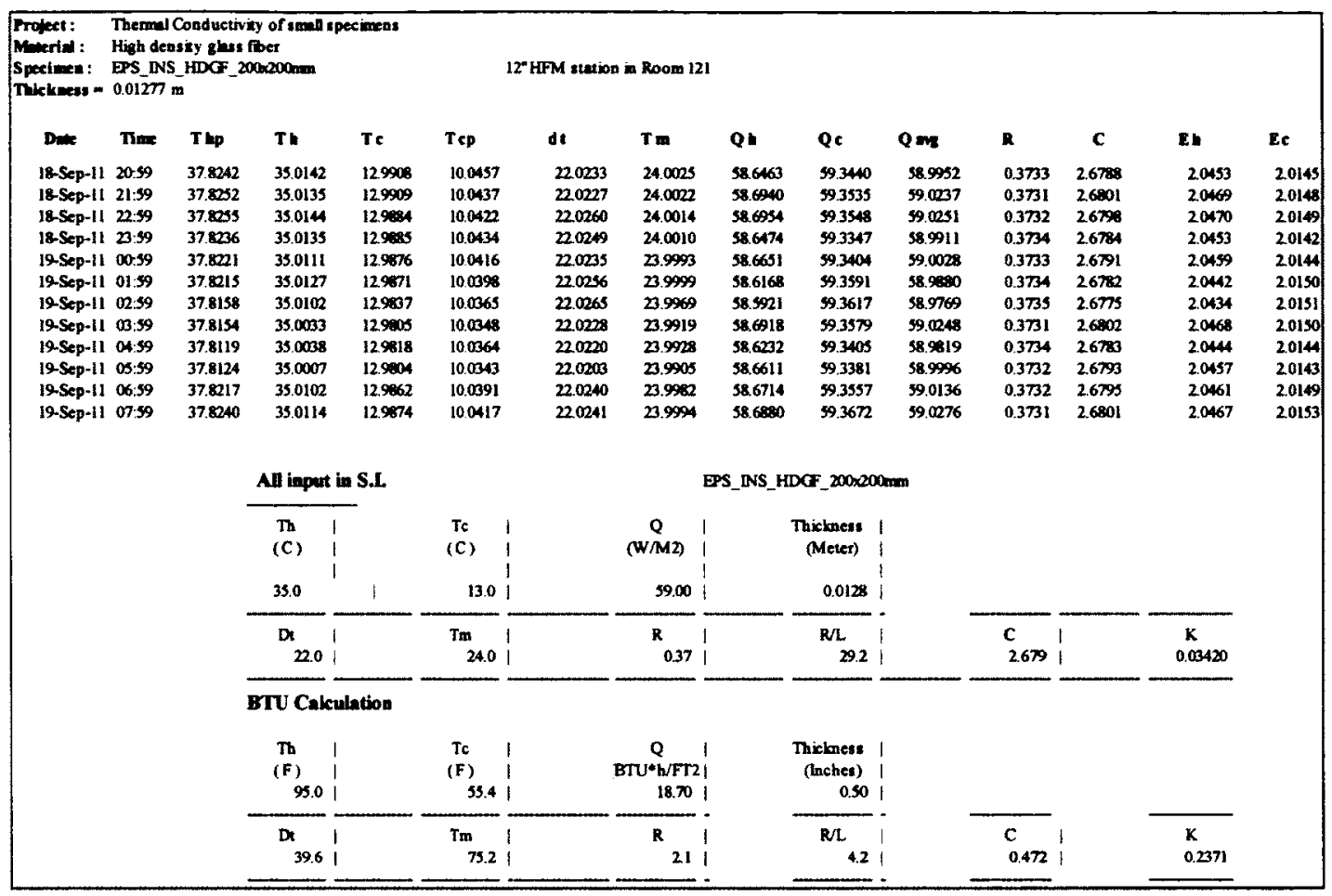

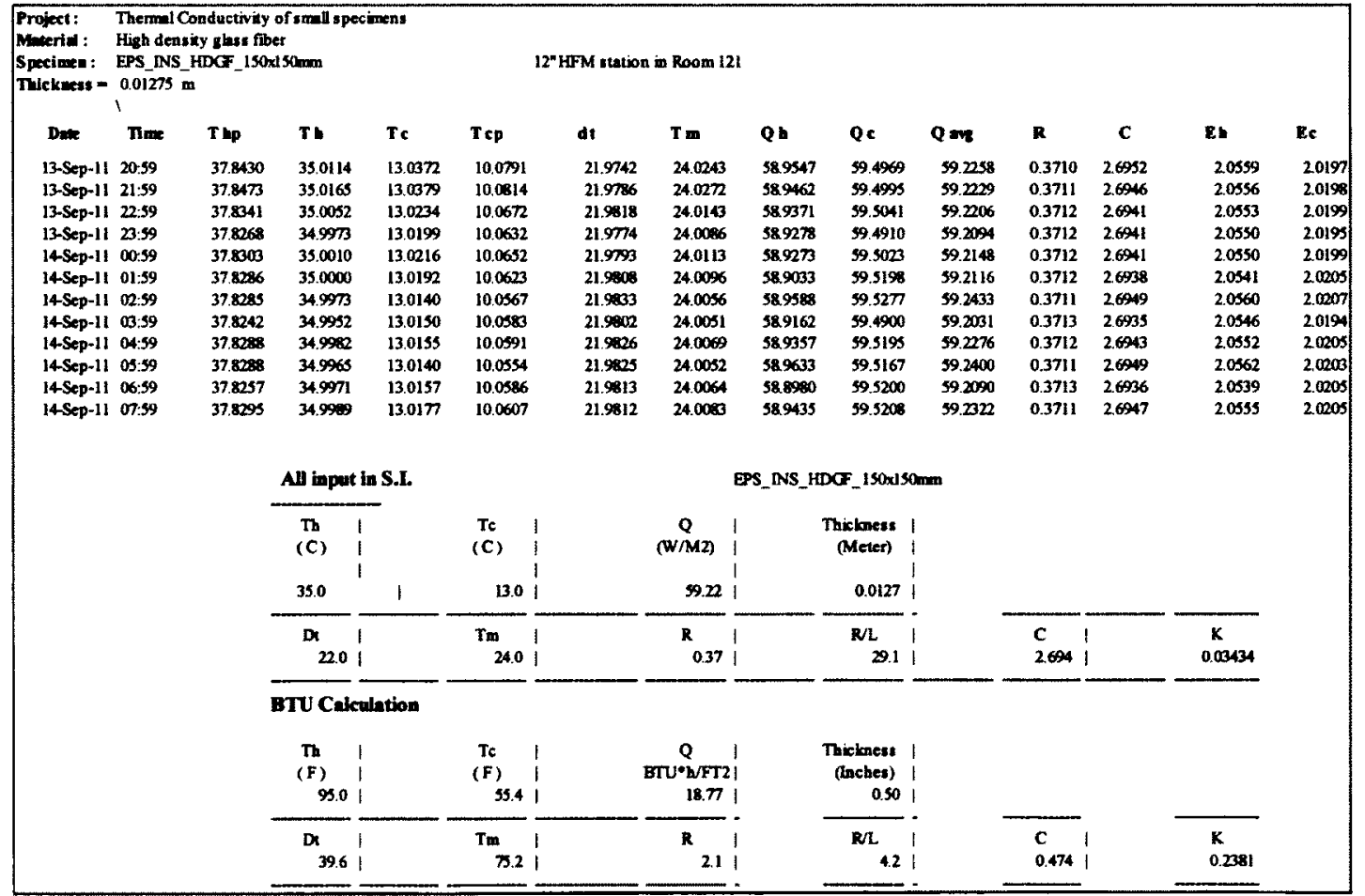




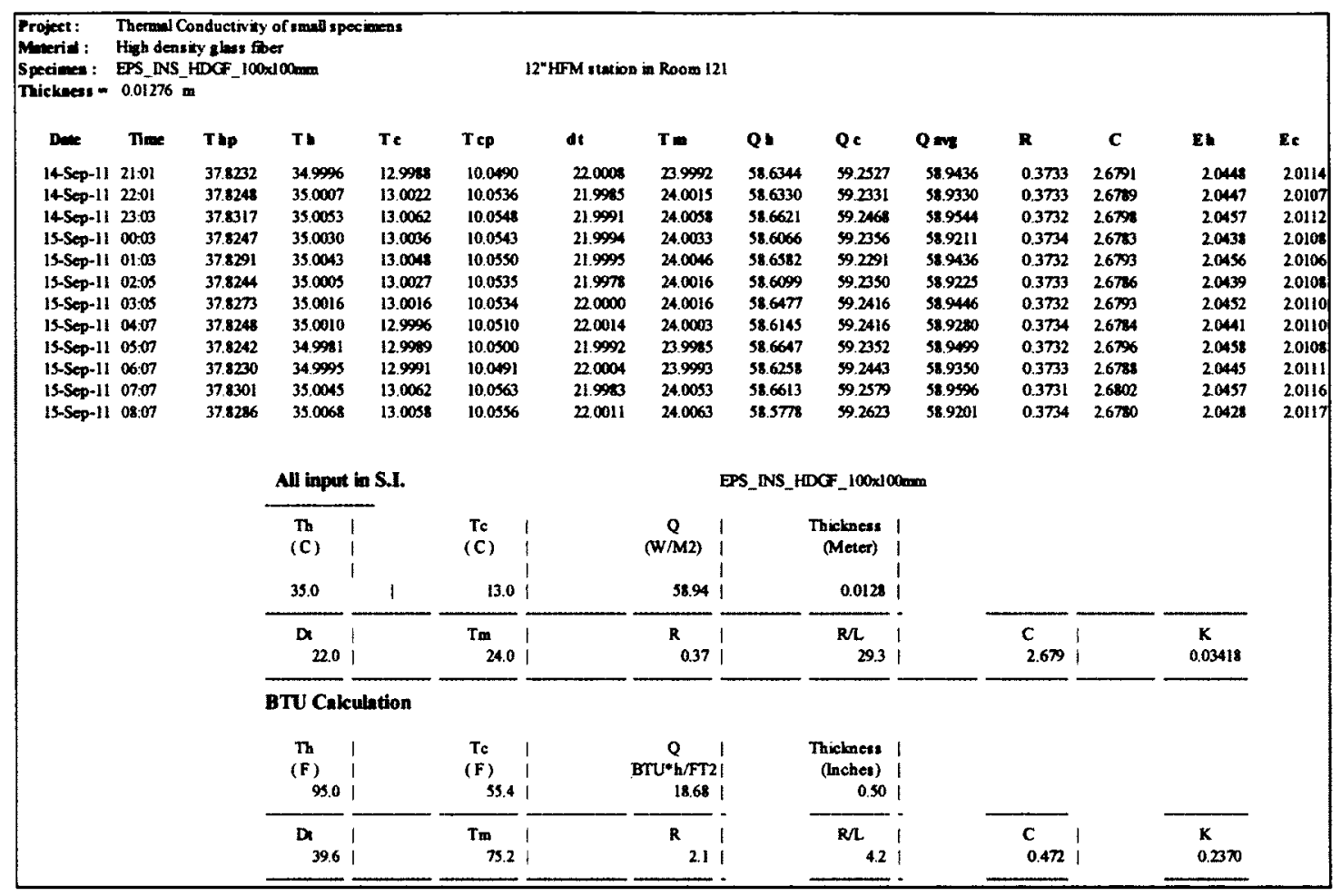

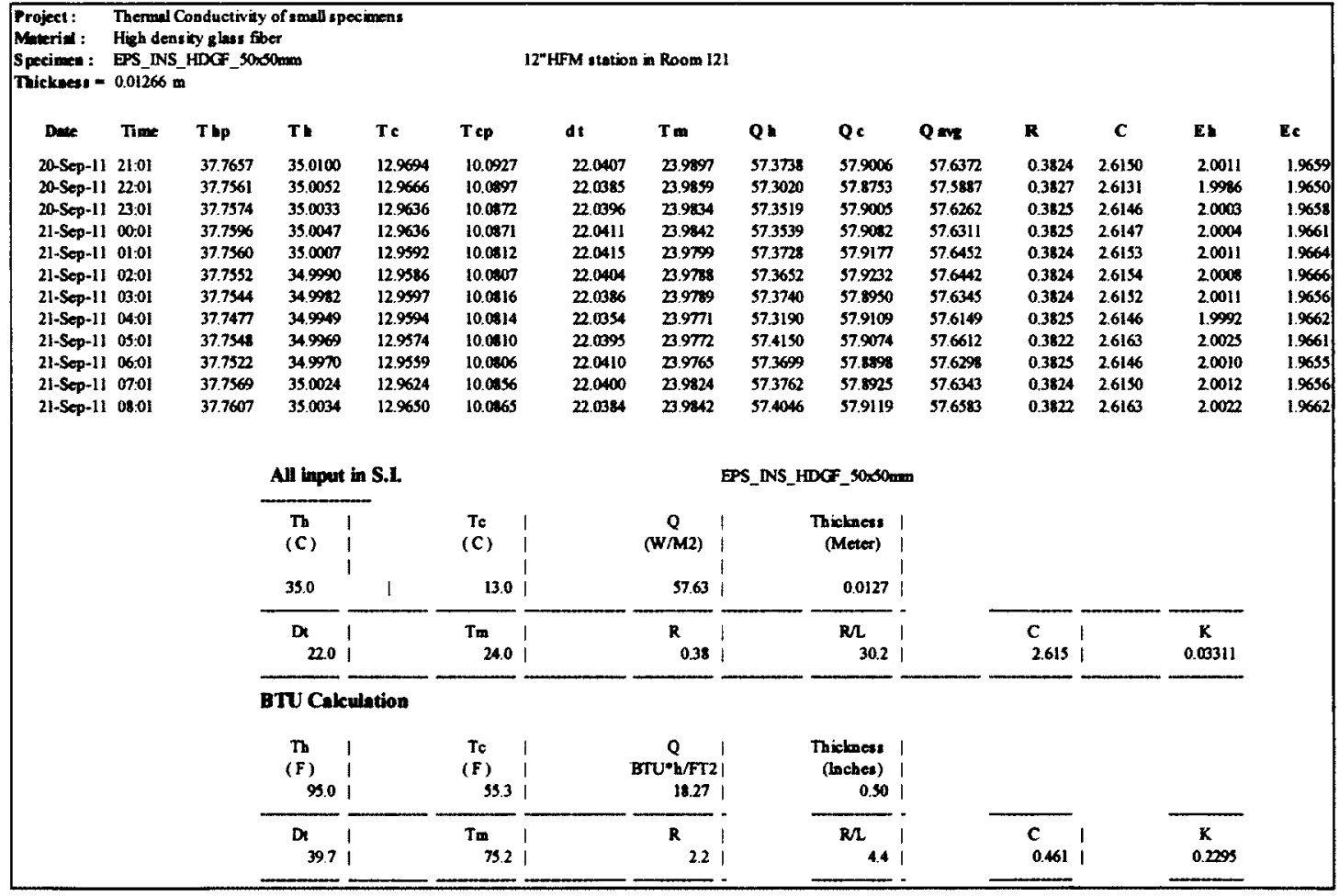

